\title{
Exploring the nature of social preferences and their economic significance : four experimental studies
}

Citation for published version (APA):

Petit Dit Dariel, A. C. (2013). Exploring the nature of social preferences and their economic significance : four experimental studies. [Doctoral Thesis, Maastricht University]. Universitaire Pers Maastricht. https://doi.org/10.26481/dis.20131106ap

Document status and date:

Published: 01/01/2013

DOI:

10.26481/dis.20131106ap

Document Version:

Publisher's PDF, also known as Version of record

\section{Please check the document version of this publication:}

- A submitted manuscript is the version of the article upon submission and before peer-review. There can be important differences between the submitted version and the official published version of record.

People interested in the research are advised to contact the author for the final version of the publication, or visit the DOI to the publisher's website.

- The final author version and the galley proof are versions of the publication after peer review.

- The final published version features the final layout of the paper including the volume, issue and page numbers.

Link to publication

\footnotetext{
General rights rights.

- You may freely distribute the URL identifying the publication in the public portal. please follow below link for the End User Agreement:

www.umlib.nl/taverne-license

Take down policy

If you believe that this document breaches copyright please contact us at:

repository@maastrichtuniversity.nl

providing details and we will investigate your claim.
}

Copyright and moral rights for the publications made accessible in the public portal are retained by the authors and/or other copyright owners and it is a condition of accessing publications that users recognise and abide by the legal requirements associated with these

- Users may download and print one copy of any publication from the public portal for the purpose of private study or research.

- You may not further distribute the material or use it for any profit-making activity or commercial gain

If the publication is distributed under the terms of Article $25 \mathrm{fa}$ of the Dutch Copyright Act, indicated by the "Taverne" license above, 
Exploring the nature of social preferences and their economic significance:

four experimental studies 
Exploring the nature of social preferences and their economic significance: four experimental studies. ( $)$ Copyright Aurélie Petit dit Dariel, Maastricht 2013

All rights reserved. No part of this publication may be reproduced, stored in a retrieval system, or transmitted, in any form, or by any means, electronic, mechanical, photocopying, recording or otherwise, without the prior permission in writing from the author.

Published by Datawyse | Universitaire Pers Maastricht ISBN 9789461592613 
Exploring the nature of social preferences and their economic significance: four experimental studies

\author{
Dissertation \\ To obtain the degree of Doctor at \\ Maastricht University, \\ on the authority of the Rector Magnificus, \\ Prof. dr. L.L.G. Soete., \\ in accordance with the decision of the Board of Deans, \\ to be defended in public \\ on Wednesday 6 November 2013, at 14.00 hours
}

By

Aurélie Petit dit Dariel 
Supervisor:

Prof. dr. Arno Riedl

Assessment Committee:

Prof. dr. Rudolf Müller (voorzitter)

Prof. dr. Urs Fischbacher (University of Konstanz)

Dr. Ronald Peeters 


\section{Contents}

$\begin{array}{ll}\text { Contents } & 1\end{array}$

List of Figures $\quad 5$

$\begin{array}{ll}\text { List of Tables } & 7\end{array}$

1 Introduction $\quad 10$

2 Imperfect reciprocators and the unravelling of gift exchange 13

2.1 Introduction . . . . . . . . . . . . . . . . . . . . 13

2.2 The experiment . . . . . . . . . . . . . . . . . . 15

2.2.1 Experimental design . . . . . . . . . . . . . . . 15

2.2.2 Part 1: Elicitation of reciprocal preferences and beliefs . . . . . . . 16

2.2.3 Part 2: The finitely-repeated gift-exchange game . . . . . . . . . 17

2.2.4 Procedures. . . . . . . . . . . . . . . . . . . . 18

2.3 Results . . . . . . . . . . . . . . . . . . . . 18

2.3.1 Reciprocal preferences . . . . . . . . . . . . . . . 18

2.3.2 The finitely-repeated gift-exchange game . . . . . . . . . . . 22

2.4 Discussion and conclusion . . . . . . . . . . . . . . . . 25

3 Cooperators and reciprocators: A within-subject analysis of pro-social $\begin{array}{ll}\text { behavior } & 29\end{array}$

3.1 Introduction . . . . . . . . . . . . . . . . . . . . . . . 29

3.2 The experiment . . . . . . . . . . . . . . . . 31

3.2.1 Part 1: The public-good game . . . . . . . . . . . . . 31

3.2.2 Part 2: The gift-exchange game . . . . . . . . . . . . 31

3.3 Results . . . . . . . . . . . . . . . . . . . . 32 
3.4 Conclusion . . . . . . . . . . . . . . . . . . . 35

4 Cooperation preferences and framing effects $\quad 36$

4.1 Introduction . . . . . . . . . . . . . . . . . 36

4.2 The experiment . . . . . . . . . . . . . . . . . 39

4.2.1 The public-good game (overview) . . . . . . . . . . . 39

4.2.2 Eliciting contribution schedules and beliefs . . . . . . . . . . . . 40

4.2.3 The one-shot public-good game . . . . . . . . . . . . . 41

4.2.4 The finitely-repeated public-good game . . . . . . . . . . . . . 42

4.2.5 Procedures. . . . . . . . . . . . . . . . . . 42

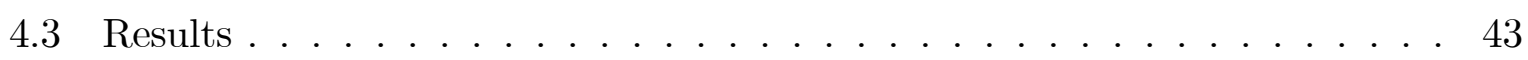

4.3.1 Non-monotonic contribution schedules . . . . . . . . . . . . 43

4.3.2 Predictive power of schedules in the one-shot public-good game . . 46

4.3.3 Predictive power of schedules in the finitely-repeated public-good game . . . . . . . . . . . . . . . . . 49

4.3.4 Cooperation preferences, contribution levels and beliefs . . . . . . . 52

4.4 Discussion . . . . . . . . . . . . . . . . . . 57

5 Social networks in an experimental labor market with adverse selection 60

5.1 Introduction . . . . . . . . . . . . . . . . 60

5.2 The experiment . . . . . . . . . . . . . . . 63

5.2.1 The No Referrals treatment (NR) . . . . . . . . . . . . . . . 64

5.2.2 The Referrals treatment $(\mathrm{R}) \ldots \ldots \ldots$. . . . . . . 64

5.2 .3 The payoff functions . . . . . . . . . . . . . . 65

5.2 .4 Information . . . . . . . . . . . . . . 66

5.2 .5 Procedures......................... 66

5.3 Theoretical framework . . . . . . . . . . . . . 67

5.4 Results . . . . . . . . . . . . . . . . . . . . . 69

5.4 .1 Main results . . . . . . . . . . . . . . . . . 69

5.4 .2 Other results: a look at the dynamics in the market . . . . . . . 73

5.5 Conclusion . . . . . . . . . . . . . . . . . . 77

$\begin{array}{llr}6 & \text { Conclusion } & 79\end{array}$ 
A.1 Additional statistics . . . . . . . . . . . . . . . . . 82

A.1.1 Individual effort of choices . . . . . . . . . . . . . . 82

A.1.2 Robustness estimates . . . . . . . . . . . . . . . . 83

A.2 Instructions . . . . . . . . . . . . . . . . . . 84

A.2.1 General instructions . . . . . . . . . . . . . . . . 84

A.2.2 Specific instructions - Part 1 . . . . . . . . . . 85

A.2.3 Specific instructions - Part 2 . . . . . . . . . . . . . . . 91

B Cooperators and reciprocators: A within-subject analysis of pro-social $\begin{array}{ll}\text { behavior } & 97\end{array}$

B.1 General instructions . . . . . . . . . . . . . . . . 97

B.2 Specific instructions - Part $1 \ldots \ldots \ldots \ldots$

B.3 Specific instructions - Part 2 . . . . . . . . . . . . . . . 105

C Cooperation preferences and framing effects $\quad 110$

C.1 Additional statistics . . . . . . . . . . . . . . . . 110

C.1.1 Individual contribution schedules per treatment . . . . . . . . . . 110

C.1.2 Determinants of beliefs in the finitely-repeated public good game . 111

C.2 Instructions . . . . . . . . . . . . . . . . . . . . . . 112

C.2.1 General instructions . . . . . . . . . . . . . . . . 112

C.2.2 Specific instructions - Part 1 . . . . . . . . . . . . . . 113

C.2.3 Specific instructions - Part 2 . . . . . . . . . . . . 120

C.2.4 Specific instructions - Part 3 . . . . . . . . . . . . . 123

D Social networks in an experimental labor market with adverse selection127

D.1 Theoretical framework concerning the impact of the social network: referral market equilibrium . . . . . . . . . . . . . . . . . . 127

D.1.1 Stage-1: Public Market . . . . . . . . . . . . . . . . . 128

D.1.2 Stage-2: Referral Market . . . . . . . . . . . . . . . . . . 129

D.2 Robustness check: all wages offered . . . . . . . . . . . . . 135

D.3 Instructions . . . . . . . . . . . . . . . . . . . . . 137

D.3.1 General instructions . . . . . . . . . . . . . . . . 137

D.3.2 Specific instructions - Firms . . . . . . . . . . . . . . . 137 
D.3.3 Specific instructions - Workers . . . . . . . . . . . . . . . 147

D.3.4 Control questions public market - decision situation . . . . . . . 156

D.3.5 Control questions referral market - decision situation . . . . . . . . 158

Bibliography 


\section{List of Figures}

2-1 Distribution of the reciprocation index . . . . . . . . . . . 21

2-2 Effort as a function of wage (all workers and by type) . . . . . . . . . 22

2-3 Average wage over time . . . . . . . . . . . . . . . . 24

2-4 Average effort over time . . . . . . . . . . . . . . . . 25

2-5 Expected profit of firms in Part 1 (preference elicitation) . . . . . . . 26

2-6 Expected profit of firms in Part 2 (repeated GEG) . . . . . . . . . 26

4-1 Percentage of subjects with non monotonic schedules . . . . . . . . . 45

4-2 Distribution of deviation from the predicted contribution (one-shot) . . 47

4-3 Distribution of deviation from the predicted contribution (finitely repeated) 50

4-4 Average conditional contribution in the strategy method . . . . . . . . . 54

$4-5$ Average contribution over time . . . . . . . . . . . 56

5-1 Cumulative distribution of accepted wages . . . . . . . . . . 71

$5-2 \quad$ Hiring rate and wage acceptance . . . . . . . . . . . . . . . 72

$5-3$ Time of wage acceptance . . . . . . . . . . . . . . . . . . 74

A-1 Individual effort of choices in the strategy method . . . . . . . . . . . . 82

A-2 Screenshot: conditional effort level . . . . . . . . . . . . . . . . 88

A-3 Screenshot: expected wage . . . . . . . . . . . . 89

A-4 Screenshot: wage offer . . . . . . . . . . . . . . . 90

A-5 Screeshot: expected effort . . . . . . . . . . . . . . . . 91

A-6 Screenshot: wage offer repeated game . . . . . . . . . . . . . . 94

A-7 Screenshot: expected effort . . . . . . . . . . . . . . . . 94

A-8 Screenshot: expected wage . . . . . . . . . . . . . . 95

B-1 Screenshot: unconditional contribution . . . . . . . . . . . . . 101 
B-2 Screeenshot: contribution table . . . . . . . . . . . . . . . . 102

B-3 Screenshot: belief determination . . . . . . . . . . . . . . . 103

B-4 Screenshot: wage offer . . . . . . . . . . . . . . 107

B-5 Screenshot: expected effort . . . . . . . . . . . . . 108

C-1 Screenshot: conditional assignment . . . . . . . . . . . . 117

C-2 Screenshot: unconditional assignment . . . . . . . . . . . . . 118

C-3 Screenshot: assignment to account B . . . . . . . . . . . . . . . 121

C-4 Screenshot: expected assignment . . . . . . . . . . . . . . 122

C-5 Screenshot: assignment to account B . . . . . . . . . . . . 125

C-6 Screenshot: expected assignment f . . . . . . . . . . . . 126

D-1 Screenshot: wage offers in the public market . . . . . . . . . . . . . 142

D-2 Screenshot: wage offers in the public and referral markets . . . . . . . . 143

D-3 Screenshot: workers' wage offers in the public market . . . . . . . . . . 151

D-4 Screenshot: workers' wage offers in the public and referral markets . . . . . 152 


\section{List of Tables}

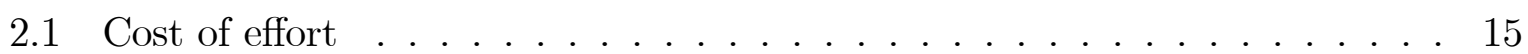

2.2 Explaining effort choices in the repeated GEG . . . . . . . . . . . 23

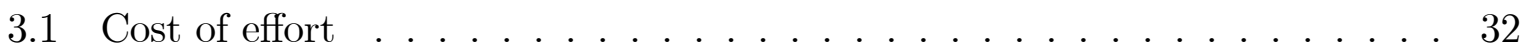

3.2 Explaining second mover's effort choices in the repeated GEG . . . . . . 34

4.1 Probability of deviating from the predicted contribution in the one-shot game 48

4.2 Probability of deviating from the predicted contribution in the finitelyrepeated game . . . . . . . . . . . . . . . . . . . 52

4.3 Distribution of types (percentages) $\ldots \ldots \ldots \ldots \ldots \ldots$

4.4 Determinants of conditional contribution in the strategy method . . . . . 55

4.5 Determinants of conditional contribution in the finitely-repeated game . . . 57

5.1 Employment rate and average wage by treatment, stage and type $\ldots \ldots 70$

5.2 Timing of wage acceptance . . . . . . . . . . . . . . . . 74

5.3 Timing of wage posting and acceptance $\ldots \ldots \ldots \ldots \ldots \ldots$

5.4 Timing of wage offer and acceptance in the referral and public market . . . 76

A.1 Explaining effort choices in the repeated GEG (tobit) . . . . . . . . 83

A.2 Explaining effort choices in the repeated GEG (GLS) $\ldots \ldots \ldots \ldots$

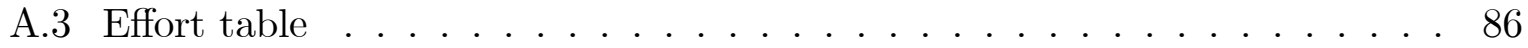

A.4 Effort table . . . . . . . . . . . . . . . . . . . 92

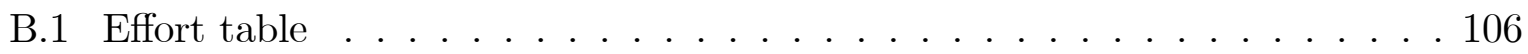

C.1 Determinants of beliefs in the finitely-repeated public good game . . . . . 112

D.1 Averages wages offered and accepted $\ldots \ldots \ldots \ldots \ldots \ldots$ 


\section{Acknowledgements}

The thesis you hold in your hands is the product of a long journey. The journey started at the age of 15 when I was first introduced to the economists' way of thinking. I recall being told about the scarcity of resources and how it affected their value. The concept of marginal utility intrigued me. I started using it in my daily life. I became eager to learn more about the economic "toolbox" and how it could help explain the way societies work and how agents interact. As my economic knowledge began to deepen, however, I started having questions about some of the fundamental assumptions made by economists. Most of all, like others before me, I was not entirely convinced by the assumption that economic agents are purely self -regarding. Are we really all selfish? Don't we care about others? This question started creating a conflict inside me about the economists' "worldview".

I remember meeting Arno Riedl for the first time. He told me about the Gift-Exchange Game. He talked of fairness motives and reciprocity. That was a pivotal moment. From then on, the concept of social preferences started occupying my mind for hours and hours. What ensued can be found here, in the 4 main chapters of my dissertation. This thesis could not have existed without my supervisor Arno Riedl. Thank you Arno for guiding me, advising me, understanding me and for your patience when external constraints arose. You helped me resolve the conflict that motivated my $\mathrm{PhD}$.

The thesis benefited greatly from the continuous support and comments of Olivier Bochet. Thank you Olivier for encouraging me to pursue my PhD, keeping me motivated, listening to me and answering my questions. I also would like to thank Thomas Troeger for whom I taught Auction Theory and Advanced Game Theory. Thomas' way of teaching and introducing important concepts helped me see familiar topics in a different light. I would like to thank Martin Strobel for giving me comments on my research as it evolved, as well as all academics at the Department of Economics at the University of Maastricht who generously gave feedback during the BEElab meetings. I also would like to thank Radu Vranceanu and Lata Gangadharan for showing interest in my work and for several interesting discussions.

My $\mathrm{PhD}$ has taken me to several places and enabled me to meet lots of people. In Bern, I would like to particularly thank Marlies for continuously making sure that everything was good for me at the department, and Simon Siegenthaler for several motivating discussions. In Maastricht, Elke and Nicole provided invaluable help when I was running the 
experiment that is presented in Chapter 5. In Grenoble, I would like to thank everybody for their hospitality, especially, Bernard Ruffieux and Laurent Muller. My discussions with Rania were very pleasant and relaxing. Good luck Rania for the next steps of you PhD. In Bonn and Lyon, I would like to thank Christoph Engel and Marie-Claire Villeval for welcoming me and showing interest in my work.

On a personal level, I would like to thank Liliane for helping me and taking care of my daughters when I was working. Thank you for caring for me and always asking me whether I needed help in order to make some progress on my dissertation. Combining my professional and personal life would not have been possible without Lori's help. Lori you are not only a good friend but a great person gifted at helping others and taking care of children. I would also like to thank Stefanos and Alexia for their help in difficult moments of life; for always smiling and being positive.

Writing my dissertation without the presence of my friends would had been more difficult. Cecile, Claire, Laure - this dissertation is to remind us of the time we used to spend together in high school and at the university. Gaelle - this is to remind us of Montreal and all the discussions we had about what we wanted to be or not in life. Que sera sera. Sophie - we met at that early point in one's life when the future is not important enough to be thought of. The dissertation is a reminder that we are not children anymore, but that a lot from our childhood stays. All girls - your friendship means a lot to me and was certainly of help while I was working on my thesis. To all my close family members - I want to thank you for always trusting me, giving me love and freedom in my choices.

I dedicate this dissertation to Nikos and my daughters Elise and Sofia.

Nikos - thank you for being next to me, your support and love. Thank you for your help, advice and your precise comments on how to improve my chapters. I have learnt a lot from the way you identify and investigate research questions. Our discussions on various ideas have always brought me a lot. The way you care for people in general shows that selfishness is definitely not in all human beings (even economists). I am grateful for the way you always look at the bright side of things and make the impossible happen. $\Sigma^{\prime}$ $\alpha \gamma \alpha \pi \omega$.

Elise and Sofia - I love you. Watching you grow is the most beautiful experience. I am and will always be proud of you, whether or not you ever write a $\mathrm{PhD}$ thesis or read mine! 


\section{Chapter 1}

\section{Introduction}

Most economic textbooks and models assume that individuals are driven by a desire to maximize their welfare without any regard for that of others. Over the past twenty years, however, laboratory experiments have repeatedly yielded evidence raising questions about whether all people are self-regarding. Participants in hundreds of different experiments around the world have been found to take actions that are costly to them in order to punish unfair behavior, reward generous actions, or simply to help others, even in one-shot interactions (see e.g., Camerer, 2003). Although different explanations for this behavior have been proposed over the years such as that subjects make errors, the explanation that has received the most attention is that at least some individuals are other-regarding.

As a response to this evidence, a new generation of economic models emerged in the last decade in which individuals are assumed to exhibit social preferences, that is, the agents' utility is assumed to depend partly on the welfare (and sometimes even the actions) of other individuals (e.g., Bolton and Ockenfels, 2000; Cox et al., 2007; Falk and Fischbacher, 2006; Fehr and Schmidt, 1999). These models have helped organize many of the behavioral regularities observed in laboratory experiments such as voluntary contributions to the production of public goods and gift exchange between firms and workers. In addition, they have provided the theoretical basis for countless new studies. However, in spite of two-decades worth of experiments, our knowledge about the nature of social preferences and their economic significance is incomplete.

This thesis aims to contribute to our understanding of social preferences and why they may matter. It consists of four chapters. The first study presented in Chapter 2 (with Arno Riedl) investigates workers' preferences for reciprocation in a gift-exchange 
game (henceforth GEG) and whether the GEG can be sustained in the long run. In the experiment, we elicit subjects' reciprocal preferences in a firm-worker gift-exchange setting and relate them to actual behavior in a repeated gift-exchange game. Our research strategy is similar to that of Fischbacher and Gächter (2010) who examine the impact of reciprocal preferences on voluntary contributions to a public good. We find that only a small minority of 10 percent of workers is materially selfish whereas 90 percent exhibit reciprocal preferences. However, the intensity of reciprocal preferences is weak in the sense that firms maximize profits by not relying on gift-exchange but by offering the lowest possible wage. Workers behavior in the repeated gift-exchange game is predicted by their elicited preferences, but the correlation between preferences and behavior is imperfect. Together with profit maximizing behavior of firms these observations can explain the observed unraveling of gift-exchange over time in our experiment and some recent field experiments. Our findings offer an explanation for the unraveling of giftexchange observed in some other gift-exchange experiments in the laboratory.

My second study discussed in Chapter 3 (with Nikos Nikiforakis) further explores the predictive power of elicited social preferences. Unlike the experiment in Chapter 2, the study examines whether individuals that behave pro-socially in one game do the same in a strategically different game. This is what is implicitly assumed by models of social preferences that aim to provide a parsimonious explanation for pro-social behavior. For example, according to these models, all else equal, an individual that dislikes strongly inequality in payoffs should be willing to reciprocate high wages in a gift-exchange game with high levels of effort, and to contribute a positive amount towards the public good if others do the same. The laboratory experiment aims to investigate the existence of a link between preferences for reciprocation and cooperation at the individual level. We perform a within-subject analysis of pro-social behavior in two of the most widely used games in the literature: the public-good (PGG) and gift-exchange game (GEG). After eliciting subjects cooperation preferences in the PGG using the method of Fischbacher et al. (2001), participants play the GEG for ten periods. We find that subjects classified as cooperators in the PGG reciprocate higher wages by exerting higher levels of effort in the gift exchange game, but they do not offer higher wages.

Chapter 4 presents the results from an experiment examining the robustness of the preferences elicited with the strategy method used in Chapter 3 (and also provided the 
inspiration for the method used in Chapter 2). Evidence from laboratory experiments indicates that many individuals are willing to cooperate provided that others in their group do the same. At the same time, there is also evidence that framing affects cooperation in public-good games and other social dilemmas. However, it remains unknown whether framing affects subjects' beliefs or whether it affects their cooperation preferences. The experiment reported in this chapter investigates whether preferences for cooperation elicited using the method of Fischbacher et al. (2001) are subject to framing effects. In particular, the experiment varies two features of the Fischbacher et al. (2001) method: the sequence and order in which the contributions of other group members are presented. The predictive power of the elicited preferences is evaluated in a one-shot and a finitely-repeated public-good game. The results indicate that the order in which the contributions of others are presented, by and large, has no impact on the elicited preferences and their predictive power. In contrast, presenting the contributions of others in a sequence has a pronounced effect on the elicited preferences and reduces substantially their predictive power.

The experiment presented in Chapter 5 (with Arno Riedl) differs from the work presented in the previous chapters in that it takes for granted the existence of social preferences. The study focuses on the impact social networks may have on alleviating one of the most well-known economic problems: adverse selection in the labor market. In the last decade, the economics literature has investigated the link between social networks and phenomena such as crime, wage dispersion, price formation, and virus spreading. In addition, empirical studies have found evidence that firms often hire workers using the social contacts of their workers. The aim of the experiment in this chapter is to investigate whether firms use the social network of their workers to hire new workers, under what conditions they do so, and ultimately, whether social networks reduce the adverse selection problem. Our results show that firms are indeed significantly more likely to make "referral offers" when the worker hired in the first stage is of high ability due to the homophily between workers. Referral offers are higher on average than public offers. We also find that firms are more likely to make higher offers to attract high-ability workers with a better network. Finally, we find that the proportion of high-ability workers in the second stage is higher when there is a social network.

Chapter 6 concludes the thesis by summarizing the main findings and considering questions for future research. 


\section{Chapter 2}

\section{Imperfect reciprocators and the unravelling of gift exchange}

\subsection{Introduction}

The question of how to overcome moral hazard has been a topic of continuing interest for economists. Several mechanisms have been proposed to reduce workers' propensity to shirk (e.g., Grossman and Hart, 1981, Shapiro and Stiglitz, 1984, Mas-Colell et al., 1995). Akerlof $(1982,1984)$ was the first to suggest that workers may be driven by fairness and a taste for reciprocity, which may help overcome moral hazard. In his model workers may be willing to exert higher levels of effort in response to higher wages, even when effort is not enforceable. In anticipation of workers' reciprocity, profit maximizing firms may be willing to offer wages above workers' reservation wages. Akerlof (1982) coined the term gift-exchange to describe this reciprocal relation between firms and workers. Fehr et al. (1993, henceforth FKR) were the first to test Akerlof's hypothesis in the laboratory and developed the gift-exchange game (henceforth, GEG) for this purpose.

The GEG is a simple two-stage game. In the first stage, a firm offers a wage to a worker who, in the second stage, decides how much effort to exert. Effort is costly for the worker and beneficial for the firm. Therefore, under standard assumptions of rationality and material self-interest, the unique subgame-perfect Nash equilibrium of the finitely-repeated GEG is for the worker to exert minimum effort and for the firm to offer the smallest possible wage, satisfying worker's participation constraint. Both parties would be materially better off, however, if the firm offered a higher wage and the worker 
reciprocated by exerting higher levels of effort. In contrast to the standard prediction and in line with Akerlof's prediction, FKR found that workers do reciprocate higher wages with higher effort levels. This result attracted considerable attention as it suggested that reciprocal behavior may indeed help to overcome the moral hazard problem inherent in incomplete contracts. Consequently, in a stream of studies the existence and robustness of gift exchange in various situations has been investigated. ${ }^{1}$

Most studies corroborate the initial finding of workers' willingness to reciprocate high wages with higher effort levels as a robust phenomenon in laboratory experiments. However, some studies have also shown that the sustainability of gift exchange may depend on a number of factors, as salience of monetary incentives (Charness et al., 2004), potential efficiency gains (Engelmann and Ortmann, 2009), participants' background (Hannan et al., 2002), the presence of a minimum wage (Kagel and Owens, 2010), or the ability to establish a long-term relationship between firms and workers (Brown et al., 2004). Further, few field experiments suggest that workers' positive effort response to an unexpectedly high wage may fade out over time (Gneezy and List, 2006, Kube et al., 2013).

This chapter presents the results from a laboratory experiment investigating the fundamental issue of workers' preferences for reciprocity in the GEG. Specifically, we investigate the intensity of these preferences, their heterogeneity among workers, and how this relates to the wage-effort dynamics in a finitely-repeated GEG. For this purpose, the experiment consists of two parts. In the first part, we elicit (amongst others) workers' reciprocal preferences in a one-shot GEG. In the second part, workers play a finitely-repeated GEG. ${ }^{2}$

The results indicate that only a minority of subjects in the role of a worker exhibits materially selfish preferences, whereas 90 percent of the workers exhibit reciprocal preferences. That is, a huge majority is willing to respond to higher wages with higher effort levels, even in a one-shot situation. Importantly, however, all reciprocal workers show a relatively weak intensity of reciprocal preferences, in the sense that firms could earn a

\footnotetext{
${ }^{1}$ See, e.g., Fehr et al. (1997, 1998b,a), Fehr and Falk (1999), Charness (2004) for studies on gift exchange and, e.g., Fehr and Gächter (2000), Charness and Rabin (2002), Camerer and Fehr (2004), Dufwenberg and Kirchsteiger (2004), Sobel (2005), Falk and Fischbacher (2006) for a more general discussion of reciprocity. Fehr et al. (2009), Charness and Kuhn (2011), Cooper and Kagel (2012), Casoria and Riedl (2013) provide recent surveys on gift exchange experiments and related issues.

${ }^{2}$ To our knowledge only a few other studies have elicited workers' preference for reciprocity in the GEG (Maximiano et al., 2007, Gächter and Thoni, 2010, Maximiano et al., 2013). These papers differ from our study as they do not classify workers types as we do in this paper and they also do not investigate the relation of elicited preferences on behavior in the finitely-repeated game. Moreover, these studies use variants of the GEG with multiple workers.
} 


\begin{tabular}{|c|c|c|c|c|c|c|c|c|c|c|}
\hline$e$ & 1 & 2 & 3 & 4 & 5 & 6 & 7 & 8 & 9 & 10 \\
\hline \hline$c(e)$ & 0 & 1 & 2 & 4 & 6 & 8 & 10 & 12 & 15 & 18 \\
\hline
\end{tabular}

Table 2.1: Cost of effort

higher profit, would they offer the smallest possible wage. In the finitely-repeated GEG we observe a steady decline of effort and wage levels over time. We observe that in the repeated GEG workers behavior is strongly correlated with their elicited preferences. However, we also observe that their exerted effort is not fully consistent with the elicited preferences. We argue that the observed downward cycle of wages and effort can be attributed to a combination of firms' maximizing profits, workers' relatively weak intensity of reciprocal preferences, and the imperfect correlation between preferences and behavior. This also offers an explanation for the unraveling of gift-exchange observed in some other gift-exchange experiments in the laboratory (Brown et al., 2004, Engelmann and Ortmann, 2009) and the field (Gneezy and List, 2006, Kube et al., 2013).

The rest of the chapter is organized as follows. In Section 2 we introduce the design of the experiment. In Section 3 we present the results and Section 4 concludes.

\subsection{The experiment}

\subsubsection{Experimental design}

The experiment consists of two parts. In the first part, we elicit participants' reciprocal preferences in the gift-exchange game using the strategy method introduced by Selten (1967) (see Brandts and Charness, 2011, for a recent survey). In the second part, participants play a finitely-repeated version of the gift-exchange game. In the following, we first introduce the gift-exchange game we implemented. Thereafter, we discuss the details of the two parts of the experiment and report on the experimental procedures.

The implemented gift-exchange game is a two-person game consisting of two stages. The first player (firm) decides on a wage $w \in\{0,5,10,15, \ldots, 100\}$ to be paid to the second player (worker). Knowing the wage, the worker decides on a level of effort $e \in$ $\{1,2,3, \ldots, 10\}$ to exert. Effort is costly for the worker and the costs of effort $c(e)$ are shown in Table 2.1 .

The profit of the firm and the earnings of the worker are given by 


$$
\begin{gathered}
\pi_{f}=10 e-w+50 \\
\pi_{w o}=w-c(e)+20
\end{gathered}
$$

respectively. These payoff functions closely resemble those used in Brown et al.(2004).

Assuming common knowledge of rationality and narrow material self-interest the unique subgame-perfect Nash equilibrium is given by the firm offering the lowest possible wage $(w=0)$ and the worker exerting the lowest possible effort $(e=1)$. The resulting payoffs are $\left(\pi_{f}, \pi_{w o}\right)=(60,20)$. However, a number of experiments have shown that many workers are willing to respond to higher wages with higher effort levels. That is, effort is an increasing function of wage: $e=e(w)$ and $e^{\prime}(w)>0$. For a profit maximizing firm anticipating this relation, the maximization problem becomes

$$
\max _{e} \pi_{f}=10 e(w)-w+50
$$

This implies that, if workers are sufficiently reciprocal, it may be profitable for firms to offer positive wages. This will be the case when $e^{\prime}(w)>\frac{1}{10}$ as this implies $\left.\frac{d \pi_{f}}{d w}\right|_{w=0}>0$. For example, let us assume that there is a linear relationship between effort and wage, that is, $e(w)=k w+c$, where $k$ captures the strength of workers' reciprocity and $c$ a constant. ${ }^{3}$ If $k>\frac{1}{10}$, then it will be profitable for a firm to offer a wage $w>0$. Conversely, if $0<k<\frac{1}{10}$, then firms maximize their profit by offering the minimal wage, $w=0$.

\subsubsection{Part 1: Elicitation of reciprocal preferences and beliefs}

To elicit workers' reciprocal preferences in the GEG we use the strategy method. Assuming that workers reciprocal preferences do not change, at least in the short term, the results from the strategy method will allow us to test the impact of these preferences on workers' effort choices in the finitely-repeated GEG. It also allows us to examine the intensity of reciprocal preferences and whether the extent of reciprocity will be sufficient for firms to earn higher profits with positive wages than with the lowest possible wage of zero.

At the start of Part 1, participants in the experiment were randomly assigned the

\footnotetext{
${ }^{3}$ As we will see, this assumption is in line with our data.
} 
role of either a firm or a worker. These roles remained fixed throughout the experiment. Each participant in the role of a worker was asked to fill out a wage-effort table were $\mathrm{s} /$ he had to state the effort level $\mathrm{s} /$ he was willing to exert for each possible wage $w \in\{0,5,10,15, \ldots, 100\}$ offered by the firm. Hence, each worker had to make 21 effort decisions.

Each participant in the role of a firm had to decide on the wage that would actually be paid to a randomly matched worker. All firms and workers made their decisions independently and anonymously. The actual wage and the chosen effort corresponding to that wage determined participants earnings in this part, ${ }^{4}$ which guaranteed incentive compatibility of both effort and wage choices.

After having made their wage and effort decisions, firms and workers were asked to state their beliefs regarding the actions of their matched counterparts. That is, each worker had to provide an estimate of the wage s/he would be offered by the firm and each firm had to provide an estimate of the effort chosen by the matched worker for the actually offered wage. Participants were rewarded for the accuracy of their estimates. If the estimate was exactly right, three additional points were earned. If the estimate deviated by one unit (two units) from the actual decision, then two (one) additional point(s) were earned. Larger deviations earned nothing. At the end of Part 1, each worker was informed about the wage actually offered by the matched firm and each firm got to know the effort exerted by the matched worker. They were also informed about the accuracy of their estimates.

\subsubsection{Part 2: The finitely-repeated gift-exchange game}

The second part of the experiment consisted of a gift-exchange game repeated for ten periods. Each participant stayed with the same role (firm or worker) as in Part 1, but workers and firms were randomly re-matched at the beginning of each period. Each period consisted of two stages. In the first stage, firms had to decide on a wage level and to provide an estimate of the effort that would be chosen by the matched worker. At the same time, workers had to indicate the wage they believed the matched firm will offer. In the second stage, workers learned the actual wage and had to decide on the

\footnotetext{
${ }^{4}$ For example if the firm offers a wage of 15 in the strategy method and the worker entered 2 in the table, the firm's earning is 55 and the worker's earning is 34 .
} 
effort level. Since the game is played for an ex ante known finite number of periods, the subgame-perfect Nash equilibrium of the stage game is also an equilibrium of the finitely repeated game.

\subsubsection{Procedures}

The experiment was conducted at the Maastricht University Behavioral and Experimental Economics laboratory (BEElab). Four sessions were run with a total of 40 participants. All participants were students at Maastricht University. They were recruited via e-mail and had to register on-line. Interactions in the experiment were fully computerized using Z-tree (Fischbacher, 2007). At the beginning of each session participants were randomly allocated to a closed cubicle where they could make their decisions in complete anonymity from the experimenter and other subjects.

The instructions (see Appendix A.2) were given to participants on paper and each of the parts was explained in detail. Instructions for Part 1 were handed out first. Participants were informed that there would be a second part to the experiment, but they had no prior knowledge of what the content of the second part would be. Instructions for the second part were not given until the end of Part 1. After participants read the instructions, they were asked to answer a set of control questions. The aim of these questions was to evaluate their understanding of the experiment. The experiment did not start until all participants had answered correctly the control questions. Procedures for the second part of the experiment were the same. On average, sessions lasted 90 minutes and participants earned on average 19 Euros per session.

\subsection{Results}

We first analyze workers' elicited reciprocal preferences in Part 1 and then proceed to examine whether they can explain the behavioral dynamics in the finitely-repeated GEG.

\subsubsection{Reciprocal preferences}

Result 1 Ninety percent of workers exhibit reciprocal preferences and only ten percent are fully selfish. 
SUPPORT: For the classification of workers as reciprocal or selfish types we adapt the method introduced by Fischbacher et al. (2001) and Fischbacher and Gächter (2010). The rules for determining the type of a worker are as follows. If the effort choices of a worker exhibit a monotonic pattern with at least one increase with increasing wage, then the worker is classified as having reciprocal preferences (or being a 'reciprocator'). A worker is also classified as being a reciprocator if there is a significant positive correlation at the 1-percent level between effort and wage, using Spearman's rank correlation coefficient. Workers who always exert the lowest possible effort (i.e., $e=1$ for all $w \in\{0,5,10,15, \ldots, 100\})$ are classified as selfish. Workers who do not meet any of these criteria are classified as other. Using the described criteria, we can classify 10 percent of workers as selfish and 90 percent as reciprocators. We do not identify any other types.

The share of reciprocators is remarkably high. However, the fact that a worker exerts higher effort for higher wages does not necessarily imply that a high wage is profitable for the firm. Whether high wages are profitable for firms depends on the intensity of the worker's reciprocal preferences. For instance, in our experiment, if $w=50$ and $e=5$ then a firm earns 50 and the worker 64 . In such a case a profit maximizing firm would be better off offering the smallest possible wage, $w=0$, which secures a profit of 60 . For $w=50$ to be more profitable for the firm than $w=0$, a worker must exert an effort of at least 6 . Hence, only if the intensity of workers' reciprocal preferences is strong enough firms' will have an incentive to offer high wages, which is a necessary condition for gift-exchange to prevail.

For this purpose, we develop a measure that allows us to quantify the intensity of reciprocal preferences and determine whether it is sufficient to sustain gift-exchange. We call this measure the reciprocation index, $R I$, which classifies workers with respect to the extent of their reciprocation. For each individual $i$, the index is defined as

$$
R I_{i}=\frac{\sum_{k=0}^{M}\left(e_{k i}-\underline{e}\right)}{M(\bar{e}-\underline{e})}
$$

where $e_{k i}$ is the effort level of individual $i$ for $w=k, \bar{e}$ is the maximum effort possible (in our case, 10) and $\underline{e}$ is the lowest effort possible (in our case, 1 ), and $M$ is the number of different wage levels (in our case, 21). The index ranges from 0 to 1 , where 0 depicts a selfish worker who always chooses the lowest possible effort, and 1 depicts a worker who 
always chooses the highest possible effort irrespective of the wage s/he receives.

In the following, we distinguish between strong and weak reciprocators. A worker is said to be a strong reciprocator when s/he displays an intensity of reciprocal preferences that makes it profitable for the firm to offer a wage above the lowest possible wage. That is, for all wages above zero the firm earns a profit at least as high as the profit it could guarantee by offering exactly zero. ${ }^{5}$ Weak reciprocators are said to be those who, although responding to higher wages with higher effort, on average, leave firms worse off when they offer wages higher than the lowest possible wage than when they offer exactly that wage.

In our experiment, the profit a firm can guarantee itself by paying the lowest possible wage $(w=0)$ is $\pi=60$. The reciprocation index of a worker $i$ who, on average, chooses effort levels that leave the firm with $\pi=60$ is $R I_{i}=0.57$. Therefore, we call worker $i$ a strong reciprocator if $R I_{i} \geq 0.57$, and a weak reciprocator if $R I_{i}<0.57$. Note, that this classification does not imply that firms matched with a weak reciprocator will be worse off for all wages larger than the lowest possible wage. However, firms matched with weak reciprocators will be better off offering them $w=0$.

Result 2: All workers with reciprocal preferences are weak reciprocators, in the sense that a firm maximizes its profit by offering the lowest possible wage.

SUPPORT: Figure 2-1 displays the distribution of the reciprocation index of workers as reciprocators. Selfish participants have an index of 0 and are not shown. As can be clearly seen none of the reciprocal workers has a reciprocation index equal to or greater than 0.57. Consequently, all workers with reciprocal preferences are weak reciprocators.

Figure 2-2 shows the average effort as a function of wage for our identified types. In the figure, 'reciprocators' and 'selfish' are defined as explained in the support of Result 1. The 'reference level of effort', $r(w)$, is the effort level that guarantees the firm a profit of at least 60 for each wage level. It is given by

$$
r(w)=\left\{\begin{array}{c}
\underset{e}{\arg \min }\{\pi(w ; e) \geq 60\} \text { if } w \leq 95 \\
10 \text { otherwise. }
\end{array}\right.
$$

for each wage $w \in\{0,5,10,15, \ldots, 100\}^{6}$

\footnotetext{
${ }^{5}$ Classifying workers in that way as strong reciprocators is rather conservative as it assumes narrowly selfish firms which engage in gift-exchange only if it increases their profits. Later we briefly discuss an alternative approach in which reciprocators are classified as strong when they choose effort levels that make firms not worse off than themselves.

${ }^{6}$ Not that for $w \geq 95$ there is no level of effort that guarantees firms a payoff of 60 . It is interesting
} 


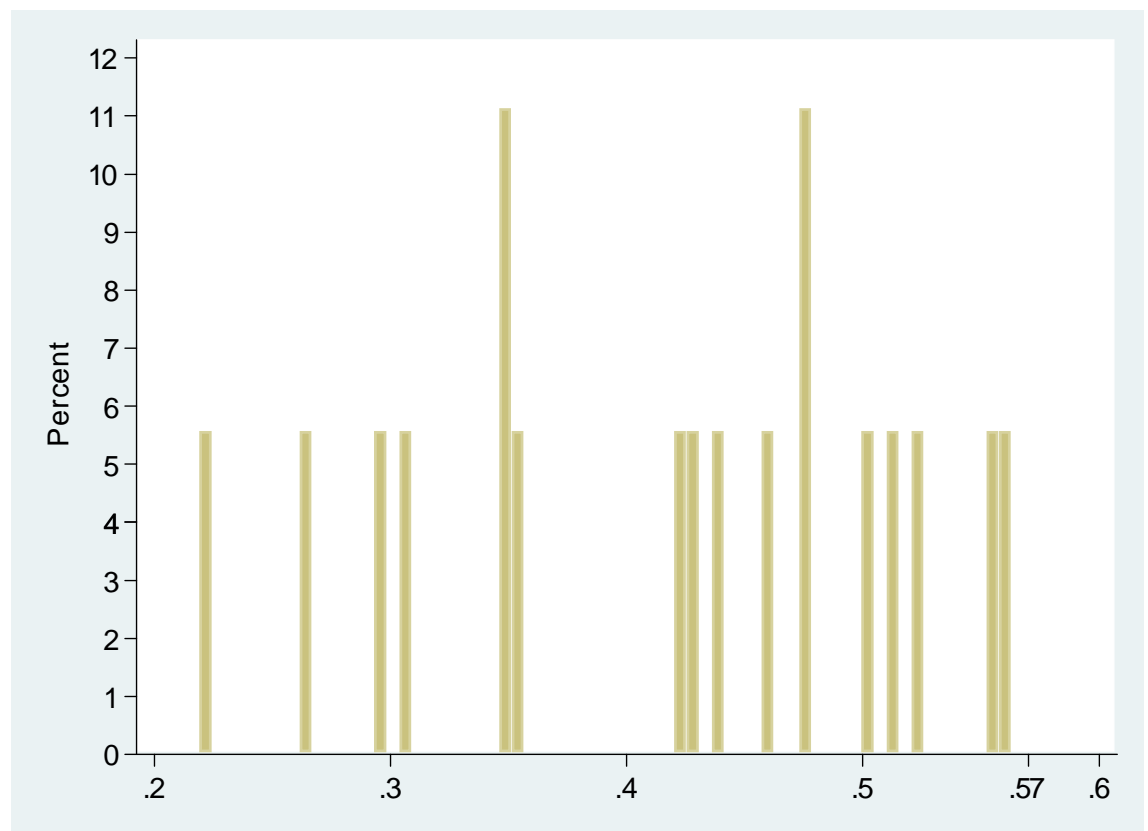

Figure 2-1: Distribution of the reciprocation index

Figure 2-2 highlights two points. ${ }^{7}$ First, overall, there is a clear positive relation between wages offered by firms and effort expended by workers. Second, while nearly all workers can be classified as reciprocators, their intensity of reciprocal preferences is below the reference level of effort, $r(w)$. A linear regression analysis (OLS and Tobit) with effort as the dependent variable and wage as the independent variable corroborates the expression gained from the figure. The OLS-estimated coefficient for wage is approximately 0.09 , which is slightly below the marginal effort of $1 / 10$, necessary for positive wages to be profitable for firms. Therefore, the extent of workers' reciprocal preferences is not sufficient to make firms better off in monetary terms, than they were when they would offer the lowest possible wage. Consequently, in case workers reciprocal preferences carry over to the finitely-repeated GEG, the prospects of sustaining gift-exchange are rather grim. This is what we explore next.

to note that, in only 2 out of 200 instances, a firm offered $w \geq 95$; a level of wage that implies $\pi_{f}<60$ for all effort levels.

${ }^{7} \mathrm{~A}$ graph showing the relationship between potential wages and level efforts for each individual can be see in the appendix A.1.1. 


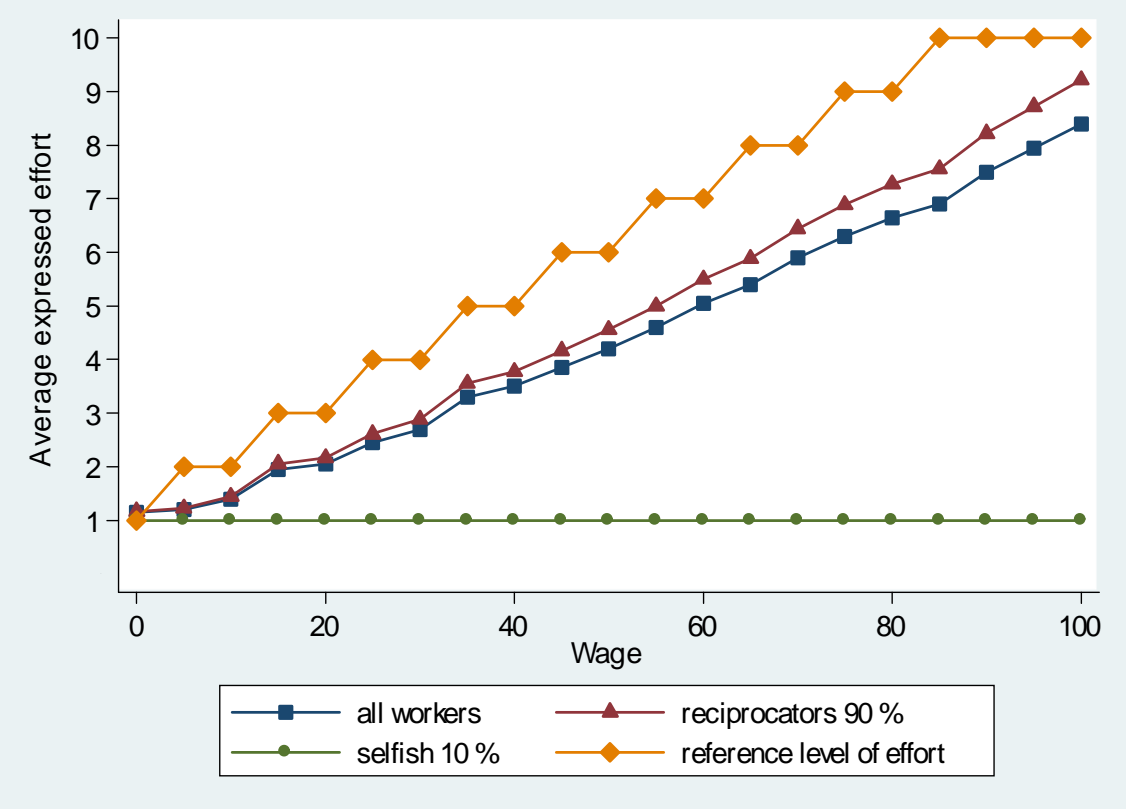

Figure 2-2: Effort as a function of wage (all workers and by type)

\subsubsection{The finitely-repeated gift-exchange game}

In this section, we will first investigate whether there is a positive wage-effort relationship in the repeated gift-exchange game and whether workers behavior is consistent with their elicited preferences. Then, we will look at the level and dynamics of wages and efforts and how these could be related to workers' preferences.

Result 3: In the repeated gift-exchange game, workers reciprocate a higher wage with higher effort. Moreover, workers' elicited reciprocal preferences are a good predictor of effort choices in the repeated game.

SUPPORT: Table 2.2 presents the results from GLS random effects panel regression analysis with the effort exerted by worker $i$ in period $t, e_{i t}$, as the dependent variable. ${ }^{8}$ Model 1 investigates how workers effort choices respond to received wages, controlling for time effects. The significantly positive coefficient of the wage variable indicates that workers reciprocate higher wages with higher effort choices, which is in line with most previous results of gift-exchange experiments. The estimated coefficient is rather small, however. As discussed above, from a firm's perspective gift exchange is profitable only if the mar-

\footnotetext{
${ }^{8}$ Since effort is bounded below by 1 and above by 10, we also ran Tobit regression with individual-level random effects. The results - reported in Appendix A.1.2 - are qualitatively similar to those reported here. See Charness et al. (2004) for a discussion of estimation methods in repeated gift-exchange games.
} 


\begin{tabular}{|c|c|c|c|c|}
\hline \multicolumn{5}{|c|}{ Dependent variable: effort } \\
\hline Model & $(\mathbf{1})$ & $(2)$ & $(3)$ & $(4)$ \\
\hline Workers used & All workers & Reciprocators & All workers & Reciprocators \\
\hline Period & $\begin{array}{l}-0.010 \\
(0.037)\end{array}$ & $\begin{array}{l}-0.021 \\
(0.040)\end{array}$ & $\begin{array}{l}-0.033 \\
(0.035)\end{array}$ & $\begin{array}{l}-0.038 \\
(0.039)\end{array}$ \\
\hline Wage & $\begin{array}{c}0.038^{* * *} \\
(0.005)\end{array}$ & $\begin{array}{c}0.042^{* * *} \\
(0.005)\end{array}$ & & \\
\hline Predicted effort & & & $\begin{array}{c}0.540^{* * *} \\
(0.059)\end{array}$ & $\begin{array}{l}0.532^{* *} \\
(0.063)\end{array}$ \\
\hline Constant & $\begin{array}{c}1.456^{* * *} \\
(0.303)\end{array}$ & $\begin{array}{c}1.560^{* * *} \\
(0.323)\end{array}$ & $\begin{array}{c}1.041^{* * *} \\
(0.318)\end{array}$ & $\begin{array}{c}1.129^{* * *} \\
(0.348)\end{array}$ \\
\hline$R^{2}$ (overall) & 0.23 & 0.26 & 0.24 & 0.22 \\
\hline Wald $\chi_{(2)}^{2}$ & 76.51 & 79.11 & 89.65 & 77.69 \\
\hline Observations & 200 & 180 & 200 & 180 \\
\hline
\end{tabular}

Table 2.2: Explaining effort choices in the repeated GEG

ginal effect is larger than 0.1. This suggests that gift-exchange will be difficult to sustain. Model 2 estimates the same relationship but excludes workers classified as selfish in Part 1. As expected the positive wage-effort relationship is stronger than in Model 1. However, given the small number of non-reciprocators in our sample, the change is only marginal.

To test whether workers' effort choices can be predicted with their elicited reciprocal preferences we construct the variable predicted effort. For each wage actually received in the repeated GEG, this variable takes the value of the effort chosen in the strategy method in Part 1. Elicited preferences have predictive power for actual effort choices in the repeated GEG when the coefficient is significantly positive. Perfect consistency would be reflected by a coefficient that equals 1 . This is tested in Model 3. As the estimated coefficient is positive and highly significant the results indicate that workers indeed show behavior consistent with their elicited preferences. However, the estimated coefficient is only slightly above one-half and, hence, elicited preferences do only imperfectly predict behavior. The same result holds when looking only at reciprocators (Model 4). Note that, because workers state reciprocal preferences in Part 1 and are behaving reciprocally in the repeated GEG, the explanatory variables wage and predicted effort are highly correlated (Spearman's $=0.785, p-$ value $<0.0001)$. Therefore, in regressions with both variables included one of them becomes insignificant and the coefficients are biased. We 


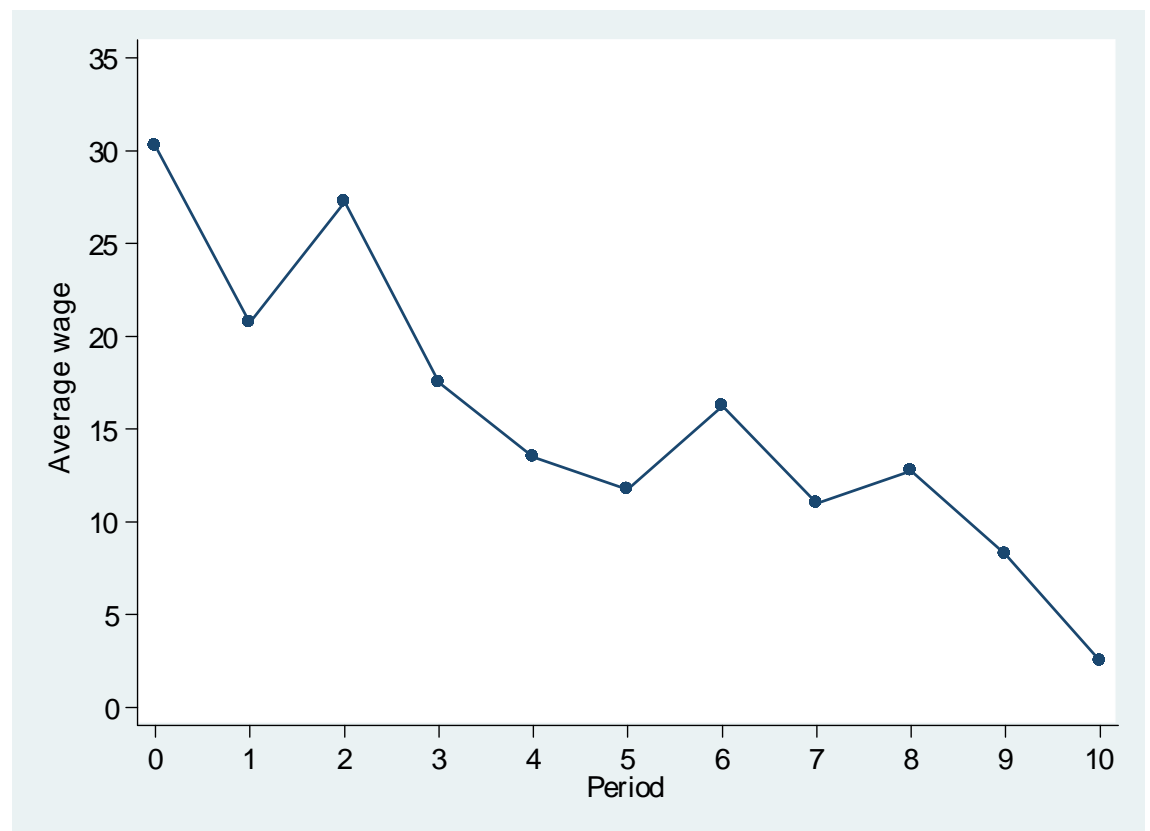

Figure 2-3: Average wage over time

have also run regressions where we added the expected wage as explanatory variable. The regression results do not change and expected wages are never significant. This indicates that any potential effect of the expected wage on effort choices is overwritten by the actually received wage.

Result 4: In the finitely-repeated game, gift-exchange unravels. That is, wages and effort levels decline over time toward the lowest possible values.

SUPPORT: Figures 2-3 and 2-4 show the evolution of average wage and effort over the 10 periods of the repeated GEG. (The figures also depict the average wage and effort for actual wages from Part 1 as "period 0".) Both, wage and effort, decline over time, although the decline is not monotonic at the aggregate level. The average wage in Part 2 of the experiment declines from 30.25 and 20.8 in period 0 and period 1 , respectively, to 2.5 in period 10. The average wage over periods $1-10$ is 14.2 . In the last period, 85 percent (17 of 20 instances) of the wages are equal to zero. The average effort in Part 2 declines from 2.9 and 2.2 in period 0 and period 1, respectively, to 1.4 in period 10. The average effort over period 1-10 is 1.9 . In the last period, the lowest possible effort level of zero is chosen in 90 percent of the cases (18 of 20) and the average effort is only 1.4. Hence, gift-exchange is clearly not maintained in Part 2 of the experiment. 


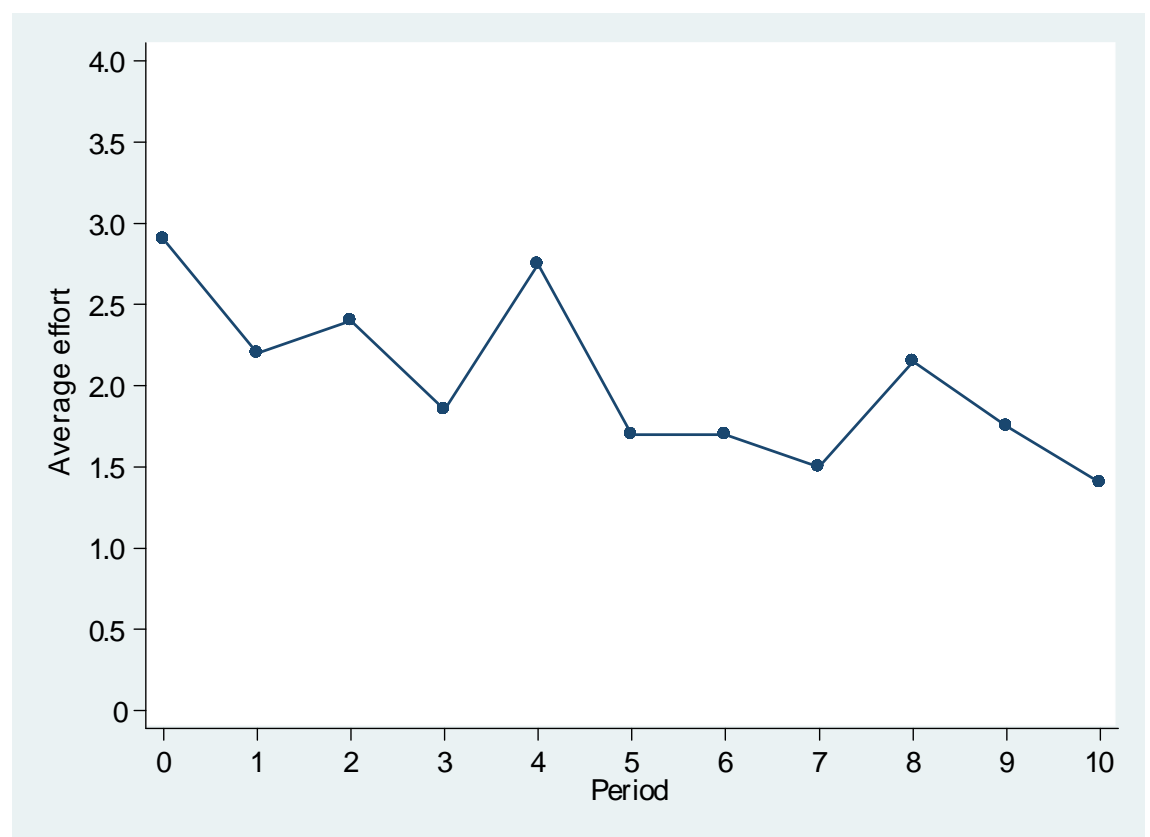

Figure 2-4: Average effort over time

Result 5: Given the workers' effort responses to wages, firms maximize profits by offering the lowest possible wage.

SUPPORT: Figure 2-5 presents the expected profit of firms in the finitely-repeated GEG for the different possible levels of wage, given the effort levels chosen by workers in Part 1 of the experiment. Figure 2-6 presents the same information, but given the effort levels in Part 2. ${ }^{9}$ These figures clearly illustrate that the profit maximizing strategy for firms is to offer $w=0$ - which guarantees $\pi=60$ - in both parts of the experiment.

\subsection{Discussion and conclusion}

There exists considerable evidence indicating individuals' willingness to reciprocate higher wages with higher effort levels in gift-exchange settings (Casoria and Riedl, 2013). Recently, however, there has been a discussion about the limits of gift-exchange in repeated

\footnotetext{
${ }^{9}$ Note that since $w>0$ was observed in only 37.7 percent of cases, we create bins of wages for Figure 4b. Bins are constructed such that there is a similar number of observation in each bin with $w>0$. In particular, there are 137 observations with $w=0,21$ observations with $w \in[5,20], 23$ observations with $w \in[25,40], 19$ observations with $w \in[45,60]$ and 20 observations with $w \in[65,100]$. To calculate the average profit in each bin, we use the actual average wage offered within this bin by firms (i.e., we do not take the midpoint of the interval). In the strategy method, there are 20 observations for each level of wage.
} 


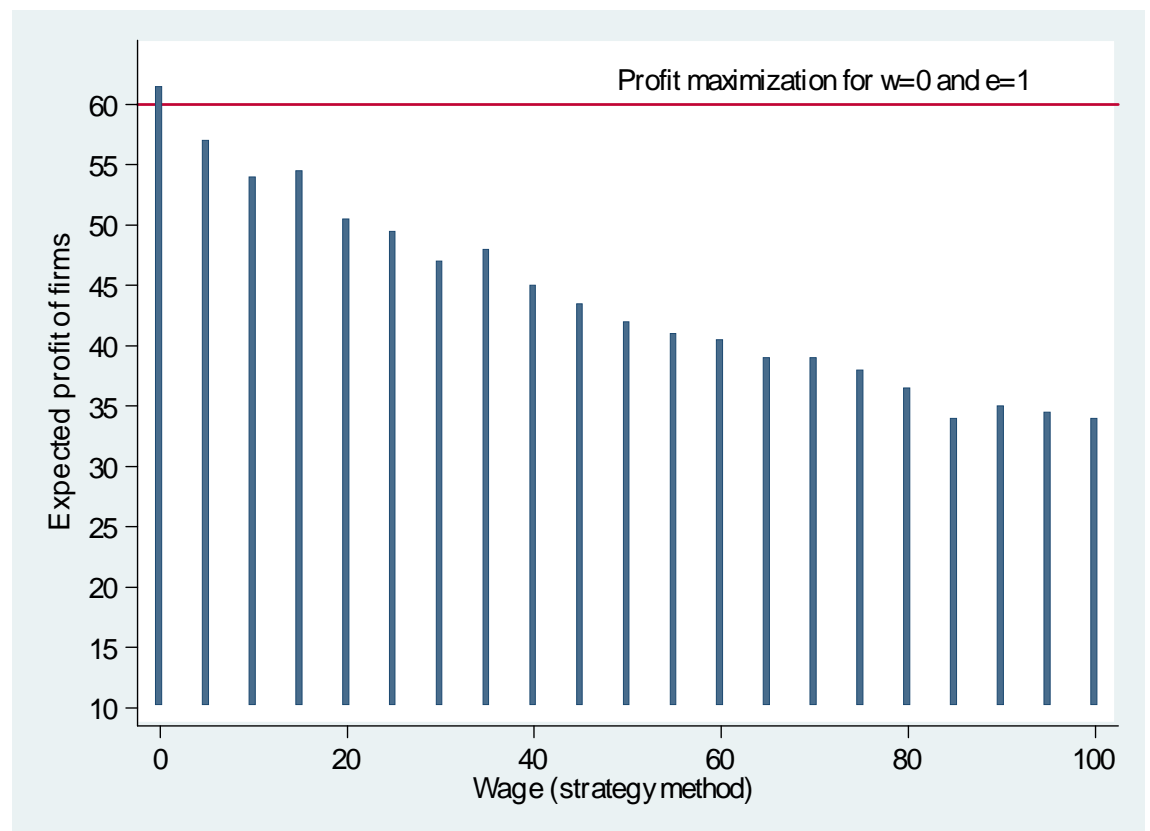

Figure 2-5: Expected profit of firms in Part 1 (preference elicitation)

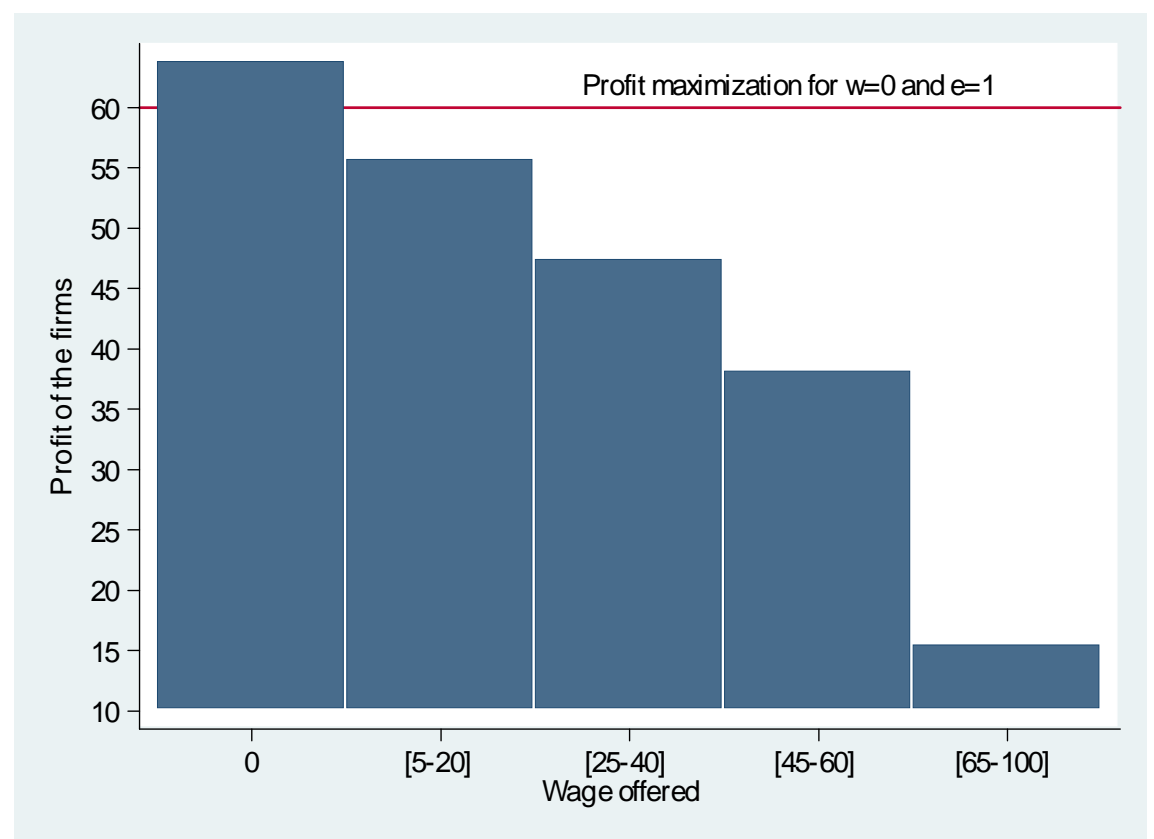

Figure 2-6: Expected profit of firms in Part 2 (repeated GEG) 
interactions in the laboratory (Brown et al., 2004, Engelmann and Ortmann, 2009) as well as in the field (Gneezy and List, 2006, Kube et al., 2013). To improve our understanding of when and why gift-exchange may unravel, we conducted a laboratory experiment using the strategy method to elicit reciprocal preferences of workers in a gift-exchange setting. In a second part, the same participants played a standard finitely-repeated gift-exchange game using random matching.

The results indicate that almost all workers (90 percent) in our sample exhibit reciprocal preferences. Nevertheless, with repetition gift-exchange unraveled as wages and efforts converged to the minimum levels possible. Two aspects of workers' behavior appear to be able to account for the observed unravelling of gift-exchange. The first factor is the relatively weak intensity of elicited preferences for reciprocation. This is reminiscent of the phenomenon of self-servingly biased fairness preferences in bargaining (Babcock et al., 1995, Gächter and Riedl, 2005) and conditional cooperation in public-good games (Fischbacher et al., 2001, Fischbacher and Gächter, 2010).

The second factor is that the extent of reciprocation is even weaker in the finitelyrepeated game than would be expected given the elicited preferences in the first part of the experiment. Fischbacher and Gächter (2010) observe a similar phenomenon in repeated public-good games. In their experiment, behavior is also only imperfectly predicted by elicited preferences. They identify "confused subjects" and beliefs about others contributions to the public good as explanatory factors for the discrepancy between elicited preferences and behavior. In our experiment none of these factors can help explaining the gap between preferences and behavior. First, none of our workers appears to be confused in the preference elicitation part. All are easily and clearly classifiable as either selfish or reciprocal. Second, beliefs - in our case expected wages - turn out to be unimportant in the determination of effort choices. This is also not too surprising given the sequential nature of the gift-exchange game. This leaves us with speculating about the reason of the imperfect correlation between elicited preferences and behavior. In our view, a reasonable explanation is that reciprocal preferences are actually not fixed but may respond to the environment the worker is in and the experiences a worker has. Such an explanation is consistent with theoretical ideas arguing that (social) preferences may respond to the economic environment and past experiences in a given environment, which recently also have been found some empirical support (Bowles, 1998, Brandts et al., 2009, Bowles and 
Polania-Reyes, 2012). In our study the relatively low wages experienced in Part 1 of the experiment and in early rounds of Part 2 of the experiment may have crowded out reciprocal preferences or at least further weakened their intensities.

An alternative explanation for the relatively weak intensity of reciprocal preferences may be that workers care about the inequality in earnings between themselves and the firms. Taking this possibility into account, one may wonder whether equality of earnings requires lower levels of effort than those which secure firms a profit of 60 . This is not the case, however. The level of effort required to minimize the earnings difference between firms and workers is indeed $e=1$ when $w \leq 20$, but it increases quickly for $w \in[25,75]$. For example, a worker who wishes to minimize inequality in earnings for $w=65$ should already choose $e=9$. Specifically, the level of effort required to minimize inequality in earnings is greater than the level of effort that guarantees firms a profit of 60 when $w>60$. To test formally how concerns for inequality may affect effort levels, we constructed the variable fair fair effort $=\arg _{e} \min \left\{\pi_{f}-\pi_{w}\right\}$ and ran a Tobit regression with individual random effects for the reciprocal workers using the level of effort expended by the worker in the strategy method as the dependent variable and fair effort as the independent variable. For comparison, we ran a similar regression using the reference level of effort $r(w)$ as the independent variable. ${ }^{10}$ Both explanatory variables are significantly correlated with effort, but the log-likelihood of the second empirical model is substantially lower than that of the first model (-461.9199 vs. -536.40822 ) suggesting that it provides a better explanation for workers behavior.

In summary, the experimental results indicate that reciprocal preferences that are too weak to make high wages profitable for the firm can help explain the unravelling of gift-exchange in previous experiments (Brown et al., 2004, Gneezy and List, 2006, Engelmann and Ortmann, 2009, Kube et al., 2013). In addition, we identify the imperfect "translation" of reciprocal preferences into reciprocal actions as another potential reason for the breakdown of gift-exchange. As neither confusion nor beliefs can explain this phenomenon, it may be a worthwhile avenue for future research.

\footnotetext{
${ }^{10}$ Recall, that $r(w)$ is the minimal effort level that guarantees the firm a profit of at least 60 for each wage level.
} 


\section{Chapter 3}

\section{Cooperators and reciprocators: A}

\section{within-subject analysis of pro-social}

\section{behavior}

\subsection{Introduction}

Behavioral economists have developed models of social preferences to provide a parsimonious explanation for the pro-social behavior observed in a wide range of games (e.g., Bolton and Ockenfels, 1999; Charness and Rabin, 2002; Cox et al., 2007; Fehr and Schmidt, 2000). Although these models have been used extensively by experimental economists to obtain theoretical predictions for their studies, there is hardly any evidence about the correlation of pro-social behavior across strategically different games at the individual level. Our study contributes to filling this gap in the literature.

We utilize a within-subject design to compare behavior in two of the most widelystudied games in the literature: the linear public-good game and the gift-exchange game. The games share an important property. They are both social dilemmas with a unique, inefficient Nash equilibrium under the standard assumptions. At the same time, they are strategically different. The public-good game is a simultaneous-move game, whereas the gift-exchange game is a sequential-move game. Therefore, they seem a natural starting point for a within-subject comparison of pro-social behavior.

Our goal is to investigate whether individuals that behave pro-socially in one game are also more likely to behave pro-socially in the other game. The aforementioned models 
of social preferences assume this to be the case. For example, individuals that dislike inequality in earnings or care strongly for the welfare of the worse-off member in their group should be willing to reciprocate high wages in the gift-exchange game and to contribute to the public good if others do the same, all else equal. If they are not, that is, if we find no correlation of pro-social behavior at the individual level, this will raise questions about whether social preferences are the cause of deviations from the standard predictions.

Despite the importance of such an analysis, there is only one study comparing prosocial behavior across strategically different games. ${ }^{1}$ Blanco et al. (2011) use four one-shot games (a modified dictator game, an ultimatum game, a two-person public-good game and a sequential prisoner's dilemma). The authors estimate individual Fehr-Schmidt utility functions and test their predictive power. While Blanco et al. find significant correlations of pro-social behavior across games, they also report a multiplicity of motives driving this behavior which cannot be easily accounted by a single behavioral model. For this reason, in our analysis below, we restrict ourselves to reporting correlations of behavior across games without testing a specific model.

Our study complements that of Blanco et al. by using different games and protocols to theirs. First, while the gift-exchange game is a sequential social dilemma, it differs from a sequential prisoner's dilemma in that each player has multiple actions available. Larger action sets have been shown to affect pro-social behavior negatively (Gangadharan and Nikiforakis, 2009). Second, Blanco et al. (2011) use four two-person games. In contrast, we examine behavior in a three-person public-good game and a two-person giftexchange game. We think this is interesting as most public-good games use more than two players. In addition, there is evidence that cooperation rates tend to be higher and not to decline over time in two-person public-good games (Gangadharan and Nikiforakis, 2009). Finally, while Blanco et al. (2011) utilize four one-shot games, for reasons we explain in the following section, we employ a finitely-repeated gift-exchange game and also use the strategy method to elicit cooperation preferences in the public-good game.

\footnotetext{
${ }^{1}$ See Andreoni and Miller (2002) and Fisman et al. (2007) for a within-subject analysis of behavior in different dictator games.
} 


\subsection{The experiment}

A total of 48 students from Maastricht University participated in the experiment that was conducted using z-tree (Fischbacher, 2007). On average, the four experimental sessions lasted 90 minutes and participants earned 19 Euros. The instructions (see Appendix B) informed subjects that the experiment consisted of two parts, but they were unaware of the content of the second part until the first part was completed.

\subsubsection{Part 1: The public-good game}

In this part, subjects played a one-shot public good-game. The payoff of individual $i$ was given by $\pi_{i}=20-g_{i}+0.5 \sum_{j=1}^{3} g_{j}$, where $g_{i} \in\{0,1, \ldots 20\}$ is $i$ 's contribution to the public account, and 0.5 is the marginal return from the public account. Subjects contributions to the public account were elicited using the method of Fischbacher et al. (2001; FGF). In particular, participants had to decide on $(i)$ an unconditional contribution to the public account and (ii) a conditional contribution for each possible (rounded) average contribution of the other two group members $(0,1, \ldots 20)$.

All decisions were incentive compatible. After all individuals made their decisions, the computer selected randomly two subjects in each group and their unconditional contribution was implemented. The contribution of the third group member was chosen based on his/her conditional contribution and the average unconditional contribution of the other two group members. Subjects did not receive feedback about the choices of the other group members until the end of the second part.

We chose to use the FGF method as it allows for a straightforward comparison of prosocial behavior in the public-good game with that in the gift-exchange game. Unlike the unconditional contribution and similar to the second mover's decision in the gift-exchange game (see below), the conditional contribution is essentially belief-free. Therefore, this method provides ideal conditions for finding a correlation of pro-social behavior at the individual level.

\subsubsection{Part 2: The gift-exchange game}

In the second part, participants played a gift-exchange game for ten periods, using random matching. In each period, the first mover (FM) had to decide a wage $w \in$ 


\begin{tabular}{|c|c|c|c|c|c|c|c|c|c|c|}
\hline$e$ & 1 & 2 & 3 & 4 & 5 & 6 & 7 & 8 & 9 & 10 \\
\hline \hline$c(e)$ & 0 & 1 & 2 & 4 & 6 & 8 & 10 & 12 & 15 & 18 \\
\hline
\end{tabular}

Table 3.1: Cost of effort

$\{0,5,10,15, \ldots, 100\}$ to offer to the second mover (SM), who upon seeing the wage, had to choose a level of effort $e \in\{1,2,3, \ldots, 10\}$. The cost of effort $c(e)$ is given in Table 3.1. FM's payoff was given by $\pi_{F M}=10 e-w+50$, and SM's by $\pi_{S M}=w-c(e)+20$. Roles remained fixed throughout this part.

The main reason for using a finitely repeated rather than a one-shot gift-exchange game is that it allows learning about the incentives in the game. Assuming that prosocial behavior is driven by social preferences, this should reduce errors and increase the chance of finding significant correlations across the two games. The repeated interactions also allow participants to learn from others' choices. Therefore, they should minimize the likelihood of a consensus effect (see Altmann et al., 2008; Blanco et al., 2011), that is, that pro-social individuals have overall more "optimistic" beliefs about the willingness of others to reciprocate high wages.

\subsection{Results}

We first explore the relation between choices in the public-good game and SM's behavior in the gift-exchange game. Based on models of social preferences, we anticipate that high contributors in the public-good game will be more reciprocal on average than others. For our analysis, we classify subjects as cooperators or non-cooperators using the FGF criteria. ${ }^{2}$ A cooperator is an individual that is willing to contribute more, the more other group members contribute.

Result 1: Only cooperators reciprocate significantly higher wages with higher levels of effort in the gift-exchange game.

\footnotetext{
${ }^{2}$ Following FGF, participants who - with respect to the contribution of others - show either a monotonic pattern with at least one increase or have a positive Spearman-rank correlation that is significant at the 1-percent level are classified as (conditional) cooperators. For brevity, we use the term cooperator rather than conditional cooperator. We pool selfish and other types in one category, unlike FGF, as there are very few non-cooperators amongst second movers (cooperators: 18, selfish: 4; other: 2). Pooling the two types together, if anything, is expected to reduce the likelihood of finding signficant differences between cooperators and non-cooperators.
} 
SUPPORT: On average, over the ten periods of the experiment, cooperators chose an effort of 2.26, while non-cooperators chose an effort of 1.53 . This is a rather small difference, but it does not take into account the wages received by individuals, which were overall low on average $(\bar{w}=17.40)$. Table 3.2 presents the results from a random-effects regression analysis with robust standard errors. The dependent variable is the effort exerted by SM, while the independent variable of interest is the wage SM received. Model 1 indicates that cooperators reciprocate higher wages with higher effort $(p-$ value $<0.001)$. Model 2 illustrates that the relationship between effort and wage is much weaker and statistically insignificant for non-cooperators $(p-$ value $=0.386)$. Model 3 shows that the responsiveness to higher wages across types is not significantly different across types. This may seem surprising at first, but as it turns out the reason is that the majority of observations involves $w \leq 20$. When $w \leq 20$, however, as effort increases so does inequality to the disadvantage of SM. Thus, even pro-social SMs would be expected to choose $e=1$. If we exclude observations with $w \leq 20$, in Model 4, we find that the difference in the responsiveness to higher wages across types is significant $(p$-value $=0.028)$. This is the case although we are left with a small fraction of the total number of observations (69 out of 240). Finally, Model 5 indicates that our conclusions are unaffected if we use a Tobit model. Further analysis (not presented here) shows that Result 1 is robust if we focus on behavior only in period 1 , while we also do not observe a decrease in effort over time. ${ }^{3}$

Next we investigate the relation between choices in the public-good game and FM's behavior in the gift-exchange game. Note that if cooperators and non-cooperators have the same beliefs about the SM's behavior, then we should not expect substantial differences in the wages offered by FMs. The reason is that even money-maximizing FMs may have an incentive to offer high wages if they believe they are likely to be reciprocated with higher effort.

Result 2: Cooperators do not offer significantly higher wages than non-cooperators in the gift-exchange game.

SUPPORT: The average wage offered by a cooperator (non-cooperator) in the first period is 33.75 (37.50). A Mann-Whitney two-sided test fails to reject the hypothesis that the two types offer the same wages $(p$-value $=0.88) .{ }^{4}$ Across the 10 periods, the average

\footnotetext{
${ }^{3}$ For completeness, we report that there is no correlation between effort in the gift-exchange game and the unconditional contribution in the public-good game (random-effects regressions: $p-$ value $>0.65$ ).

${ }^{4}$ There were 12 cooperators and 12 non-cooperators amongst FMs (6 selfish, 6 others) using the FGF
} 


\begin{tabular}{lccccc}
\hline \hline \multicolumn{5}{c}{ Dependent variable: effort exerted by SM } \\
\hline \hline Model & $(\mathbf{1})$ & $(\mathbf{2})$ & $(\mathbf{3})$ & $(\mathbf{4})$ & $(\mathbf{5})$ \\
\hline Information used & cooperators & non-cooperators & all SM & wages $>20$ & Tobit \\
\hline Wage received & $0.058^{* *}$ & 0.019 & 0.020 & -0.007 & -0.037 \\
& $(0.015)$ & $(0.020)$ & $(0.022)$ & $(0.013)$ & $(0.062)$ \\
Cooperator & & -0.010 & -1.230 & -1.132 \\
& & & $(0.273)$ & $(2.248)$ & $(19.252)$ \\
Cooperator ${ }^{*}$ wage & & 0.038 & $0.056^{* *}$ & $0.112^{*}$ \\
& & & $(0.026)$ & $(0.024)$ & $(0.058)$ \\
Constant & $1.211^{* * *}$ & $1.233^{* * *}$ & $1.227^{* * *}$ & 2.776 & 0.471 \\
& $(0.157)$ & $(0.215)$ & $(0.225)$ & $(2.107)$ & $(19.232)$ \\
\hline Observations & 180 & 60 & 240 & 69 & 69 \\
\hline \hline
\end{tabular}

${ }^{*}$ p-value $<0.1,{ }^{* *}$ p-value $<0.05,{ }^{* * *}$ p-value $<0.01 ;$

Jackknife-robust standard errors are in parentheses;

Linear regressions with individual-level random-effects

Table 3.2: Explaining second mover's effort choices in the repeated GEG

wage offered by cooperators is higher than that offered by non-cooperators (22.79 vs. 12.00). However, even if we treat the average wage of each individual across periods as an independent observation (which increases statistical power, but is rather "heroic" given the random-matching protocol), the difference fails to be significant at the 10-percent level $(p$-value $=0.132)$. Similar conclusions are derived if we perform a random-effects linear (or Tobit) regression analysis with wage offered as the dependent variable and a cooperator dummy as the independent variable $(p$-value $>0.20) .{ }^{5}$ We also fail to find a significant relationship at the 10-percent level between wage offered and the unconditional contribution in the public-good game as the explanatory variable $(p$-value $>0.118) .{ }^{6}$ It is worth noting that the coefficient of the unconditional contribution is relatively small. In particular, we find that an individual contributing 10 ECUs more to the public account than others will give only a 7.3 ECUs higher wage in the gift-exchange game (recall $w$ can be 100). We also find no evidence of cooperators having more optimistic expectations about the extent of SM's willingness to reciprocate either in the first period or across all rounds $(p$-value $>0.20)$. As mentioned, this could account for the absence of a significant difference in the wages offered by cooperators and others.

\footnotetext{
criteria for classification.

${ }^{5}$ We ran several random-effects regressions with and without clustering at the individual or session level.

${ }^{6}$ Note that we also do not find a correlation if we restrict our analysis to the first period of the experiment $(p-$ value $>0.6)$.
} 


\subsection{Conclusion}

This chapter has presented the first evidence linking pro-social behavior at the individual level in two of the most commonly-used games in the experimental literature. In our experiment, individuals willing to cooperate with other group members in a publicgood game were also willing to reciprocate higher wages with higher levels of effort in a gift-exchange game. This is not the case for individuals who did not show a propensity to cooperate with others. Our findings therefore contribute to a still small body of evidence investigating the consistency of pro-social behavior in different environments. Such research is important for better understanding how this behavior can be captured in behavioral models. 


\section{Chapter 4}

\section{Cooperation preferences and framing effects}

\subsection{Introduction}

This chapter presents the results from a laboratory experiment investigating the sensitivity of cooperation preferences to framing effects. Cooperation preferences can be defined as the willingness to cooperate with others when private and group interest are at odds (Fischbacher and Gächter, 2010). Evidence from laboratory experiments indicates that, while some people are unwilling to cooperate with others, many individuals are willing to cooperate provided that others in their group do the same (e.g., Fischbacher, Gächter and Fehr, 2001; Kocher et al., 2008; Rustagi, Engel and Kosfeld, 2010; Thöni, Tyran and Wengström, 2012). At the same time, there is also evidence that framing affects cooperation in public-good games and other social dilemmas. Despite this, it remains unknown whether cooperation preferences are sensitive to framing effects.

A framing effect is said to occur when seemingly superficial changes in the presentation of a task affect behavior without affecting material incentives. For example, Andreoni (1995) finds that contributions in a public-good game are considerably lower when the experimental instructions emphasize the negative externality imposed to others by not contributing to the public good, than when they highlight the positive externality generated by contributions. Similarly, individuals are more likely to cooperate with others when the prisoner's dilemma is called the "Community Game" than when it is called the "Wall Street Game" (Kay and Ross, 2003; Liberman et al., 2004; Ross and Ward, 1996) 
or the "Stock Market Game" (Ellingsen et al., 2012). ${ }^{1}$

Recent studies have argued that framing affects cooperation not by changing preferences, but by changing beliefs about the actions of others (Dufwenberg et al. 2011; Ellingsen et al., 2012; Nikiforakis, 2010). However, none of the aforementioned studies has elicited individuals' preferences for cooperation. Framing has been known to affect choices in non-strategic environments where beliefs about the actions of others should play no role, such as when choosing a lottery (e.g., Kahneman \& Tversky, 1986). Therefore, it remains an open question whether cooperation preferences are unaffected by framing.

To elicit cooperation preferences in the present experiment I use the method of Fischbacher, Gächter and Fehr (2001; henceforth, FGF). This method has been used in a number of studies, including Fischbacher and Gächter (2010) who showed that the elicited preferences for cooperation are positively correlated with contributions in a finitelyrepeated public-good game. ${ }^{2}$ Participants in the experiment are asked in an incentivecompatible way to state how much they are willing to contribute to a public account given the average contribution of the others' group members. The elicited contribution schedules reflect a subject's cooperation preferences. The findings indicate that the majority of participants provides monotonic and increasing contribution schedules. That is, they are willing to contribute more as the average contribution of others increases.

In the present study, framing takes the form of altering the way in which the strategy method is administered. Two features of the FGF method, as it has been used so far, are that the possible contributions of others are presented $(i)$ simultaneously in a table, and (ii) in an order (i.e., 0, 1, 2, .. 20). These features, however, could affect the elicited preferences for cooperation. For example, the ordering of others' contributions could serve as a cue for subjects to condition their contribution on that of others. Similarly, the simultaneous frame in the strategy method may place subjects in a "cold" state when making their decisions (e.g., Brandts and Charness, 2000; Brosig, Weimann and Yang, 2003; Gueth, Huck, and Mueller, 2001), while the sequential frame may place them in a

\footnotetext{
${ }^{1}$ Other studies that find framing effects in social dilemmas are Bougherara, Denant-Boemont, Masclet (2011), Brandts and Schwieren (2009), Brewer and Kramer (1986), Cookson (2000), Cubitt et al., (2011), Fosgaard, Garn Hansen and Wengström (2011), Kotani, Managi, Tanaka (2008), McCusker and Carnevale (1995), McDaniel and Sistrunk (1991), Nikiforakis (2010), Park (2000), Rege and Telle (2004), Sell and Son (1997), Sonnemans et al. (1998), van Dijk and Wilke (2000), and Willinger and Zielgelmeyer (1999).

${ }^{2}$ For other studies using this method see Burlando and Guala (2005), Cheung (2012), Herrmann and Thöni (2009), Kocher et al., (2008), Muller, Sefton, Steinberg, Vesterlund (2008), Rustagi, Engel and Kosfeld (2010), Thöni, Tyran and Wengström (2009), and Volk, Thöni and Ruigrok (2012).
} 
state that is more similar to that in the standard public-good game. At the same time, however, ordering and sequentiality could affect the level of noise in the elicitation of cooperation preferences and affect its predictive power. ${ }^{3}$

The experiment consists of three parts. In the first part, I elicit subjects' cooperation preferences using the FGF method under three different frames. In the CONTROL treatment, all possible contributions of others are presented simultaneously in a table, but, unlike FGF, in a random order. In the second treatment (ORDERED), as in FGF, the possible contributions of others are presented simultaneously and in an ascending order. In the third treatment (SEQUENTIAL), the possible contributions of the other group members are presented in the same random order as in the CONTROL treatment, but sequentially, one by one. In the second and third part of the experiment, I evaluate the predictive power of the elicited cooperation preferences in a one-shot and a finitelyrepeated public-good game in which subjects are rematched in every period.

In a recent article, Levy-Garboua, Maafi, Masclet and Terracol (2012) elicit subjects' risk preferences using the Holt and Laury (2002) method under a variety of frames and find that both the ordering of options as well as whether choices are made simultaneously or sequentially affect the consistency of choices and the extent of risk aversion. ${ }^{4}$ These findings suggest that the number of participants with non-monotonic elicited cooperation preferences may be higher in the SEQUENTIAL relative to the CONTROL treatment but lower in the ORDERED compared to the CONTROL treatment. ${ }^{5}$ However, it is unclear under which condition the elicited preferences will be better predictors of actual contributions in the public-good game. For example, although the extent of noise may be greater in the SEQUENTIAL relative to the CONTROL treatment, contribution schedules may still be better predictors of behavior, if the sequential frame places individuals in a similar (hot) state as in the one-shot and finitely-repeated game.

The experimental results indicate that this is not the case. The predictive power of

\footnotetext{
${ }^{3}$ For example, Fischbacher and Gächter (2010) classify 10 percent of their subjects as "confused" if they could not be classified as either selfish, conditionally cooperative or triangular. The authors report that contributions in the finitely-repeated game of confused subjects were not well predicted by their contribution schedules.

${ }^{4}$ A subject is said to be inconsistent in Levy-Garboua et al. (2012) when their preferences cannot be explained with a standard utility function. The authors find that the rate of inconsistent choices and the level of risk aversion are higher when choices are made sequentially, and when choices are not orderred. Levy-Garboua et al. (2012) do not test the predictive power of the elicited risk preferences.

${ }^{5}$ As I discuss later in the paper, non-monotonic contribution schedules cannot be explained by most standard models used to explain behavior in social dilemmas.
} 
the contribution schedules is higher in CONTROL than in SEQUENTIAL, both in the one-shot and in the finitely-repeated game. This is partly due to the high number of individuals providing non-monotonic contribution schedules (90 percent of all subjects in this treatment). In contrast, the ordering of others' contributions, by and large, does not affect the predictive power of the elicited schedules. This is the case, despite the fact that, similar to Levy-Garboua et al. (2012), the rate of participants' with non-monotonic contribution schedules is higher in CONTROL (50 percent) than in ORDERED (30 percent). In general, the frames affect neither contributions nor beliefs in the first two parts of the experiment, but some differences are observed in the third part in SEQUENTIAL. I conclude that the simultaneous presentation of others' contributions in an order are appealing features of the FGF method.

The chapter proceeds as follows. In the next section, I present the experimental design in detail. In section 3, I discuss the experimental results, while section 4 concludes.

\subsection{The experiment}

The experiment consists of three parts. The existence of the three parts is public knowledge, but participants are not informed about the content of each part in advance. In the first part, I elicit participants' contribution schedules using variants of the FGF strategy method. In the second part, participants play a one-shot public-good game, and in the third part, they play a finitely-repeated version of the game. The experiment consists of three treatments. The treatment manipulation occurs only in the first part of the experiment. The second and third part are identical across treatments.

This section begins by presenting the basic public-good game. This is followed by a detailed presentation of each of the three parts and the experimental treatments. The section concludes with a discussion of the experimental procedures.

\subsubsection{The public-good game (overview)}

Participants are randomly divided into groups of three players. Each group member is given an endowment of 20 tokens and has to decide how to divide them between a private and a public account. The payoff function for each group member $i$ is: 


$$
\pi_{i}=20-g_{i}+0.5 \sum_{j=1}^{3} g_{j}
$$

where $g_{i} \in\{0,1, \ldots 20\}$ is the contribution of individual $i$ to the public account. The marginal return of the public account is 0.5 , i.e., contributing 1 token to the public account yields a private return of 0.5 . Therefore, if an individual wishes to maximize his/her material payoff, s/he should not contribute to the public account. However, since there are three individuals in the group, each token contributed to the public account increases group earnings by 1.5. Therefore, there is a tension between private and group interest.

In a one-shot public-good game, individuals wishing to maximize their material payoff have a dominant strategy to contribute zero to the public account. However, as mentioned, this prediction fails to account for the fact that many subjects contribute positive amounts to the public account, and the fact that many of them are classified as "conditional cooperators", i.e. individuals who contribute if they believe others do so. Fehr and Schmidt (1999, Proposition IV) show that if some group members dislike inequality in material payoffs sufficiently, then positive contributions can be sustained in equilibrium in the public-good game. The authors also show that the contribution of inequality-averse individuals will increase monotonically with the average contribution of other players in their group. Therefore, the model of Fehr and Schmidt (1999) provides an explanation for conditional cooperation in public-good experiments. ${ }^{6}$ The intuition is that the inequalityaverse individuals will suffer from the inequality when contributing less than the others. Similar predictions are obtained using the model of Bolton and Ockenfels (2000).

\subsubsection{Eliciting contribution schedules and beliefs}

In the first part of the experiment, I employ the method of Fischbacher, Gächter, Fehr (2001) for eliciting contribution schedules in the public-good game. Participants are randomly matched to form an anonymous group of three players and told that they will have to make three kinds of decisions. First, they have to decide on an unconditional contribution to the public account. Second, they have to decide how much they are willing

\footnotetext{
${ }^{6}$ Note that the Fehr-Schmidt model cannot readily explain conditional cooperation in the experiment of FGF (or the one in this paper) as subjects are allowed to condition their behavior only on the average contribution of their peers and not on the existence or the extent of inequality in earnings.
} 
to contribute for each possible (rounded) average contribution of the other two members of his group $(0,1, \ldots 20)$. I will refer to this set of 21 decisions as the contribution schedule. Third, participants have to estimate the (rounded) average unconditional contribution of the other two group members.

The three treatments differ only with regards to the way in which the contribution schedule is elicited. In the CONTROL treatment, the possible contributions of the other group members are presented simultaneously, i.e, in a contribution table, but in a random order. ${ }^{7}$ In the ORDERED treatment, all possible contributions by the other group members are presented simultaneously in a table, in an ascending order. That is, the ORDERED treatment replicates the design of FGF. In the SEQUENTIAL treatment, the ordering of others' contributions was the same as in the CONTROL treatment, but others' contributions were presented sequentially, in 21 successive screens.

All decisions are incentive compatible. In particular, after all participants made their decisions, two subjects in each group were randomly selected and their unconditional contribution was the one relevant for determining their contribution to the public account. For the third subject, the contribution schedule determined their contribution to the public account. In particular, their contribution was chosen based on their contribution schedule and the average unconditional contribution of the other two group members. To incentivize participants to truthfully reveal their beliefs, they are told that they will receive 3 tokens for stating a belief that exactly matches the average contribution of the other two group members. If their belief is within $+/-1$ of the average, they will receive 2 tokens. If their estimate is within $+/-2$ of the average they will receive 1 token. Otherwise, they will not receive any additional tokens.

\subsubsection{The one-shot public-good game}

In the second part of the experiment, participants are informed that they will be placed in a new group and that they will play a one-shot public-good game. The one-shot game allows to analyze players' individual responses in a one-shot interaction without repetition effect and learning.

\footnotetext{
${ }^{7}$ The order was determined by placing 21 numbered pieces of paper in a basket and picking them out sequentially and without replacement before the start of the first experimental session. The order was kept constant in subsequent sessions.
} 
In order to evaluate the predictive power of the individuals' contribution schedule, I also elicit their beliefs about the average contribution of the other group members. Furthermore, to avoid choices in the strategy method affecting decisions in the one-shot game, participants do not receive feedback about the outcomes of the first part of the experiment.

\subsubsection{The finitely-repeated public-good game}

At the start of the third and final part of the experiment, participants are informed that they will play the public-good game for ten periods and that the composition of their group would be randomly determined at the start of each period. I note that, following Fischbacher and Gächter (2010), before playing the finitely-repeated game, they are informed about their earnings from the first and second part of the experiment, and the average contributions of their fellow group members. In each period, participants have to decide how much to contribute to the public account and, in addition, provide an estimate of how much they believe the other two group members would contribute on average. Participants receive feedback similar to that in the one-shot game at the end of each period.

\subsubsection{Procedures}

The experiment was conducted at the University of Zurich using Z-tree (Fischbacher, 2007). Three sessions were run for each treatment with a total of 96 participants (30 in CONTROL, 33 in ORDERED, and 33 in SEQUENTIAL). Each subject participated only in one experimental treatment. At the beginning of each session participants were randomly allocated to a closed cubicle, where they could make their decisions in complete anonymity from the other participants. Sessions lasted on average 90 minutes and participants earned 46.17 $\mathrm{CHF}$ on average. At the time of the experiment, the exchange rate between the Swiss Franc and the American Dollar was $1 \mathrm{CHF}=\$ 1.23$

The experimental instructions (see Appendix C.2) were adopted from FGF and given to subjects on paper. Instructions for Part 1 were handed out first. Participants were informed that there would be a second and third part to the experiment, but they had no prior knowledge of what the content of these parts would be. Instructions for the second part were not handed out until the end of first part, and similarly for the third part. In the 
instructions, the contribution table was presenting and explained in the CONTROL and ORDERED treatments. In the SEQUENTIAL treatment, two screens were presented to the participants and they did no know the sequence of others' contribution before playing the game.

After participants had read the instructions, they had to answer control questions which tested their understanding of the experiment. The experiment did not start until all participants had answered correctly the control questions. The procedures for the second and third part of the experiment were the same. At the end of the experiment the total amount of tokens earned by participants was converted to Swiss francs at the rate of 1 token $=0.6 \mathrm{CHF}$ for the strategy method and the one-shot game, and, since each individual made 10 decisions in the third part, at the rate of 1 token $=0.06 \mathrm{CHF}$ for the finitely-repeated game.

\subsection{Results}

This section is divided into four parts. The first part examines the impact of the different frames on the contribution schedules and, in particular, whether it affects the rate of non-monotonic contribution schedules. The second part investigates the predictive power of the contribution schedules under the different frames in the one-shot publicgood game, while the third part does the same for the finitely-repeated game. The fourth part discusses other experimental findings such as the impact of the different frames on the distribution of cooperation preferences and the levels of contribution in the one-shot and finitely-repeated games.

\subsubsection{Non-monotonic contribution schedules}

All studies using the FGF method for eliciting cooperation preferences find that a nontrivial fraction of individuals provides non-monotonic contribution schedules. As mentioned, there are reasons to expect that there may be more (less) non-monotonic contribution schedules in the SEQUENTIAL (ORDERED) treatment compared to the CONTROL treatment.

Let $G$ denote the average contribution of one's group members, $G \in\{0,1, \ldots 20\}$, and $g_{i}(G)$ the contribution of individual $i$ given the average contribution of his peers. 
A contribution schedule is weakly monotonic if $g_{i}(G+1) \geq g_{i}(G)$ for all $G \in[0,19]$, or $g_{i}(G+1) \leq g_{i}(G)$. A contribution schedule that does not satisfy either of these conditions is non-monotonic. For example, an individual who always contributes $g_{i}(G)=$ 0 has a weakly monotonic schedule. A perfect conditional cooperator contributes $g_{i}(G)=$ $G$ and has a strictly monotonic schedule. An individual who contributes $g_{i}(0)=0$, $g_{i}(1)=2, g_{i}(2)=1$, and $g_{i}(3)=4$ has a non-monotonic schedule. To have a measure of how "noisy" these schedules are, I will sometimes refer to the number of switches in the non-monotonic schedule of an individual. For example, in the previous example, individual $i$ made one switch when he contributed $g_{i}(2)=1$ (since before that he had an increasing contribution schedule), and a second switch when he contributed $g_{i}(3)=4 .^{8}$ The individual contribution schedules can be seen in Appendix C.1.

Result 1: The proportion of individuals with non-monotonic contribution schedules is substantially higher in the SEQUENTIAL treatment than in the CONTROL treatment, and substantially lower in the ORDERED treatment than in the CONTROL treatment.

SUPPORT: Figure 4-1 shows that the proportion of individuals with a non-monotonic contribution schedule is 50.0 percent in CONTROL, 30.3 percent in ORDERED, and 87.9 percent in SEQUENTIAL. A Chi-square test using each individual as an independent observation indicates that the rate of non-monotonic contribution schedules is statistically higher in SEQUENTIAL than in CONTROL $(p$-value $=0.0011)$ and ORDERED $(p-$ value $=0.0001)$. While the rate is considerably higher in CONTROL than in the ORDERED (65 percent higher), the difference marginally fails to be significant at a conventional level $(p-$ value $=0.1292) .{ }^{9}$

Result 2: The average number of switches is significantly greater in the SEQUENTIAL than in the CONTROL treatment. The number of switches is not significantly different in the ORDERED and in the CONTROL treatment. Amongst the subjects with non-monotonic contribution schedules, the average number of switches does not differ

\footnotetext{
${ }^{8}$ Such contribution schedules are difficult to reconcile with most models of social preferences as discussed in the previous section. Models of non-linear altruism could provide a justification for nonmonotonic contribution schedules. According to these models an individual could contribute more when she believes other contribute low amounts, and less when others contribute more. These models however cannot account for contribution schedules exhibiting multiple "switching points". Most subjects who do not have a weakly monotonic schedule have multiple switching points (9 out of 10 in ORDERED, 25 out of 29 in SEQUENTIAL and 12 out of 15 in CONTOL).

${ }^{9}$ For completeness, I report that the rate of non-monotonic contribution schedules is significantly higher in SEQUENTIAL than in ORDERED ( $p$-value $=0.0001)$.
} 


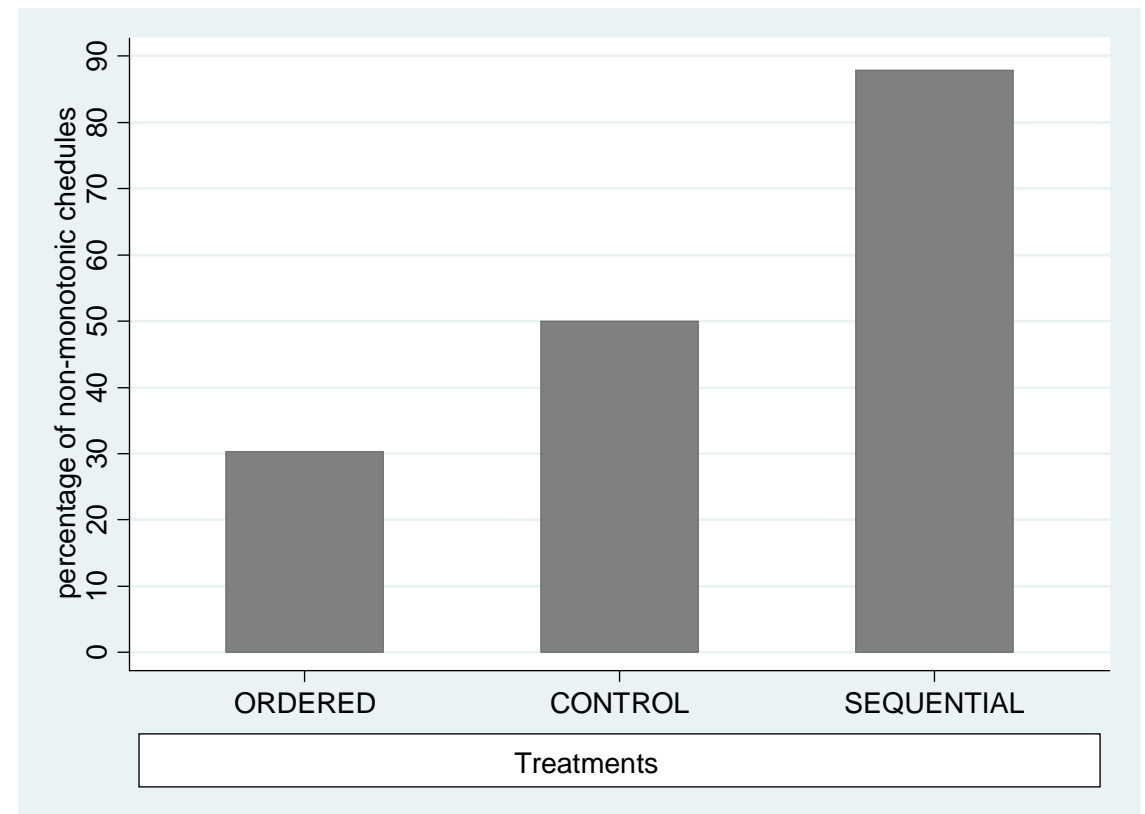

Figure 4-1: Percentage of subjects with non monotonic schedules

significantly across treatments.

SUPPORT: The average number of switches is 2.0 in the CONTROL treatment, 3.5 in SEQUENTIAL and 1.2 in ORDERED. Since there are more than two treatments, I first report the results from a two-tailed Kruskal-Wallis test. I then proceed to pairwise treatment comparisons only if the Kruskal-Wallis indicates significant differences across treatments. The Kruskal-Wallis test reveals a significant difference across treatments $(p-$ value $=0.0001)$. Using a two-tailed Mann-Whitney test with each individual as an independent observation, I find that the difference is significant between $C O N$ TROL and SEQUENTIAL and ( $p$-value=0.0084). The difference between CONTROL and ORDERED narrowly misses the 10 -percent level of significance $(p$-value $=0.1084) .{ }^{10}$ Nevertheless, the number of switches amongst individuals with non-monotonic schedules is similar across treatments (3.9 in ORDERED, 4.0 in CONTROL and 4.0 in SEQUEN$T I A L)$ and not significantly different (Kruskal-Wallis; $p$-value=0.8776). This indicates that the difference in the number of switches on average is due to the higher percentage of non-monotonic contribution schedules in SEQUENTIAL (see Result 1).

The greater extent of non-monotonic schedules in SEQUENTIAL may be partly at-

\footnotetext{
${ }^{10}$ The difference between $S E Q U E N T I A L$ and $O R D E R E D$ is highly significant $(p-$ value $=0.0000)$
} 
tributed to the fact that individuals cannot revise their choices once made. However, half of the participants also fail to report a weakly monotonic contribution schedule even in CONTROL where revisions are possible. Given the impact of the frames on the monotonicity of contribution schedules, the next subsection investigates whether and how the different frames also affect the predictive power in the one-shot public-good game.

\subsubsection{Predictive power of schedules in the one-shot public-good game}

A natural way to investigate the predictive power of the contribution schedules is to examine whether the actual contributions of participants in the one-shot game deviate from those in the contribution schedules. Recall that participants were asked to state how much they believed their peers would contribute on average in the one-shot game. Following Fischbacher and Gächter (2010), I use this belief and the contribution schedule to obtain a prediction about how much an individual will contribute in the one-shot game. For example, if someone believes that his peers will contribute on average 5 , the predicted contribution is obtained by looking at the contribution the individual stated he would make if the others contributed 5 on average in the contribution schedule.

Result 3: On average, contribution schedules are accurate predictors of contributions in the one-shot game only in the ORDERED treatment.

SUPPORT: Let Deviation be the difference between a subject's actual and predicted contribution. Figure 4-2 presents the distribution of Deviation in each treatment. As can be easily seen, relative to the CONTROL treatment, more subjects deviate from the predicted contribution in the SEQUENTIAL treatment, and less in the ORDERED treatment. The average deviation is 1.4 tokens in CONTROL, 1.8 tokens in SEQUENTIAL and 0.2 in the ORDERED. A two-tailed Wilcoxon signed-rank test using each individual as an independent observation indicates that the deviation is not significantly different from 0 in the ORDERED condition $(p-$ value $=0.8266)$, but it is in the CONTROL $(p-$ value $=0.0653)$ and in the SEQUENTIAL treatment $(p-$ value $=0.0047) .{ }^{11}$

\footnotetext{
${ }^{11}$ This difference is not statistically significant between SEQUENTIAL and CONTROL $(p$-value $=0.3300)$. Despite the large difference, a Mann-Whitney test fails to reject the hypothesis that average devation is the same in ORDERED and CONTROL $(p$-value $=0.2406)$. The difference in average devation between ORDERED and SEQUENTIAL is statistically significant $(p-$ value $=0.0375)$.
} 


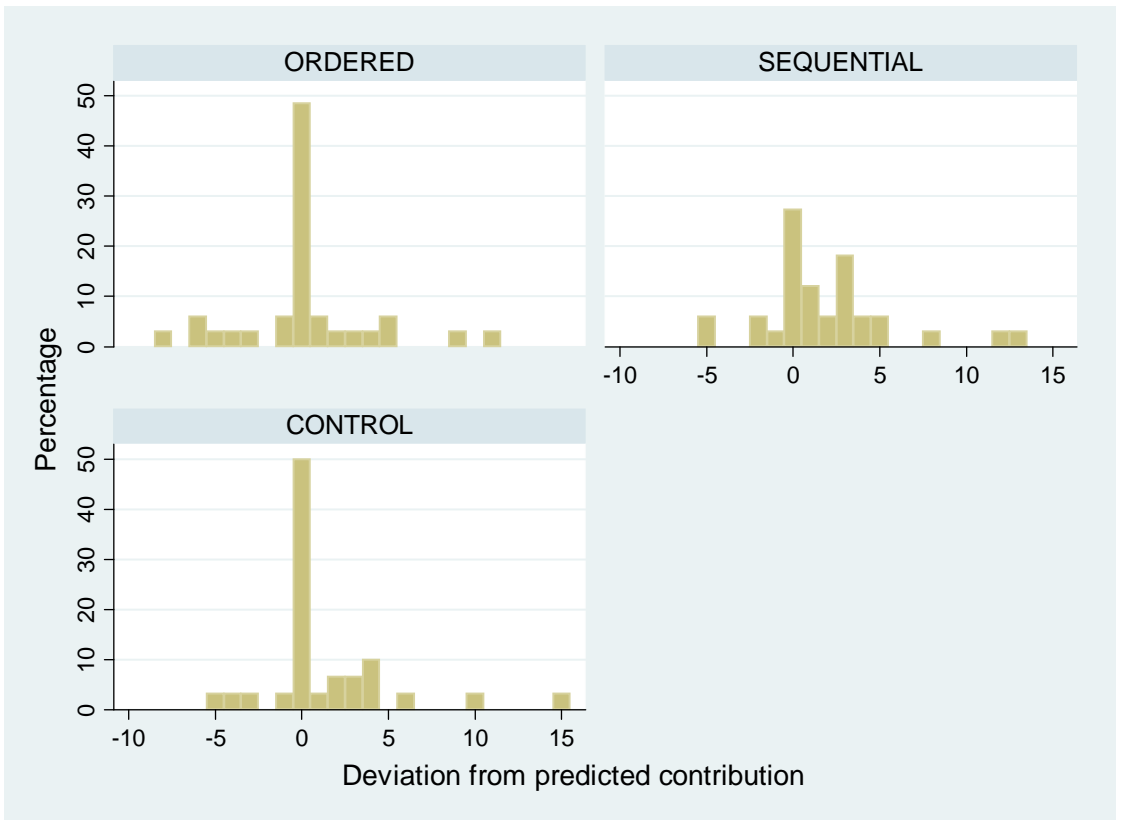

Figure 4-2: Distribution of deviation from the predicted contribution (one-shot)

The average deviation from the predicted contribution is one obvious indicator for evaluating the predictive power of contribution schedules. In this case, however, it masks the fact that the schedules predict perfectly the contribution of nearly 50 percent of subjects in the CONTROL and ORDERED treatments. Figure 4-2 shows that the relative efficacy of the schedules in ORDERED is due to the (roughly) equal number of positive and negative deviations from the predicted contribution. For this reason, next, I investigate the predictive power of the contribution schedules using a different measure.

Result 4: Relative to the CONTROL treatment, the probability an individual's contribution differs from their predicted contribution is higher in SEQUENTIAL, and (insignificantly) lower in ORDERED. This probability of deviation is higher for individuals with noisy contribution schedules and for those with high beliefs about the contribution of their peers.

SUPPORT: Table 4.1 reports the results from a regression analysis investigating the determinants of an individual's deviation from their predicted contribution. The dependent variable is a binary variable taking the value of 1 if Deviation $\neq 0$ and the value of 0 if Deviation $=0$. Model 1 includes only treatment dummies as regressors (CONTROL being the omitted category). The regression shows that the probability of deviating from 


\begin{tabular}{ccccc}
\hline \hline \multicolumn{5}{c}{ Dependent variable: rate of deviation } \\
\hline \hline Model & 1 & 2 & 3 & 4 \\
\hline ORDERED & 0.0147 & 0.0588 & 0.0678 & 0.0872 \\
& $(0.1227)$ & $(0.1252)$ & $(0.1299)$ & $(0.1303)$ \\
SEQUENTIAL & $0.2263^{* *}$ & 0.1273 & 0.1219 & 0.1414 \\
& $(0.1153)$ & $(0.1296)$ & $(0.1336)$ & $(0.1300)$ \\
Switcher & & $0.3138^{* * *}$ & $0.2933^{* * *}$ & \\
& & $(0.1041)$ & $(0.1089)$ & \\
Beliefs & & $0.0322^{* * *}$ & $0.0308^{* * *}$ \\
& & & $(0.0113)$ & $(0.0113)$ \\
Totalswitch & & & & $0.0621^{* *}$ \\
& & & & $(0.0255)$ \\
\hline Observations & 96 & 96 & 96 \\
\hline \hline *p-value $<0.1{ }^{* *}$ p-value $<0.05,{ }^{* * *}$ p-value $<0.01 ;$ Probit regression; \\
Entries are marginal effects. Standard errors are in parentheses
\end{tabular}

Table 4.1: Probability of deviating from the predicted contribution in the one-shot game the predicted contribution is 22.6 percent points higher in SEQUENTIAL than in $C O N$ TROL $(p$-value $=0.050)$. The difference between CONTROL and ORDERED is small (1.5 percent points) and statistically insignificant $(p$-value $=0.904)$. Model 2 includes the variable "Switcher" as an explanatory variable. Switcher is a dummy variable taking the value of 1 if the contribution schedule of a particular individual includes more than 1 switches. ${ }^{12}$ Model 2 indicates that the probability a "switcher" deviates from his predicted contribution across treatments is 31.38 percent points higher than that of a non-switcher $(p-$ value $=0.003)$. The fact that the size of the SEQUENTIAL coefficient is approximately halved and is no longer significantly different from zero $(p-$ value $=0.326)$ indicates that the difference across the two treatments is mainly due to the higher number of individuals with non-monotonic contribution schedules in this treatment. To test this explanation further, I ran a regression which in addition to the regressors in Model 2, included interaction terms between the treatment and switcher dummies (not reported). The only significant variable in this regression is the Switcher variable (marg. effect: 36.27 percent points; $p$-value=0.047). The coefficient for SEQUENTIAL is slightly lower than in Model 2 and remains statistically insignificant (marg. effect: 10.78 percent points; $p$-value $=0.591$ ). The fact that the interaction terms are insignificant indicates the switchers are as likely

\footnotetext{
${ }^{12}$ The rationale for this is that, as mentioned earlier, none of the standard models of social preference can account for more than one switches. Note that "triangle" contributors have one switch in their contribution schedules.
} 
to deviate from the predicted contribution in all treatments and corroborates Result 2 . Model 3 adds an individual's Belief as a regressor. The results indicate that the higher the belief of an individual about the average contribution of his peers, the higher is the probability they deviate from their predicted contribution (marginal effect: 3.22 percent points; $p$-value $=0.005)$. This seems intuitive. For example, while an individual may have stated that she would contribute 15 if she knew for sure that others did the same (strategy method), in the one-shot game, she cannot be sure whether this will be the case. Therefore, she may be more likely to deviate from her predicted contribution than if she believed others would contribute 5. The reason is that participants, on average, contribute less than their beliefs. Therefore, the extent of the deviation is lower when beliefs are low. A similar finding regarding beliefs is also reported in Fischbacher and and Gächter (2010). Finally, Model 4 replaces the Switcher dummy variable with the total number of switches in an individual's contribution schedule. As can be seen, the higher the number of switches in a contribution schedule, the higher is the probability that an individual deviates from his predicted contribution $(p$-value $=0.015) .{ }^{13}$ The marginal effect shows that an additional switch in the contribution schedule increases the probability of deviating from the predicted contribution by 6.21 percent points.

\subsubsection{Predictive power of schedules in the finitely-repeated public- good game}

The approach for evaluating the predictive power of the contribution schedules in the finitely-repeated game is the same as in the previous section. In each of the ten periods, I estimate an individual's Deviation by comparing their actual to their predicted contribution. ${ }^{14}$

Result 5: Contribution schedules accurately predict contributions in the finitely-repeated game in the CONTROL and the ORDERED treatments, but not in the SEQUENTIAL treatment.

SUPPORT: Figure 4-3 presents the distribution of Deviation in each treatment. As

\footnotetext{
${ }^{13}$ The results are qualitatively unaffected if we use dummies to control for the number of switches instead of the total number of switches.

${ }^{14}$ Note that participants received feedback about the contributions of their peers and their private earnings at the end of each period, but also at the start of the first period (i.e., regarding decisions in the one-shot game).
} 


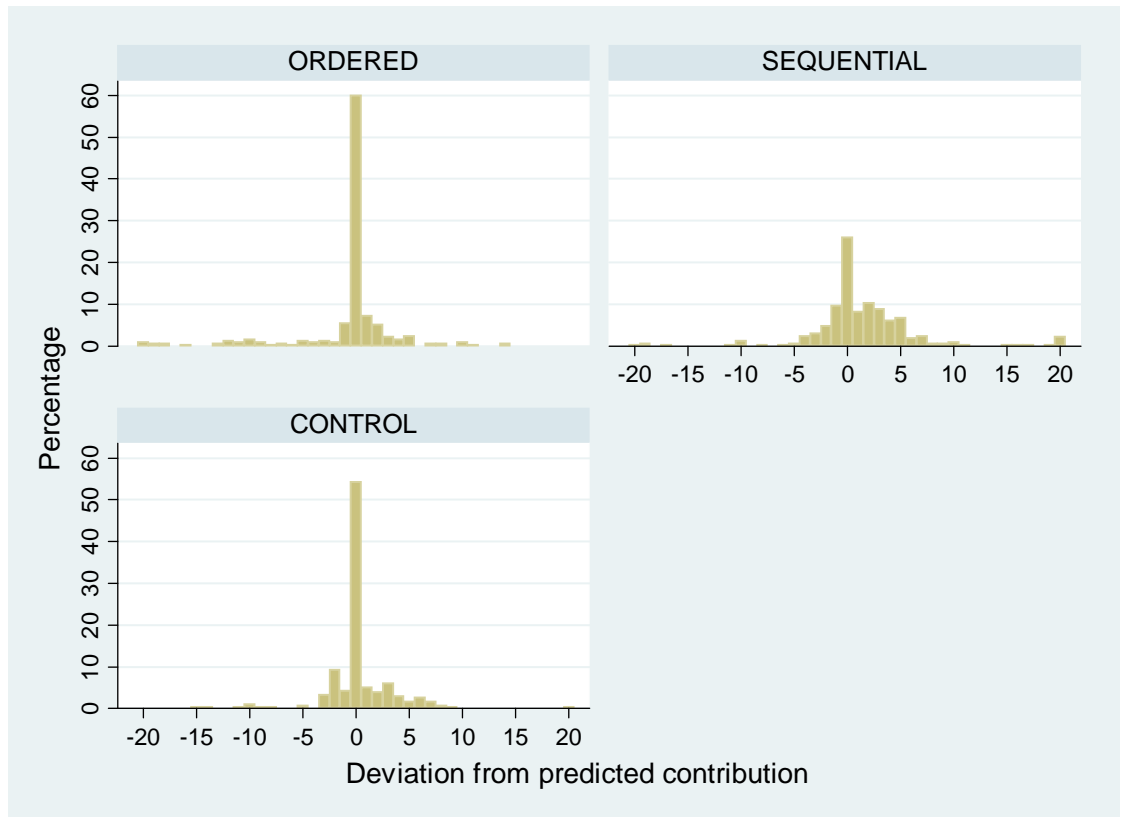

Figure 4-3: Distribution of deviation from the predicted contribution (finitely repeated)

can be seen, more subjects appear to deviate from their predicted contribution in the SEQUENTIAL than in the CONTROL treatment. The CONTROL and ORDERED treatments give similar results. The average deviation across the 10 periods is 0.3 in CONTROL, -0.6 in the ORDERED, and 1.4 in SEQUENTIAL. To control for the panel nature of the data in the third part of the experiment, I ran a linear regression controlling for random effects at the session level. The average deviation is significantly different from zero in SEQUENTIAL ( $p$-value=0.003), but not in CONTROL and ORDERED $(p-$ value $=0.637$ and 0.322 , respectively $) .{ }^{15}$ These results are robust if I evaluate behavior at different points of part 3 , such as in period 1 and the first five periods.

Result 6: The probability an individual's contribution differs from their predicted contribution in the finitely-repeated game is higher in SEQUENTIAL than in CONTROL. The difference between CONTROL and ORDERED is not statistically significant. The probability of deviating from the predicted contribution is higher for individuals with noisy contribution schedules and with high beliefs about the contribution of their peers.

\footnotetext{
${ }^{15}$ Average deviation is signficantly different between $S E Q U E N T I A L$ and $C O N T R O L$ ( $p$-value $\left.=0.081\right)$, and between ORDERED and SEQUENTIAL ( $p$-value=0.005). Average devation is not significantly different between ORDERED and CONTROL ( $p$-value $=0.302)$.
} 
SUPPORT: Table 4.2 reports the results from a regression analysis investigating the determinants of an individual's deviation from their predicted contribution. The dependent variable, as in the previous subsection, is a binary variable taking the value of 1 if Deviation $\neq 0$ and the value of 0 if Deviation $=0$ for a given subject in a given period. Given the interdependence of contributions at the session level, the model controls for random effects at the session level. The logic of the empirical investigation is the same as in the previous section for the one-shot game, building the model up gradually.

The results in Table 4.2 are qualitatively the same as those in Table 4.1 for the one-shot game. The regression shows that the probability of a subject deviating from her predicting contribution is 29.5 percent points higher in the SEQUENTIAL than in the CONTROL treatment $(p-$ value $<0.001)$. Contributions in the ORDERED treatment are 4.9 percent points less likely to differ from the predicted contribution than in the CONTROL treatment, but the difference is far from being statistically significant ( $p$-value $=0.427)$. Model 2 shows that a "Switcher", that is, an individual with noisy contribution schedule is 28.2 percent points more likely to deviate from his predicted contribution $(p$-value $<0.001)$. However, unlike in the one-shot game, the coefficient for SEQUENTIAL remains significant in Model $2(p$-value $=0.002)$, although the coefficient drops from 28.2 to 21.1 percent points. Model 3 controls for an individual's Belief about other's contribution. Similar to the one-shot game, the higher the belief of an individual about the average contribution of her peers, the higher is the probability she deviates from her predicted contribution (marg. effect: 4.7 percent points; $(p$-value $<0.001)$. Note that the coefficient for SEQUENTIAL is no longer significant in Model 3. This indicates that the higher rate of deviations in this treatment is mostly due to the higher beliefs about the contributions of others. ${ }^{16}$ Model 4 replaces the Switcher variable with the total number of switches in an individual's contribution schedule, and adds a (linear) control for time effects. The results indicate that the higher the number of switches in a contribution schedule, the higher is the probability that an individual deviates from his predicted contribution $(p-$ value $<0.001)$. The marginal effect shows that, similar to the one-shot game, an additional switch in the con-

\footnotetext{
${ }^{16}$ To test this explanation, I ran a regression separately for each treatment with the sole regressors being Switcher and Belief. The latter is always statistically significant, while the former is signficant in all treatments except in the SEQUENTIAL. A closer inspection at the data indicates the both switchers and non-switchers have substantially higher levels of beliefs in this treatment. As a result, both are about 75 percent likely to deviate from their predicted contribution - a rate which is considerably higher than in the other treatments. I discuss the impact of framing on contributions and beliefs in more detail in the next subsection.
} 


\begin{tabular}{ccccc}
\hline \hline Model & 1 & 2 & 3 & 4 \\
\hline \hline ORDERED & -0.0492 & -0.0127 & -0.03480 & -0.0154 \\
& $(0.0620)$ & $(0.0725)$ & $(0.0576)$ & $(0.0592)$ \\
SEQUENTIAL & $0.2950^{* * *}$ & $0.2112^{* * *}$ & 0.0646 & 0.0717 \\
& $(0.0558)$ & $(0.0690)$ & $(0.0610)$ & $(0.0616)$ \\
Switcher & & $0.2822^{* * *}$ & $0.2649^{* * *}$ & \\
& & $(0.0346)$ & 0.0356 & \\
Beliefs & & & $0.0474^{* * *}$ & $0.0486^{* * *}$ \\
& & & $(0.0059)$ & $(0.0063)$ \\
Totalswitch & & & & $0.0603^{* * *}$ \\
& & & & $(0.0079)$ \\
Period & & & & $0.0107^{*}$ \\
& & & & $0.0063)$ \\
\hline Observations & 960 & 960 & 960 & 960 \\
\hline \hline
\end{tabular}

${ }^{*}$ p-value $<0.1,{ }^{* *}$ p-value $<0.05,{ }^{* * *}$ p-value $<0.01 ;$

Probit regression with random effects at the session level;

Entries are marginal effects. Standard errors are in parentheses

Table 4.2: Probability of deviating from the predicted contribution in the finitely-repeated game

tribution schedule increases the probability of deviating from the predicted contribution by 6 percent. The probability of deviating from one's predicted contribution decreases by 1 percent in every period. The reason is that, as in all public-good experiments, contributions decline over time. As we will see in the next subsection, most people contribute small amounts in response to low contribution by their peers.

\subsubsection{Cooperation preferences, contribution levels and beliefs}

So far, the analysis has focused on how the different frames affect the monotonicity and predictive power of the contribution schedules. In this section, I investigate the impact of the different frames on the levels of contribution in the three parts of the experiment and subjects' beliefs. Before doing this, however, I will examine how the frames impact the different types of cooperation preferences seen in previous studies. Fischbacher, Gächter and Fehr (2001) proposed a classification of the different patterns observed in the contribution schedules. In particular, individuals that always contribute zero in the strategy method, irrespective of the contribution of their peers, are classified as "free riders". Individuals who have a contribution schedule with either a weakly monotonic pattern with at least one increase or a positive Spearman rank correlation significant at 


\begin{tabular}{cccc}
\hline \hline Treatments/types & CONTROL & ORDERED & SEQUENTIAL \\
\hline \hline Free Riders & 30.00 & 36.36 & 3.03 \\
Conditional Cooperators & 43.33 & 39.39 & 78.79 \\
Triangles & 3.33 & 3.03 & 0.00 \\
Others & 23.33 & 21.21 & 18.18 \\
\hline \hline
\end{tabular}

Table 4.3: Distribution of types (percentages)

the 1-percent level are classified as "conditional cooperators". ${ }^{17}$ "Triangle contributors" are participants who have a significantly increasing schedule up to some maximum and a significantly decreasing schedule thereafter, using again as a criterion the Spearman rank test at the 1-percent level of significance. Participants that could not be classified in one of the above categories are classified as "others" or "confused".

Result 7: The sequential treatment has a pronounced impact on the elicited contribution schedules relative to the CONTROL treatment. In contrast, the ordering of the others' contribution does not affect the elicited contribution schedules.

SUPPORT: Table 4.3 presents the results of the FGF classification method in each treatment. While the distribution of types appears to be similar in CONTROL and ORDERED, it is strikingly different in SEQUENTIAL. As can be seen, only 1 out of 33 participants (3 percent) can be classified as selfish in the SEQUENTIAL treatment, compared to 12 out of 33 in the ORDERED treatment (36.4 percent), and 9 out of 30 in the CONTROL treatment (30 percent). Similarly, 43 percent of individuals are classified as conditional cooperators in the CONTROL treatment, 39.4 percent in ORDERED, and 78.8 percent in SEQUENTIAL. ${ }^{18}$ A Fischer's exact test rejects the hypothesis that the distribution of types is the same across the three treatments $(p$-value $=0.003)$. Pairwise Fischer exact tests reveal that this difference is due to the SEQUENTIAL treatment. In particular, the difference between CONTROL and SEQUENTIAL is significant ( $p$-value=0.004), while

\footnotetext{
${ }^{17}$ Note that conditional cooperators can have non-monotonic schedules and, indeed, some of them did.

${ }^{18}$ It is also worthwhile pointing out that only 3 of the 13 individuals classified as conditional cooperators in ORDERED have a non-monotonic contribution schedule. In contrast, 8 of 13 conditional cooperators in CONTROL, and 24 of the 26 in SEQUENTIAL have non-monotonic schedules. The proportion of conditional cooperators with non-monotonic schedules, relative to the CONTROL treatment, is lower in ORDERED ( $p$-value $=0.0183)$ and higher in SEQUENTIAL $(p$-value $=0.03)$. Conditional cooperators are switching more often on average in SEQUENTIAL (3.0 switches) and CONTROL (2.1 switches) compared to ORDERED (0.5 switches). A Mann-Whitney test indicates that the difference between ORDERED vs CONTROL is statistically significant $(p-$ value $=0.0398)$, while that between $C O N T R O L$ and SEQUENTIAL is not ( $p$-value $=0.1239$ ).
} 


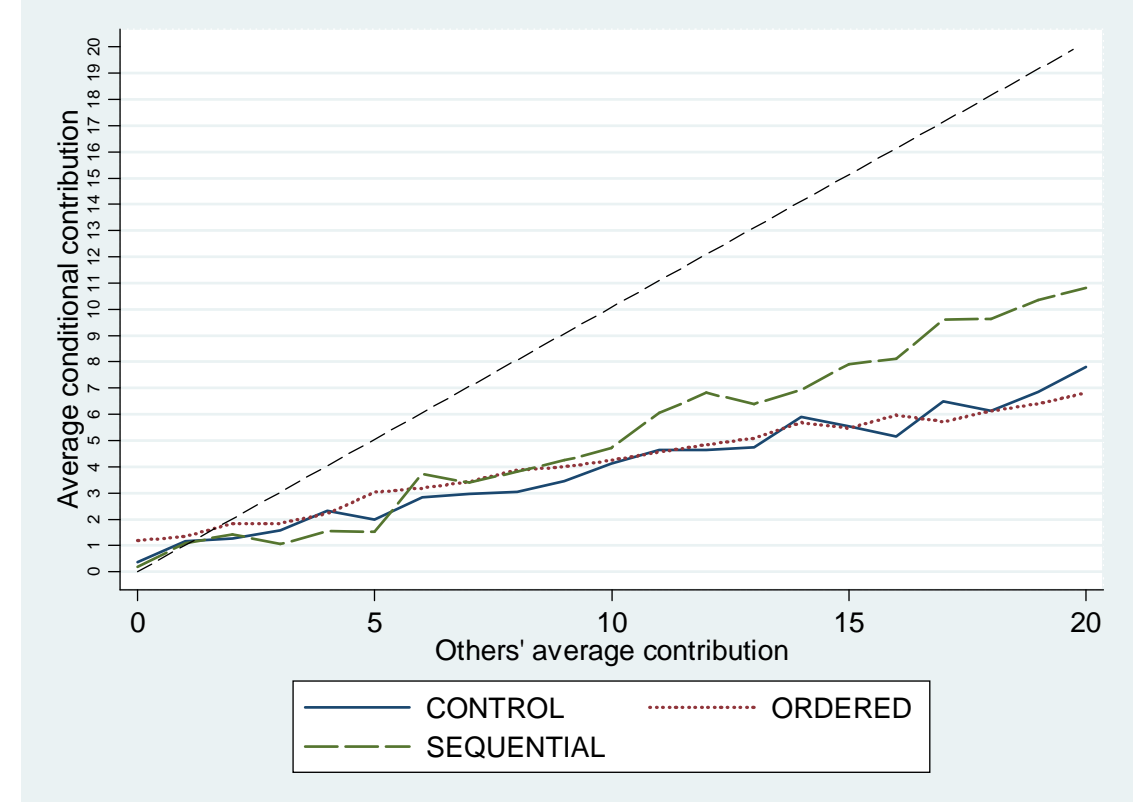

Figure 4-4: Average conditional contribution in the strategy method

that between ORDERED and CONTROL is not ( $p$-value=0.947).

Additional support for Result 7 can be found in Figure 4-4 and Table 4.4. ${ }^{19}$ Figure 4-4 presents the average conditional contribution in the first part of the experiment. Similar to previous experiments, the average conditional contribution is monotonically increasing and lies below the 45-degree line in all treatments. However, as can be seen, conditional contributions tend to be higher in SEQUENTIAL, than in the other two treatments. The results of a linear regression with individual random effects reported in Table 4.4 confirm that the average conditional contribution differs significantly in SEQUENTIAL. In particular, the slope of the conditional contribution is higher by 20.9 degrees in $S E$ QUENTIAL than in CONTROL. This difference is non-trivial and statistically significant $(p$-value $<0.001)$. It implies that for every additional token contributed to the public account by one's peers, the contribution will be 0.209 higher than in the CONTROL. The difference in slopes between CONTROL and ORDERED is smaller (5.2 degrees) and narrowly misses the 10 -percent level of significance $(p-$ value $=0.101)$.

Result 8: By and large, beliefs and unconditional contributions are not significantly different across treatments in the first and second part of the experiment. In the third part,

\footnotetext{
${ }^{19}$ Figure 4.4 and Table 4.4 below excludes subject 1202 who gave 20 when others gave 0 and had a Spearman correlation coefficient of -1
} 


\begin{tabular}{cc}
\hline \hline \multicolumn{2}{c}{ Dependent variable: conditional contribution strategy method } \\
\hline \hline Model & 1 \\
\hline Others' contribution & $0.3320^{* * *}$ \\
& $(0.2296)$ \\
ORDERED & 0.7085 \\
SEQUENTIAL & $(1.0552)$ \\
& -0.0320 \\
ORDERED * Others' contribution & $(1.0474)$ \\
& -0.0524 \\
SEQUENTIAL * Others' contribution & $(0.0319)$ \\
& $0.2087^{* * *}$ \\
Constant & $(0.0317)$ \\
& 0.6331 \\
Observations & 0.7580 \\
\hline * & 95 \\
Linear regression with individual random effects
\end{tabular}

Table 4.4: Determinants of conditional contribution in the strategy method

contributions are higher in SEQUENTIAL, due to higher beliefs about the contributions of others.

SUPPORT: [FIRST PART OF THE EXPERIMENT] The average belief regarding others' average (unconditional) contribution in the first part of the experiment is 7.16 (CONTROL), 5 (ORDERED), and 8 (SEQUENTIAL). A Kruskal-Wallis test rejects the hypothesis that beliefs are the same across treatments $(p$-value=0.0408). Using a two-tailed MannWhitney test with each individual as an independent observation, the difference between CONTROL and ORDERED is marginally statistically significant ( $p$-value $=0.0999)$, while that between CONTROL and SEQUENTIAL is not ( $p$-value=0.6265). In contrast, a Kruskal-Wallis test fails to reject the hypothesis that subjects' unconditional contributions $(6.23,4.42,6.57$, in CONTROL, ORDERED and SEQUENTIAL, respectively) are the same across treatments in the first part of the experiment $(p-$ value $=0.1413)$.

[SECONd PART of The EXPERIment] A Kruskal-Wallis test fails to reject the hypothesis that subjects' beliefs $(6.03,5.81,6.72$, in CONTROL, ORDERED and SEQUENTIAL, respectively) are the same across treatments $(p-$ value $=0.6003)$. While the test rejects the same hypothesis for contributions $(4.93,3.85,5.82$, in CONTROL, ORDERED and SEQUENTIAL, respectively; $p$-value=0.0703), a two-tailed Mann-Whitney test with each individual as an independent observation indicates that neither the differ- 


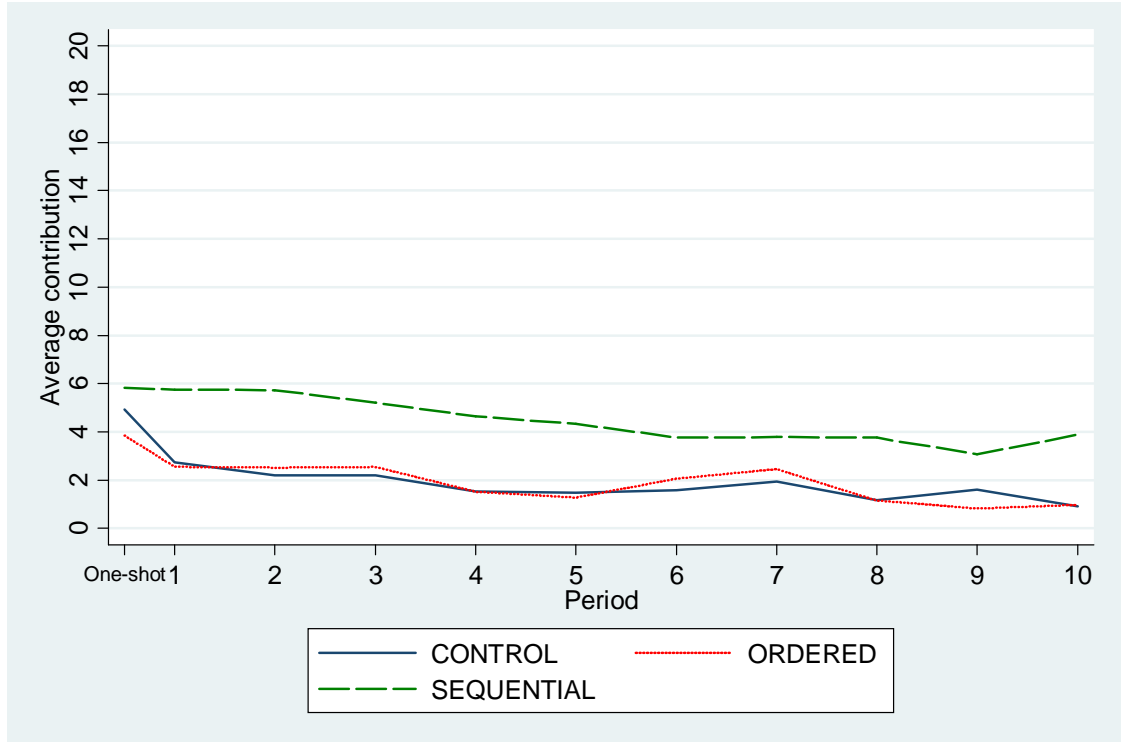

Figure 4-5: Average contribution over time

ence between CONTROL and ORDERED is statistically significant ( $p$-value $=0.3170)$ nor is that between CONTROL and SEQUENTIAL ( $p$-value=0.2714).

[THIRD PART OF THE EXPERIMENT] As can be seen in Figure 4.5, while contributions appear to be very similar across all periods in CONTROL and ORDERED, contributions tend to be higher in the SEQUENTIAL treatment than in the CONTROL. In particular, average contribution is 1.7 in CONTROL, 1.8 in ORDERED and 4.3 in SEQUENTIAL. Similarly, on average, beliefs are higher in SEQUENTIAL (5.5), than in CONTROL (2.12) and ORDERED (2.42). This seems surprising given that beliefs and contributions did not differ significantly in the first two parts of the experiment (Result 7). The difference appears already in the first period of the third part where beliefs in SEQUENTIAL are 6.2, 3.8 in CONTROL, and 4.8 in ORDERED. Given the panel nature of the data and the use of random matching in this part of the experiment, to compare behavior across treatments Table 4.5 presents the results from a linear regression with random effects at the session level. Model 1 illustrates that the difference between CONTROL and SEQUEN$T I A L$ is statistically significant $(p$-value $=0.005$ ), but not that between $C O N T R O L$ and ORDERED ( $p$-value $=0.945)$. The addition of subjects' beliefs as an explanatory variable in Model 2 indicates that once I control for beliefs, the difference between CONTROL and SEQUENTIAL is no longer significant $(p-$ value $=0.921)$. The coefficient of subjects' beliefs is highly significant $(p$-value $<0.001)$ and indicates that a one unit increase in beliefs, 


\begin{tabular}{cccc}
\hline \hline \multicolumn{3}{c}{ Dependant Variable: Determinant of contribution in the repeated game } \\
\hline \hline Model & 1 & 2 & 3 \\
\hline ORDERED & 0.0708 & -0.1913 & -0.01871 \\
& $(1.0328)$ & $(0.2533)$ & $(0.3622)$ \\
SEQUENTIAL & $2.8676^{* *}$ & -0.0276 & -0.2773 \\
& $(1.0328)$ & $(0.2780)$ & $(0.4298)$ \\
Period & $-0.2035^{* * *}$ & 0.0201 & 0.0167 \\
& 0.0433 & $(0.0369)$ & $(0.0374)$ \\
Beliefs & & $0.8011^{* * *}$ & $0.7678^{* * *}$ \\
& & $(0.0342)$ & $(0.1094)$ \\
Beliefs * ORDERED & & & 0.0025 \\
& & & $(0.1190)$ \\
Beliefs * SEQUENTIAL & & & 0.0660 \\
& & $0.1184)$ \\
Constant & $2.8173^{* * *}$ & -0.0793 & 0.0099 \\
& $(0.7697)$ & $(0.2961)$ & $(0.3890)$ \\
\hline Observations & 960 & 960 & 960 \\
\hline \hline
\end{tabular}

${ }^{*} \mathrm{p}$-value $<0.1,{ }^{* *} \mathrm{p}$-value $<0.05,{ }^{* * *} \mathrm{p}$-value $<0.01$

Linear regression with individual random effects

Table 4.5: Determinants of conditional contribution in the finitely-repeated game

increases the contribution of an individual by 0.80 tokens. Finally, Model 3 shows that the relationship between beliefs and contributions is similar across treatments. This implies that higher beliefs about others' contribution drive the higher levels of contribution in SEQUENTIAL. In Appendix C.1.2, I provide additional evidence from a regression analysis of subjects' beliefs. I show that the higher beliefs in SEQUENTIAL are due to a stronger relationship between contributions in parts 1 and 2 (i.e., the feedback subjects receive at the start of part 3), and beliefs. It is difficult to explain why the sequential frame has the effect on belief formation.

\subsection{Discussion}

The aim of the experiment was to evaluate the sensitivity of cooperation preferences to changes in the frame which have been recently shown to affect the elicitation of (risk) preferences (Levy-Garboua et al., 2012). In particular, using the method of Fischbacher, Gächter and Fehr (2001; FGF) for eliciting cooperation preferences, I varied $(i)$ the order in which others' contributions appeared in the experiment, and (ii) whether these contributions were presented simultaneously or in sequence. In addition, the experiment aimed 
to evaluate the predictive power of cooperation preferences in a one-shot and a finitelyrepeated public-good game. In general, I found that the order in which the contributions of others was presented had no impact on the elicited preferences and their predictive power. However, presenting the contributions of others in a sequence had a significant effect on the elicited preferences and reduced their predictive power. In this sense, my findings are similar to those of Levy-Garboua et al. (2012) who found that risk preferences are affected more by changes in whether the options are presented sequentially or simultaneously, rather than the order in which the options are presented. Overall, elicited preferences are more accurate at predicting behavior when others' contributions are presented simultaneously and in ascending order, like in Fischbacher, Gächter and Fehr (2001).

What could explain the impact of the sequential frame in our experiment? One explanation for the number of non-monotonic schedules in SEQUENTIAL may be that individuals cannot revise their choices once made. While this explanation can partly account for the level of noise in the contribution schedules, it cannot account for the much higher levels of conditional cooperation and near absence of free riders seen in this treatment. An explanation for this finding may be that individuals wish to maintain a positive self-image. Gneezy et al. (2011) found that donations to charity are more likely to happen after people lie or fail to return money they had received by mistake. The authors discuss the concept of "conscience accounting" which means that people try to compensate "bad" activities to protect their identity and self-image". It seems possible that making 21 consecutive decisions not to contribute to the public account may be more damaging for one's self image than submitting once a table with zero contributions.

An issue which may be interesting for future study is when cooperation preferences are elicited. Fischbacher and Gächter (2010) ran experiments with the FGF strategy method either at the start or the end of the experiment to evaluate whether the timing of the elicitation affected contributions in a finitely-repeated game. They found that this was not the case and that contributions were the same when cooperation preferences were elicited at the start and the end of the experiment. This finding is the reason I elicited preferences only at the start of the experiment. However, the finding that beliefs and contributions in the finitely-repeated game are higher in SEQUENTIAL suggests that eliciting cooperation preferences at the start of the experiment may influence outcomes, 
at least under some frames. Therefore, it may be useful for future studies to randomize when the strategy method is administered.

Finally, given the findings from the present experiment, I believe that the FGF method could be used to investigate whether other kinds of frames that have been shown to affect contributions in public-good games, such as the warm-glow/cold-prickle effect of Andreoni (1995) and the labelling of the game or strategies (e.g., Ellingsen et al., 2012; Kay and Ross, 2003; Liberman et al., 2004; Ross and Ward, 1996) affects only subjects' beliefs, as suggested in previous articles (Dufwenberg et al. 2011; Ellingsen et al., 2012; Nikiforakis, 2010) or also cooperation preferences. 


\section{Chapter 5}

\section{Social networks in an experimental}

\section{labor market with adverse selection}

\subsection{Introduction}

Social networks play an important role in labor markets. A number of empirical studies have found evidence that firms often hire workers using the social contacts of their current employees. Workers also find jobs to apply for through their social network. For example, Ioannides and Datcher Loury (2004) report that 30 to 60 percent of job vacancies in the U.S. labor market are filled through friends or relatives. Similarly, Pellizari (2010) finds that social networks are widely used in the European labor market, with half of job vacancies in some countries being filled through personal contacts. Recently, Brown, Setren and Topa (2012) using a dataset on individual employees' referral status in the US find that referred workers are more likely to be hired, have a higher initial wage and are less likely to quit. ${ }^{1}$ Firms like Ernst \&Young, Deloitte, Rent-A-Car report that they are increasingly using their current workers to find new hires (New York Times, January 2013).

A factor that can explain the wide use of social networks is that they may alleviate the problem of adverse selection firms face when hiring workers. Studies have shown that workers have a tendency to refer other workers of similar ability (Rees, 1966; Granoveter, 1985, 1995). This tendency is sometimes referred to in the literature as "inbreeding" bias. Therefore, firms may rely on the information provided by their workers when looking to fill

\footnotetext{
${ }^{1}$ See Jackson (2008) and Topa (2011) for reviews of the economics literature.
} 
job vacancies, especially if the workers are considered to be of high ability (Montgomery, 1991).$^{2}$

In this chapter, we study whether social networks can alleviate the problem of adverse selection in labor markets. In contrast to previous studies on social networks, our focus is not on the quality of workers that are being referred to the firms, but rather on when firms decide to use the social network of their employees to fill job vacancies. The advantage of conducting a laboratory experiment is that it allows us to control for the probability that a referred worker is of a certain ability. ${ }^{3}$ Our aim is to investigate whether firms use the social network of their workers to hire new workers, under what conditions they do so, and ultimately, whether social networks improve the quality of workers hired and increase efficiency.

In the experiment, workers can be either of high or low ability. Our game consists of two stages. A firm seeks to hire one worker from a set of potential employees in each stage. In our baseline treatment, workers in the two stages are not linked into a social network and they can only make public offers to workers via a public market. In our main treatment, each worker in the first stage is connected to another worker in the second stage, and vice versa. The worker in the second stage is 75 percent likely to be of the same ability as that of the worker in the first stage. In the second stage, firms are given the option of either making a referral offer to the worker in the social network of the worker hired in the first stage via a referral market, or make a public offer to all available workers.

We have four research questions that we wish to address with our experiment. First, we are interested to see whether firms are more likely to make referral offers in the second stage of our main treatment when the worker hired in the first stage is of high ability, than when they are of low ability. Second, are wages in the referral market higher than in the public market? Third, are firms willing to make higher offers in the first stage of the game in order to attract workers with a better network (i.e., high-ability workers). Four, does the existence of a social network lead to a greater proportion of high-ability workers

\footnotetext{
${ }^{2}$ Of course, other reasons such as the lower cost of hiring may explain partly why firms use the social networks of their employees to attract workers.

${ }^{3}$ There is a long tradition in economics of using laboratory experiments to examine issues pertaining to labor markets. Most experimental studies have focused on the moral hazard problem and ways of overcoming it. For example, Fehr, Kirchsteiger, and Riedl (1993), in line with Akerlof (1982, 1984), developed the gift exchange game to capture extreme contractual incompleteness in a labor market setting. They show that reciprocal fairness may overcome the moral-hazard problem.
} 
in the second stage, relative to the baseline treatment?

Our experimental results show that firms are indeed significantly more likely to make offers in the referral market when the worker hired in the first stage is of high ability, and that referral offers are higher on average than public offers. With regards to our third research question, we find that firms are more likely to make offers that satisfy the participation constraint of high-ability workers in the first stage in the presence of social networks. Finally, we find that the proportion of high-ability workers in the second stage is higher when there is a social network.

Our study contributes to two related literatures. The first investigates the role of social networks in labor markets. In this mostly theoretical literature, most studies focus on either how workers use their social networks to search for jobs or on the impact of different network structures on market outcomes, while relatively few focus on the decision of firms to use social networks for hiring. ${ }^{4}$ The study which is most closely related to ours is that of Montgomery (1991) who develops a model that focuses on the decision of firms to make referral offers to workers belonging to the social network of their employees. While there are differences between our set up and that of Montgomery, the model predicts that referral offers will be higher than public offers when there is a social network similar to that in our experiment, and that firms will be more likely to make referral offers if their employee is one of high ability. ${ }^{5}$ The model also predicts that firms will be willing to offer higher wages in order to attract workers with a better social network.

The empirical studies on the role of social networks in labor markets to date have focused on the quality of workers that are being referred to firms through social networks. Although there are apparent methodological issues with regards to measuring the extent of inbreeding bias among workers and the latter's productivity, the evidence seems to indicate that social networks may improve the overall quality of workers hired and workers and firms allocation, under certain conditions. Beaman and Magruder (2011) show that social networks reduce adverse selection in a field experiment in India, but only when

\footnotetext{
${ }^{4}$ See Boorman (1975), Mortensen and Vishwanath (1994), Pissarides (2000), Topa (2001), CalvoArmengol (2003), Calvo-Armengol and Jackson (2004), Calvo-Armengol and Zenou (2005), Loury (2006), Bayer, Ross and Topa (2008), Beaman (2010), Galeotti and Merlino (2010), Magruder (2010) and Zenou (2013) for studies focusing on the workers' decision. See Montgomery (1991), Kugler (2002), Munshi (2003), and Casella and Hanaki (2008) for studies focusing on the firm's problem.

${ }^{5}$ In Montgomery's words "given the inbreeding bias between workers of similar ability, a firm will attempt to hire through referral only if it employs a high-ability worker...". Also see McPherson et al (2001) who refers to people who interact with others who are like themselves as the homophily principle.
} 
existing workers have correct incentives for referring their contacts. Dustmann, Glitz and Schönberg (2011) show that job-search networks in a German metropolitan city give raise to better matches of the workers with the firms and enhance efficiency. In contrast, using data from the Ghanian Colonial Army, Fafchamps and Moradi (2010) find that social networks do not lead to a better quality of workers, which they attribute to "referee opportunism". As mentioned, in contrast to theses studies, our focus is on the use of a social network given a specific inbreeding bias and not on the existence of the inbreeding bias.

The second literature this chapter makes a contribution to is that investigating ways of overcoming problems that arise from contractual incompleteness. Social networks are one way of overcoming such problems. Another way is through the establishment of long-term relationships. The relation between contractual incompleteness and long-term relationships is studied in an experiment by Brown, Falk and Fehr (2004) who show that successful long-term relationships can lead to high effort levels and high wages. They investigate multilateral relationships and the possibility of social ties between firms and workers. However, they do not allow for links between workers as we do in our experiment. Our market experiment resembles the one by Brown, Falk and Fehr (2004) except that we focus on adverse selection and social networks instead of moral hazard and long-term relationships.

The chapter proceeds as follows. In Section 2, we discuss the experimental design and theoretical predictions. In Section 3, we present the results from the experiment, while Section 4 concludes.

\subsection{The experiment}

The experiment consists of two treatments. In the first treatment - the No Referrals treatment $(N R)$ - there are no links among workers, and firms hire workers in an anonymous setting. In the second treatment - the Referrals treatment $(R)$ - social ties are introduced, and firms and workers can enter in a private relationship through a social network.

The implementation is as follows. At the beginning of the experiment, each participant was randomly assigned the role of either a firm or a worker. Roles remained fixed through 
the experiment. In total 4 firms and 12 workers were active in each of the 15 trading period. Moreover, each of the 15 trading periods consisted of two stages. Workers in each stage were divided into two equally-sized groups of $L$ and $H$ workers. A different set of workers was active in each of the two stages: six of the 12 workers were active in stage 1 (3H and $3 L$ stage-1 workers) and six other workers were active in stage 2 (3 $H$ and $3 L$ stage-2 workers). The productivity of a worker and whether he was active in stage 1 or stage 2 was randomly assigned at the beginning of each period. Firms could offer a contract to the workers in a posted-offer market. Each firm could employ at most one worker per stage, and workers could accept at most one wage. If a worker accepted the wage offer, a labor contract was concluded between the firm and the worker. After a contract was concluded, firms were informed of the productivity of their worker. Wage offers followed an improvement rule, that is, subsequent offers involved higher wages. We next discuss each of the treatments in detail.

\subsubsection{The No Referrals treatment (NR)}

In this treatment, contracts are offered and accepted in a public market in both stages. That is, all parties involved can observe the wages offered and accepted.

\subsubsection{The Referrals treatment (R)}

The $R$ treatment is our main treatment of interest as it allows firms to utilize the social network of their workers. In particular, in the second stage of the $R$ treatment, contracts can be offered either in a public or in a referral market. The social network is characterized by a link between two workers. Each stage-1 worker is (randomly) linked to one stage2 worker. Workers are randomly assigned to a social network at the beginning of each period. The probability that the worker in stage 2 is of the same type as that of the worker in stage 1 is equal to 0.75 . Following Montgomery (1991), we refer to this probability as the "inbreeding-bias parameter". Firms can only use the referral market to make an offer to the worker in the social network of their stage- 1 worker. Offers made in the referral market can be seen only by referral workers. In any given period, firms can make multiple offers in both markets. After a contract is concluded, firms are informed of the productivity of their worker. 


\subsubsection{The payoff functions}

The problem of adverse selection in our experiment arises from the fact that there are low and high productivity workers. Firms cannot observe the type of each worker. A low-productivity worker $(L)$ produces an output $\theta_{L}$, while a high productivity worker $(H)$ produces an output of $\theta_{H}$. The payoff of a firm in stage $i=1,2$ is given by:

$$
\pi_{f}^{i}\left(\theta_{S}, w\right)=\left\{\begin{array}{l}
\theta_{S}^{i}-w^{i}+B, \text { if a contract is concluded } \\
0, \text { if no contract is concluded }
\end{array}\right.
$$

where $w^{i}$ refers to the wage that is accepted in stage $i$ and $\theta_{S}^{i}$ refers to the productivity of the worker in stage $i=1,2, S=L, H$, with $\theta_{L}^{i}=20$ and $\theta_{H}^{i}=60 .{ }^{6}$ A firm can submit wages (any integer) between 0 and 60 points. To minimize the chance of losses for firms hiring low-productivity workers which could make some participants unwilling to offer positive wages, a "baseline productivity" $B=20$ is added to the firm's payoff if a contract is concluded.

The payoff of a firm at the end of the period is the sum of payoff in stage 1 and 2 and is given by:

$$
\pi_{f}\left(\theta_{S}^{1}, w^{1}, \theta_{S}^{2}, w^{2}\right)=\pi_{f}^{1}\left(\theta_{S}^{1}, w^{1}\right)+\pi_{f}^{2}\left(\theta_{S}^{2}, w^{2}\right)
$$

The payoff of a worker in stage $i$ is given by:

$\pi_{w}^{i}\left(\theta_{S}^{i}, w^{i}\right)=\left\{\begin{array}{l}w^{i}, \text { if a contract is concluded } \\ \lambda_{S}, \text { if a contract is not concluded or the worker is inactive in the stage }\end{array}\right.$

where $\lambda_{S}$ is the reservation wage of an unemployed worker who did not trade or is inactive. In the experiment, $\lambda_{L}=10$ and $\lambda_{H}=30$. The reservation wages imply that a low ability worker would not accept any wages less than 10 and a high ability worker would not accept any wages less than 30. Each worker is either inactive in stage 1 or 2 and will then receive $\lambda_{S}$.

\footnotetext{
${ }^{6}$ A firm's payoff can be negative if it hires an $L$ worker at a high wage. At the beginning of each session, each firm is given an "endowment" of 120 points. The endowment is meant to prevent participants from going bankrupt. A firm could receive the lowest payoff six times in a row without going bankrupt by offering a wage of 60 and hiring a low productivity worker $(20-60+20) * 6=-120$. To ensure that experimental earnings are approximately the same for firms and workers, workers were also given an endowment of 120 points once, at the start of the experiment.
} 
The payoff of a worker at the end of the period is the sum of payoff in stage 1 and 2 and is given by:

$$
\pi_{w}\left(\theta_{S}, w\right)=\pi_{w}^{i}\left(\theta_{S}, w\right)+\lambda_{S}
$$

\subsubsection{Information}

In both treatments, the number of periods, the payoff functions, the number of firms and workers, the proportion of high and low productivity workers are public knowledge. In the $R$ treatment, "the inbreeding-bias parameter" is also public knowledge. As mentioned above, firms and workers can observe all offers made in the public market. In the $R$ treatment, offers made in the referral market can be seen only by referral workers who receives the offer. Referral workers can also see offers made in the public market and decide whether to accept an offer made in the public or the private market.

\subsubsection{Procedures}

There were 16 participants in each experimental session. We ran 6 sessions for the Referral treatment and 5 sessions for the No Referral treatment. A total of 176 subjects participated in the experiment and were recruited via ORSEE (Greiner, 2004) at Maastricht University. The experiment was conducted in the BEElab using Z-tree (Fischbacher, 2007).

At the beginning of each session participants were randomly allocated to a closed cubicle where they could make their decisions in complete anonymity from the experimenter and other subjects. The experimental instructions (available in the Appendix D.3) were given on paper. After participants read the instructions, they were asked to answer a set of control questions. The aim of these questions was to evaluate their understanding of the experiment. The experiment did not start until all participants had answered correctly all control questions.

Each of the 15 trading periods lasted 4 minutes; 2 minutes for each stage. On average, sessions lasted 120 minutes (including instruction time). Participants, on average, earned 19 Euros. 


\subsection{Theoretical framework}

As a benchmark for evaluating the experimental results, we perform a Walrasian market analysis (see Mas-Colell, 1995) for the $N R$ treatment and stage 1 of the $R$ treatment,i.e., the public market. We then derive some hypotheses for the impact of social networks in the $\mathrm{R}$ treatment.

As assumed typically in the Walrasian analysis, we assume that firms are risk neutral, seek to maximize their expected profits, and act as price takers. Similarly, we assume that workers aim to maximize their profit from their labor. A unique wage $w$ is an equilibrium wage if the firms' expectations regarding the average productivity of the workers are fulfilled in equilibrium. We consider two types of self-confirming beliefs: optimistic and pessimistic beliefs.

Let $p_{L}$ and $p_{H}$ be a firm's subjective probabilities that a worker of type $L$ and $H$ will be hired, respectively. The expected profit of a firm hiring a worker of either type at wage $w$ is given by:

$$
E \pi\left(w,\left(p_{L}, \theta_{L}\right),\left(p_{H}, \theta_{H}\right)\right)=p_{L}\left(\theta_{L}-w\right)+p_{H}\left(\theta_{H}-w\right)+B .^{7}
$$

1. Optimistic beliefs of the firms: If all firms believe that all workers (i.e. workers of both types) will be willing to offer their services for the wage they offer, the expected revenue of a firm is:

$$
E R\left(\left(p_{L}, \theta_{L}\right),\left(p_{H}, \theta_{H}\right)\right)=\frac{1}{2} 20+\frac{1}{2} 60=40
$$

which is the maximum wage the firm will be willing to offer. ${ }^{8}$ Both types of workers will accept a wage of 40, since it exceeds their reservation wage. However, since there are more workers than firms, a firm can reduce the offered wage a bit and it will still be accepted by all workers. The minimum wage for which this holds is 30 . For wages lower than 30, $H$ workers will not accept a contract and receive instead their reservation wage of 30 . Since at a wage of 30 both $L$ and $H$ workers will be willing to accept a contract, these beliefs are self-confirming. Hence, for this set of

\footnotetext{
${ }^{7}$ Since $B$ does not affect a firm's marginal incentives, we omit it from the analysis that follows.

${ }^{8}$ Note that, in our experiment, a firm can have negative earnings only if it offers a wage higher than 40 and hires a low-ability worker.
} 
beliefs, $w^{*}=30$ is the unique equilibrium wage. Note that this equilibrium holds if $H$ workers are indifferent between accepting the wage or opting for the reservation wage. Since at a wage of 30 both $L$ and $H$ workers will be willing to accept a contract, these beliefs are self-confirming. If firms believe that workers will always reject an offer of $w=30$ then the equilibrium wage becomes $w^{*}=31$

2. Pessimistic beliefs of the firms: If all firms believe that only $L$ workers will be willing to accept a given wage, the expected revenue of a firm is

$$
\operatorname{ER}\left(\left(p_{L}, \theta_{L}\right)\right)=20
$$

Therefore, $w=20$ is the maximum wage a firm will be willing to offer given these beliefs. Since only $L$ workers will be willing to accept such a wage, and given that there are more firms than $L$ workers in the market, a wage less than 20 cannot be an equilibrium wage. Moreover, since only $L$ workers will be active in the market when $w=20$, these beliefs are self-confirming and $w^{* *}=20$ is the unique equilibrium wage.

In terms of market efficiency, the equilibrium $w^{* *}=20$ is inefficient as it excludes $H$ workers from the market. The equilibrium wage $w^{*}=30$ maximizes the aggregate surplus when three $H$ workers and one $L$ worker are employed. Therefore, we will say that the market shows adverse selection if less than three $H$ workers are hired in a given period.

Having established these benchmarks, we now present some hypotheses regarding the impact of the social network in treatment $R$. Our experiment was inspired by Montgomery (1991) who presents a model with inbreeding bias in a labor market. The main findings of Montgomery's model are the following: $(i)$ A firm will offer a wage in the referral market if, and only if, it employed an $H$ worker in stage 1. (ii) Wages in the referral market will be higher than in the public market. (iii) Firms will be willing to pay a "wage premium" in stage 1 in order to attract $H$ workers as this will improve their chances of also hiring an $H$ worker in stage 2. In Appendix D.1, we show that our game has equilibria with similar properties. 


\subsection{Results}

We begin our analysis by presenting our main results. We then proceed to examine other interesting aspects of the data and, in particular, the dynamic of the market where we investigate how wage offers and acceptances evolve within a given period. In general, we are interested to see if the existence of social networks affects the distribution of wages, the productivity of workers that are being hired, and how firms use the opportunity to make referral offers. As we focus on labor market outcomes, our analysis considers accepted wages. For completeness, Appendix D.2 presents the results with all wages offered (i.e., even those that are not accepted)

\subsubsection{Main results}

Our first result discusses the impact of the social network on the allocation of $H$ and $L$ workers.

Result 1: There are more low-ability (L) than high-ability (H) workers hired in both treatments. Nevertheless, the existence of a social network in treatment $R$ increases the proportion of high-ability $(H)$ workers that are hired.

SUPPORT: Table 5.1 presents a summary of the experimental results. As can be seen, in both stages of treatment $N R$, approximately, $1 H$ worker and $3 L$ workers are hired on average. The proportion of $H$ workers that are employed is larger in treatment $R$ (32.84\% and $31.74 \%$ in stages 1 and 2 , respectively). Using the average number of $H$ workers hired in each session and in each stage as an independent observation, we find that the proportion of $H$ workers hired across stages is significantly higher in treatment $R$ (Mann-Whitney; $p$-value=0.0285). This difference cannot be explained by the wages offered by firms as they are not significantly different across treatments (Mann-Whitney; $p-$ value $=0.7150)$.

Table 5.1 illustrates that firms are more likely to hire $H$ workers in the second stage of the game in treatment $R(31.74 \%)$ where their workers belong to a social network, than in treatment $N R$ where such a network does not exist (25\%). Moreover it is interesting to see that in stage 1 of the $R$ treatment the proportion of $H$ workers hired $(32.84 \%)$ is larger than in the $N R$ treatment (25.19\%) despite that wages are similar (Mann-Whitney; $p-$ value $=0.58)$. Firms may be more willing to make offers that satisfy the participation 


\begin{tabular}{|r|cc|ccc|cc|cc|}
\hline \multicolumn{8}{|c|}{ Description of employment rate and average wage } \\
\hline \hline Treatment & \multicolumn{3}{|c|}{ No Referrals } & \multicolumn{4}{c|}{ Referrals } \\
\hline Stage & \multicolumn{2}{|c|}{1} & \multicolumn{2}{|c|}{2} & \multicolumn{2}{|c|}{1} & \multicolumn{2}{c|}{2} \\
\hline Type & $H$ & $L$ & $H$ & $L$ & $H$ & $L$ & $H$ & $L$ \\
\hline \% employed & 25.19 & 74.81 & 25 & 75 & 32.84 & 67.16 & 31.74 & 68.26 \\
\hline Average wage & 30.82 & 24.31 & 31.05 & 23.71 & 30.9 & 23.71 & 31.62 & 21.85 \\
\hline \hline
\end{tabular}

Table 5.1: Employment rate and average wage by treatment, stage and type

constraint of high-ability workers in stage 1 as this increases the probability that they will also hire a high-ability worker in the private market in stage 2 . Our second result investigates whether this is the case.

Result 2: Firms are more likely to make offers that satisfy the participation constraint of high-ability workers in the first stage of treatment $R$, than in treatment $N R$.

SUPPORT: The reservation wage for $H$ workers is 30 . Therefore, $H$ workers will accept only wages that are higher than 30 . Figure 5-1 shows the cumulative distribution of accepted wages in stage 1 in each treatment. This figure indicates that there is a higher percentage of accepted $w>30$ in the first stage of the $R$ treatment. Indeed in stage 1 of the $N R$ treatment $57.41 \%$ of the accepted wages are below 30 against $45.67 \%$ for the $R$ treatment. The fraction of accepted wages with $w>30$ is greater in the first stage of treatment $R(54.33 \%)$ than in treatment $N R(42.59 \%)$. Using the proportion of accepted wages strictly greater than 30 in stage 1 in each session as an independent observation, we find that the difference is statistically significant (Mann-Whitney; $p$-value=0.0446). In consequence, the median accepted wage is higher in the first stage of treatment $R$ (median wage $=31$ ) than in treatment $N R$ (median wage $=25$; Mann-Whitney; $p$-value $=0.1601) \cdot{ }^{9}$ This result is interesting because it corroborates Montgomery's findings concerning the "wage premium" in stage 1 of the period. In the experiment, firms seem to anticipate the prospect of profits coming from the stage- 2 worker of high ability who will be recruited in the referral market. Our third result investigates the distribution of wages accepted.

Result 3: Two wages are the most accepted in each treatment, $w^{*}=31, w^{* *}=20 . H$ workers accept mainly $w^{*}=31$ and $L$ workers accept mainly $w^{* *}=20$ but also $w^{*}=31$. SUPPORT: Figure 5-2 presents the distribution of accepted wages by treatment, stage

\footnotetext{
${ }^{9}$ To calculate the p-value we take the median wage in each session and treatment.
} 


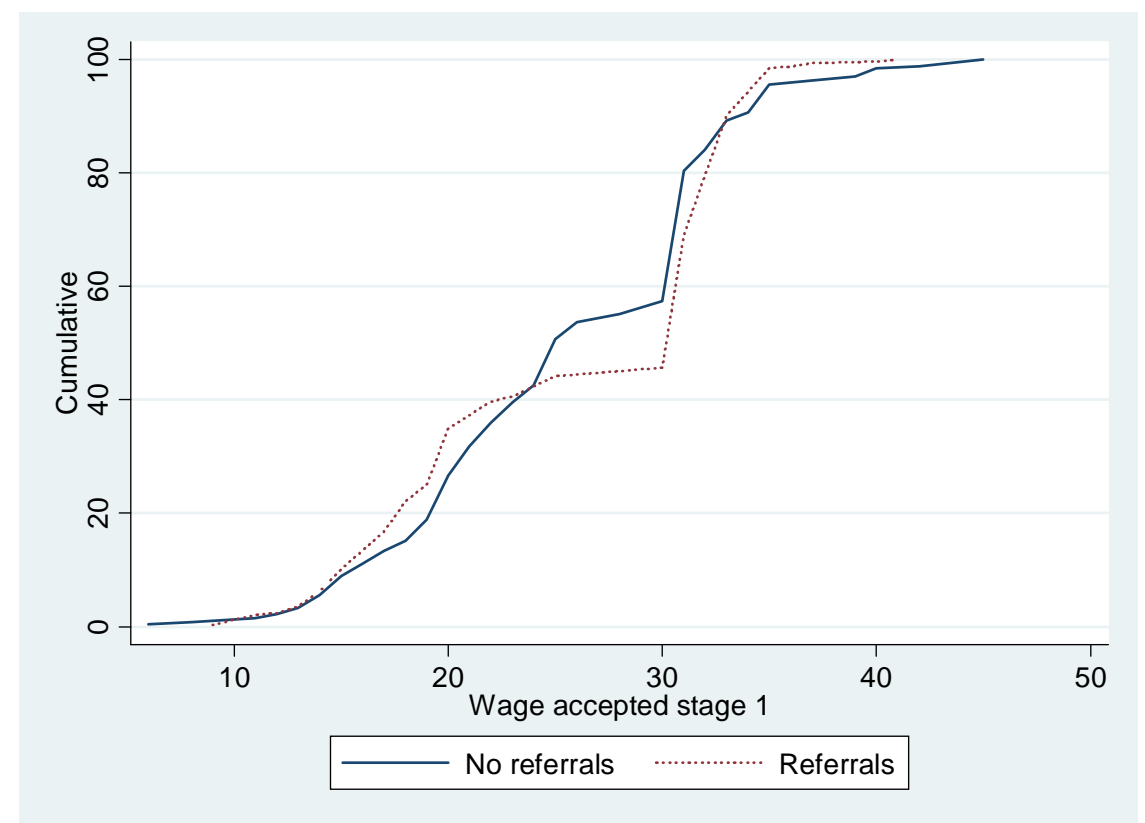

Figure 5-1: Cumulative distribution of accepted wages

and type of worker. As mentioned, given the productivity of $H$ and $L$ workers, the former should not accept a wage that is strictly less than 30. An $L$ worker should not accept a wage strictly less than 10. Therefore, both types of workers should accept a wage offer $w \geq 30$. In each treatment and stage, we observe a concentration of wages between 15 and 25 and between 31 and 35 with a peak at 20 and 31. Wages of 20 mainly concern $L$ workers and wages of 31 and more were allocated among $L$ and $H$ workers. ${ }^{10}$ In each stage and treatment, 31 is the modal wage, low productivity workers had a rent of 11 and high ability workers had a rent of 1 . On average, in both stages and treatments wages accepted by $H$ workers are not significantly different from 31 (Wilcoxon sign-rank test; $p$-value $=0.5002$ for the $N R$ treatment; $p$-value $=0.3400$ for the $R$ treatment). Since $L$ workers often manage to accept wages that were also meant for $H$ workers, the wages they accept are significantly greater than 20 (Wilcoxon sign-rank test; $p$-value $=0.0431$ for the $N R$ treatment; $p-$ value $=0.0277$ for the $R$ treatment).

Our next results focus on how firms make use of referral offers and how they affect

\footnotetext{
${ }^{10}$ Somewhat suprisingly, in stage 1 of the NR treatment, $15 \% H$ workers accept wages that are below $30(9.09 \%$ in stage 2$)$. In the $\mathrm{R}$ treatment, this number is $8.18 \%$ in stage 1 versus $5.66 \%$ in stage 2 . This behavior may be due to errors, but we continue to observe this type of behavior also later in the game. Only $1 \%$ of the low ability workers accept a wage that is lower than 10 over the two treatments and stages.
} 


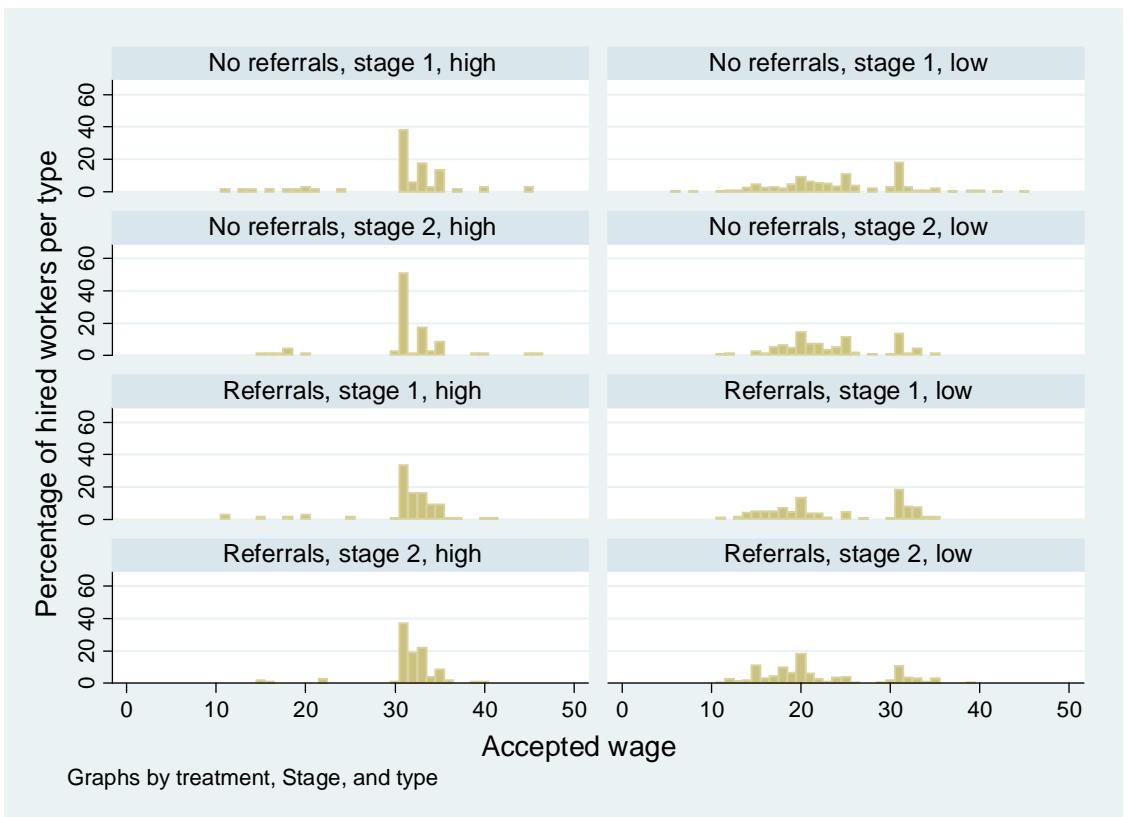

Figure 5-2: Hiring rate and wage acceptance

the hiring of workers and the wages.

Result 3: Firms are significantly more likely to make referral offers when the worker hired in stage 1 is of high ability.

SUPPORT: In treatment $\mathrm{R}$, the probability that a firm employing an $H$-worker in stage 1 hires in the referral market in stage 2, is $48 \%$ higher than that of a firm that hired a low-ability worker (Random-effects Probit, $p$-value $<0.01) .{ }^{11}$ This probability does not change significantly over time (Random-effects Probit, $p$-value $=0.40$ ). This finding indicates that firms use the social network of their workers in order to overcome the problem of asymmetric information.

Result 4: Accepted wages in the referral market are higher on average than those in the public market.

SUPPORT: The average accepted wage in the referral market in the second stage of treatment $R$ is 29.05. In contrast, the average accepted wage in the public market is 23.15 in the second stage of the $R$ treatment. In line therefore with our expectations and Montgomery (1991), private offers are significantly higher than public offers (Wilcoxon

\footnotetext{
${ }^{11}$ Random effects are at the session level. The dependent variables are a dummy taking the value of 1 if the firm hired an $\mathrm{H}$ worker and 0 otherwise, and Period to control for any time effect.
} 
signed-rank test at the session level; $p$-value $=0.0277$ both for accepted wages). For completeness, we report that wages accepted in the second stage of treatment $N R$ are significantly lower than those in the referral market of treatment $R$ (Mann-Whitney at the session level; $p$-value $=0.010$ for accepted wages $).{ }^{12}$

Result 5: The probability of hiring a $H$ worker is higher in the referral than in the public market.

SUPPORT: The probability of hiring a $H$ worker is higher in the referral than in the public market (Wilcoxon signed-rank test at the session level; $p$-value= 0.0277). In particular, $66.34 \%$ of the private offers that are accepted are from a firm that hired a $H$ worker in stage 1 . In contrast, in the second stage of the $\mathrm{R}$ treatment, $22.74 \%$ of the employed workers in the public market are $H$ workers.

In the next section we investigate the dynamic of the trading phases by looking at how time enters in the decision process of firms and workers.

\subsubsection{Other results: a look at the dynamics in the market}

In this section, we first take an overview at when wages were accepted, before examining the temporal aspects of the data in more detail.

Recall that firms and workers have 120 seconds ( 2 minutes) to post and accept offers. We report the time in seconds and the results show the exact second an offer is posted or accepted. In all figures, on the horizontal axis, an observation close to 0 means that an offer was accepted or offered at the beginning of the trading phase. If an observation is close to 120 it means that an offer was offered or accepted towards the end of the trading phase. Crosses refer to $L$ workers and circles to $H$ workers. The tests use average time of acceptance or average time wages were posted at the session level.

Figure 5-3 shows the time of acceptance at the individual level for each treatment and each type and stage. Intuitively, $L$ workers could wait until they have a significant surplus and accept wages earlier than $H$ workers since their reservation value is lower. $H$ workers could also wait in order to accept $w>30$ and accept wages later than $L$ workers.

\footnotetext{
${ }^{12}$ Note that wages for $L$ workers in the referral market are significantly higher than those in the public market in stage 2 (Wilcoxon signed-rank test; $p$-value= 0.02 ). Conversely, $H$ workers don't have statistically significant higher wages in the private market than in the public market (Wilcoxon signed-rank test; $p$-value $=0.24$ ).
} 


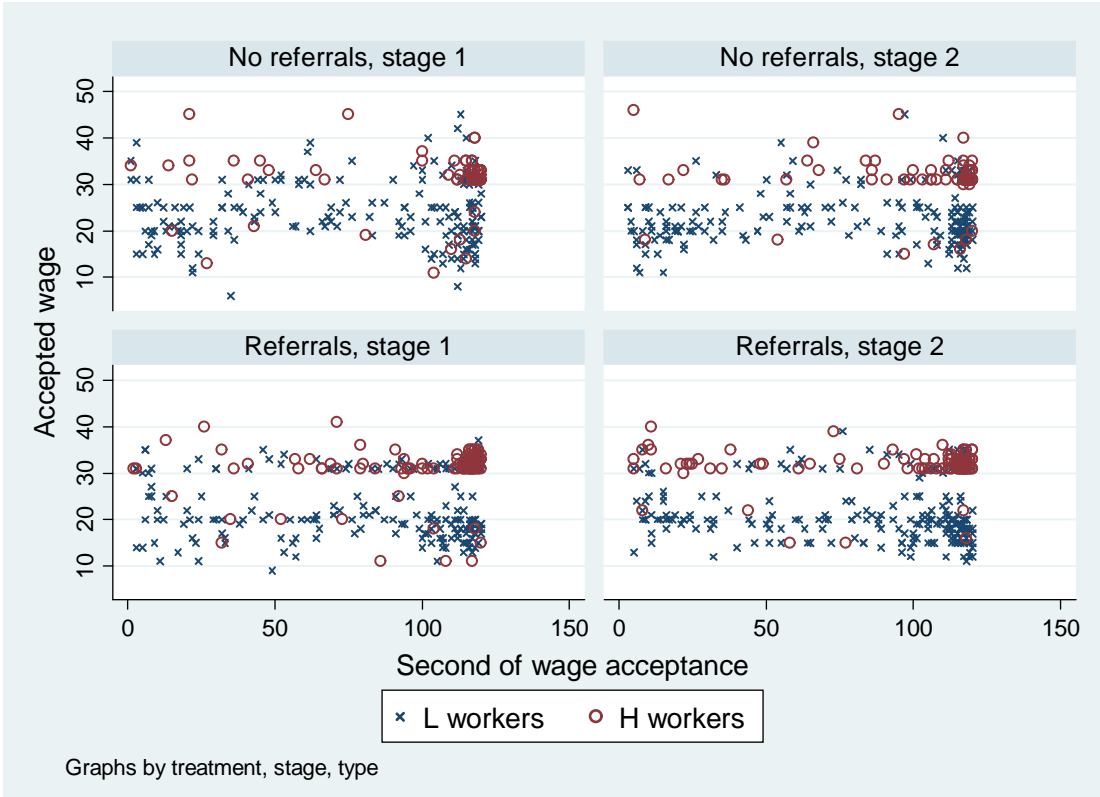

Figure 5-3: Time of wage acceptance

\begin{tabular}{|c|c|c|}
\hline \multicolumn{3}{|c|}{ Average time of acceptance in seconds } \\
\hline Treatment & No Referrals & Referrals \\
\hline$L$ workers & 78.66 & 86.06 \\
\hline$H$ workers & 98.52 & 101.13 \\
\hline
\end{tabular}

Table 5.2: Timing of wage acceptance

In line with our previous results we notice that the market is characterized by adverse selection in the sense that there are more crosses than circles. Nevertheless, in both stages of the $\mathrm{R}$ treatment we notice more circles suggesting that the fraction of $H$ workers is higher than in the NR treatment. Moreover, we can see that $L$ workers accept on average lower wages than $H$ workers (except some outliers). We also observe a high concentration of crosses and circles at the right of the horizontal axis, indicating that most participants wait until the end of a trading phase to accept a wage offer.

To complement our previous results we wish to answer the following questions: Do $H$ workers accept offers later than $L$ workers? Are higher wages offered and accepted later? How does the option to have referral offers affect the dynamic of the market?

Result 7: In both treatments and stages, $H$ workers accept wage offers later than $L$ workers .

SUPPORT: Table 5.2 presents the average time a wage offer was accepted in each treat- 


\begin{tabular}{|c|c|c|c|c|}
\hline \multicolumn{4}{|c|}{ Average time in seconds by treatment } \\
\hline \hline Treatment & \multicolumn{2}{|c|}{ NR } & \multicolumn{2}{c|}{$\mathrm{R}$} \\
\hline wage & $w \leq 30$ & $w>30$ & $w \leq 30$ & $w>30$ \\
\hline Average time $w$ was offered & 45.74 & 97.47 & 39.50 & 91.57 \\
\hline Average accepted $w$ was offered & 60.2 & 96.5 & 67.85 & 93.94 \\
\hline Average time $w$ was accepted & 74.11 & 97.67 & 80.47 & 96.92 \\
\hline
\end{tabular}

Table 5.3: Timing of wage posting and acceptance

ment, for each type, pooling observations across stages and periods. In both treatments we observe a tendency for $H$ workers to accept wage offers later than $L$ workers. In the $N R$ treatment, $L$ workers accept wages on average 78.66 seconds after the start of a trading phase against 98.52 seconds for $H$ workers. In the $R$ treatment, $L$ workers accept wages on average 86.06 seconds after the start against 101.13 seconds for $H$ workers. The difference is confirmed by a Wilcoxon signed-rank test ${ }^{13}$ (p-value $=0.0796$ for the $N R$ treatment and p-value $=0.0277$ for the $R$ treatment). Further, in the $N R$ treatment, 23.96 $\%$ of the $L$ workers and $52.55 \%$ of the $H$ workers accept wages in the last 5 seconds of the trading phase. In the $R$ treatment, $18.7 \%$ of the $L$ workers and $37.5 \%$ of the $H$ workers accept wages in the last 5 seconds of a trading phase. ${ }^{14}$

It is now interesting to see the distinction between wage above and below 30 . We also look at firms' behavior by analyzing the time wages are offered.

Result 8: Firms offer wages above 30 later on in a trading period. Workers accept wages above 30 faster than wages less or equal to 30.

SUPPORT: Table 5.3 presents the average time wages were posted and accepted in both treatments for $w \leq 30$ and $w>30$, pooling observations across stages and periods. The row "Average time $w$ was offered" refers to the time all wages were offered. The row "Average accepted $w$ was offered" refers to the time accepted wages were offered. Finally, the last row "Average time $w$ was accepted" refers to the time at which a wage was accepted. As can be seen, on average, in both treatments, $w \leq 30$ is posted and

\footnotetext{
${ }^{13}$ For the Wilcoxon signed-rank test we take the average time of acceptance per session.

${ }^{14}$ The dynamic of the employment could be explained in the following way. In the $\mathrm{R}$ treatment on average $3 \mathrm{~L}$ and $1 \mathrm{H}$ workers are employed. $3 \mathrm{~L}$ workers accept offers between 10 and 30 before $\mathrm{H}$ workers make any decision. Then, once all $L$ workers are employed a $H$ worker accept an offer above 30 in the last 5 last second. Two High ability workers remain therefore unemployed. For $w=30$ it is attractive for $L$ worker to accept this wage. Nevertheless, it is less appealing for $H$ workers who may want to wait more in order to increase their surplus. Once all $L$ workers have been hired, the firm faces $3 H$ workers and has a probability of one of hiring a $H$ worker and therefore it is optimal for it to offer $w=31$ ( $H$ worker prefers to have a profit of 1 instead of 0 by being unemployed)
} 


\begin{tabular}{|c|c|c|}
\hline Average time in seconds $R$ Treatment & Public market & Private market \\
\hline \hline Time of acceptance by $H$ workers & 101.23 & 86.65 \\
\hline Time of acceptance by $L$ workers & 86.83 & 73.07 \\
\hline Time of acceptance by $H$ and $L$ workers & 90.12 & 80.12 \\
\hline Time accepted $w$ was offered & 70.55 & 62.62 \\
\hline
\end{tabular}

Table 5.4: Timing of wage offer and acceptance in the referral and public market

accepted before $w>30$. Using each session as independent observation, the difference is statistically significant in both treatments (Wilcoxon signed-rank test; p-value $=0.0796$ for "Average accepted $w$ was offered" and "Average time $w$ was accepted" for the $N R$ treatment; $p$-value $=0.0747$ for "Average time $w$ was accepted" and $p$-value $=0.0277$ for "Average accepted $w$ was offered" in the $R$ treatment). The results are similar if we consider all wage offered (Wilcoxon signed-rank test; p-value $=0.041$ in the $N R$ treatment; $p$-value $=0.0277$ in the $R$ treatment). Further, we notice that workers wait on average longer before accepting a $w \leq 30$ (13.93 seconds in $N R$ and 12.62 seconds in $R$ ) than $w>30$ (1.17 seconds in $N R$ and 2.98 second in the $R$ ). A Wilcoxon signed-rank test indicates that the difference is statistically significant ( $p$-value $=0.0431$ in the $N R$ and $p$-value $=0.0277$ in the $R$ treatment.)

In the second stage of the $\mathrm{R}$ treatment we may wonder whether the introduction of a social network may influence the time wages are offered and accepted in the referral market. Result 9 explores this question.

Result 9: In the referral market, referral offers are posted and accepted before public offers and more $H$ workers are hired quicker.

SUPPORT: Table 5.4 describes the average time $H$ and $L$ workers accepted an offer in the public and private markets in the second stage of the $R$ treatment as well as the average time a wage offer was posted. In the public market, $H$ workers wait on average 101.23 seconds before accepting a wage offer against 86.83 seconds for $L$ workers. In the private market, $H$ workers wait 86.65 seconds and $L$ workers 73.07 before accepting a wage offer. We find that both types accept offers more quickly in the private market than in the public market. The difference is statistically significant (Wilcoxon signedrank test; $H$ workers $p$-value $=0.0747$, Wilcoxon signed-rank test; $L$ workers $p$-value $=$ 0.1159). Moreover, similar to the NR treatment, $H$ workers accept wage offers after $L$ workers in both markets (Wilcoxon signed-rank test; $p$-value $=0.0277$ for both markets). 
On the firms' side, we notice that on average, wages that were subsequently accepted were offered first in the private market (62.62 seconds) and then in the public market $(70.55$ seconds). Nevertheless, the difference is not statistically significant (Wilcoxon signed-rank test; $p$-value $=0.2489)$.

\subsection{Conclusion}

This chapter has presented the results from a lab experiment investigating how firms use the social network of existing employees to overcome adverse selection in a labor market. We find that the introduction of social ties affects the functioning of the market. The referral market alleviates the problem of adverse selection in the sense that more $H$ workers are hired. Firms take the opportunity of a referral market to hire $H$ workers and for that they will also have a tendency to offer more $w>30$ and more quickly. The inbreeding bias reduces the uncertainty for firms that are willing to increase the wage they offer. More specifically, we find that $(i)$ firms makes more referral wage offers when they current employee is a high ability worker, $(i i)$ wages are higher in the referral market, (iii) current workers in the referral treatment earn a "wage premium" due to the prospect of hiring a high ability worker in the referral market and, $(i v)$ the existence of a social network reduces the proportion of low ability workers that are hired and creates a referral market dominated by high ability workers.

Our experiment contributes to the literature on social and economic networks. Moreover, the experiment complements the experiment by Brown, Falk and Fehr (2004) who showed that implicit contracts as long-term relationship could overcome the moral hazard problem. In line with them we find that implicit contracts, i.e, social networks help overcome adverse selection.

In this chapter we are also interested in the dynamics of the market. We find that low ability workers accept lower wage offers earlier than high ability workers. On the firm's side, they first offer wages below 30 and then higher wages. Finally, in the referral market wages are offered and accepted before those in the public market.

We note that despite the existence of a social network the problem of adverse selection is not totally overcome. Further research could investigate the impact of a higher inbreeding bias on the labor market outcomes. Moreover, our study uses insights of 
Montgomery's (1991) model, nevertheless, differences such as the number of links allowed between workers, free entry and exit of firms could be introduced and analyzed in future research. 


\section{Chapter 6}

\section{Conclusion}

The four studies presented in this thesis investigated the nature and significance of social preferences in a variety of contexts. In doing so, they contribute to the vast but still growing literature on the topic. I believe - and hopefully readers of this thesis will agree - that the experiments have yielded some interesting insights. However, as is typically the case with scientific investigation, the findings raise a number of new questions that could be interesting for future research. I would like to conclude my thesis by discussing some of them.

In Chapter 2 we saw that only 10 percent of workers (i.e., second movers) in the giftexchange game exhibited no willingness to respond to higher wages with higher effort. The remaining 90 percent of workers exhibited reciprocal preferences. What is equally noteworthy is the fact that reciprocal preferences were quite weak. This implies that firms in the experiment were better off not offering "gifts" (i.e., higher wages) but the lowest possible wage. In line with this, we observed gift-exchange unraveling over time in the finitely-repeated game.

An obvious question that arises is how can one reconcile the evidence from the experiment reported in Chapter 2 with those in early studies in which gift-exchange was sustained over time. Different factors may account for the differences. Future studies could use the strategy method presented in Chapter 2 to examine them. For instance, one possibility is that different experimental samples may exhibit stronger preferences for reciprocation. Thus, one could try to replicate the findings from this experiment using different samples in different countries. However, I believe that the results may not be very different in other subject pools. The reason is that the elicited cooperation prefer- 
ences of our experimental sample (in Chapter 3) resemble closely those in other studies. Another factor may be the different parameters used in earlier studies. Our experiment used payoff functions similar to those in Brown et al. (2004). They also found low levels of gift-exchange. Future experiments thus could investigate how different payoff functions affect individuals' preferences for reciprocation. This would help improve our understanding of how reciprocal preferences may best be modelled and assess the robustness of gift-exchange.

The study reported in Chapter 3 presented evidence linking preferences for reciprocation to those for cooperation at the individual level. In particular, we saw that participants classified as cooperators in a public-good game were the only subjects reciprocating higher wages by exerting higher levels of effort in the gift-exchange game. The evidence is broadly consistent with models of social preferences that aim to provide a parsimonious explanation for pro-social behavior. An open question is, what is the model that can best predict pro-social behavior? Since there are still few within-subject analyses of pro-social behavior, more experiments are needed to uncover behavioral regularities and help answer this question. These studies could investigate behavior in different games, different environments and under different information conditions. Importantly, future experiments should investigate the robustness of pro-social behavior over a longer time horizon than the one investigated in our experiment.

The experiment presented in Chapter 4 provided evidence that cooperation preferences are subject to framing effects. The study varied the sequence and order in which the contributions of other group members are presented in the Fischbacher et al. (2001) method. As we saw, the order, by and large, had no impact on the elicited preferences and their predictive power. In contrast, presenting the contributions of others in a sequence had a pronounced effect on the elicited preferences and reduced substantially their predictive power. Importantly, the method as introduced by Fischbacher et al. (2001) seems to be a good predictor of behavior both in the one-shot and the finitely-repeated public-good game. One surprising finding seemingly worthy of future investigation is the substantially higher contributions observed in the sequential frame. It suggests that the administration of the strategy method at the start of the experiment could affect behavior in later stages of the experiment. It would also be worthwhile investigating different variants of the method in which, for example, participants are presented with the vector of 
individual contributions (rather than the average contribution of others) or the maximum contribution of others.

The study in Chapter 5 examined the ability of social networks to alleviate adverse selection in an experimental labor market. The social ties between workers is a form of social preferences. The aim of the experiment in this chapter was to investigate whether firms used the social network of their workers to hire new workers of similar ability and, hence, whether social networks reduced adverse selection. As we saw, firms in the experiment were more likely to make "referral offers" when the worker hired previously was of high ability due to the homophily between workers. Firms were also more likely to make higher offers to attract (high-ability) workers with a better network, while referral offers were higher on average than public offers. Importantly, we saw that the proportion of high-ability workers in the second stage was higher in the presence of social networks.

One interesting extension for future work would be to vary the extent of homophily in the experiment. For example, are referral offers more likely and referral wages higher if workers are 90 percent (rather than 75 percent) likely to be matched with another worker of similar ability? Does the proportion of high-ability workers increase? Another interesting question is whether similar social networks can help overcome moral hazard. Workers may be less willing to shirk if performing better than others improves the chances of a friend or family member to be hired in the future. These are questions I intend to investigate next. 


\title{
Appendix A
}

\section{Imperfect reciprocators and the unravelling of gift exchange}

\author{
A.1 Additional statistics
}

A.1.1 Individual effort of choices

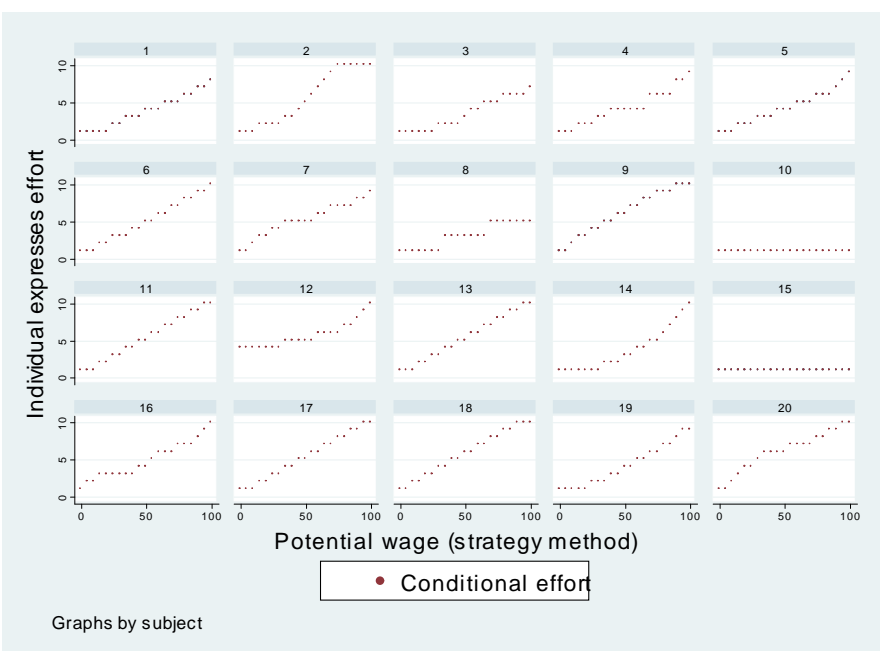

Figure A-1: Individual effort of choices in the strategy method 


\section{A.1.2 Robustness estimates}

\begin{tabular}{|c|c|c|c|c|}
\hline \multicolumn{5}{|c|}{ Dependent variable: effort } \\
\hline$\overline{\text { Model }}$ & 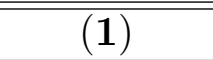 & 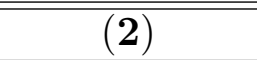 & 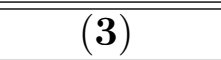 & (4) \\
\hline Workers used & All workers & Reciprocators & All workers & Reciprocators \\
\hline Period & $\begin{array}{l}-0.071 \\
(0.127)\end{array}$ & $\begin{array}{l}-0.083 \\
(0.125)\end{array}$ & $\begin{array}{l}-0.140 \\
(0.121)\end{array}$ & $\begin{array}{l}-0.144 \\
(0.122)\end{array}$ \\
\hline Wage & $\begin{array}{c}0.106^{* * *} \\
(0.016)\end{array}$ & $\begin{array}{c}0.106^{* * *} \\
(0.016)\end{array}$ & & \\
\hline Predicted effort & & & $\begin{array}{c}1.387^{* * *} \\
(0.201)\end{array}$ & $\begin{array}{c}1.340^{* * *} \\
(0.201)\end{array}$ \\
\hline Constant & $-3.109^{* *}$ & $-2.430^{* *}$ & $-3.889^{* * *}$ & $-3.377^{* * *}$ \\
\hline & $(1.239)$ & $(1.160)$ & $(1.295)$ & $(1.280)$ \\
\hline Log-L & -194.33 & -189.94 & -193.61 & -191.77 \\
\hline Wald $\chi_{(2)}^{2}$ & 47.92 & 49.14 & 51.02 & 48.19 \\
\hline Observations & 200 & 180 & 200 & 180 \\
\hline
\end{tabular}

***(**) indicates significance at 1 (5) percent level;

Regressions are random effects Tobit models clustered on individuals;

Standard errors in parantheses

Table A.1: Explaining effort choices in the repeated GEG (tobit) 


\begin{tabular}{|c|c|c|c|c|}
\hline \multicolumn{5}{|c|}{ Dependent variable: effort } \\
\hline Model & $(\mathbf{1})$ & $(2)$ & $(3)$ & $(4)$ \\
\hline Workers used & All workers & Reciprocators & All workers & Reciprotors \\
\hline Period & $\begin{array}{l}-0.013 \\
(0.041)\end{array}$ & $\begin{array}{l}-0.024 \\
(0.044)\end{array}$ & $\begin{array}{l}-0.040 \\
(0.040)\end{array}$ & $\begin{array}{l}-0.046 \\
(0.044)\end{array}$ \\
\hline Wage & $\begin{array}{c}0.037^{* * *} \\
(0.005)\end{array}$ & $\begin{array}{c}0.040^{* * *} \\
(0.005)\end{array}$ & & \\
\hline Predicted effort & & & $\begin{array}{c}0.465^{* * *} \\
(0.061)\end{array}$ & $\begin{array}{c}0.454^{* * *} \\
(0.065)\end{array}$ \\
\hline Constant & $1.526^{* * *}$ & $1.615^{* * *}$ & $1.274^{* * *}$ & $1.359^{* * *}$ \\
\hline & $(0.368)$ & $(0.372)$ & $(0.386)$ & $(0.406)$ \\
\hline$R^{2}$ (overall) & 0.23 & 0.26 & 0.24 & 0.23 \\
\hline Wald $\chi_{(2)}^{2}$ & 60.95 & 63.36 & 62.91 & 52.83 \\
\hline Observations & 200 & 180 & 200 & 180 \\
\hline
\end{tabular}

Table A.2: Explaining effort choices in the repeated GEG (GLS)

\section{A.2 Instructions}

\section{A.2.1 General instructions}

Welcome to this economic experiment. In the experiment you and other participants will make decisions. Next to the fee of 3 Euro for showing up in time, you can earn money in the experiment. How much you earn depends on your own decisions and the decisions of other participants. At the end of the experiment the show-up fee and the earnings from the different parts will be added up and confidentially paid out to you in cash.

The experiment consists of different parts that are all independent of one another. For each part you will receive specific instructions. These instructions will explain how you make decisions and how your decisions and the decisions of other participants influence your earnings. Therefore, it is important that you read the instructions carefully.

From now on you are not allowed to communicate in any other way than specified in the instructions. Please obey to this rule because otherwise we have to exclude you from the experiment and all earnings you have made will be lost. Please also do not ask questions aloud. If you have a question raise your hand. A member of the experimenter team will come to you and answer your question in private.

Before we start with the first part of the experiment we ask you to fill in a ques- 
tionnaire. This questionnaire is unrelated to the other parts of the experiment. You do neither earn extra money for answering theses questions nor do your answers influence your earnings in the other part.

\section{A.2.2 Specific instructions - Part 1}

In this part of the experiment you can earn money with the decisions you make. How much you earn depends on your own decisions and the decisions of other participants. We will not speak of Euro during the experiment, but rather of points. All you earnings will first be calculated in points. At the end of the experiment the total amount of points you earned in this part will be converted to Euro at the following rate:

$$
1 \text { point }=12 \text { Euro cent }
$$

At the beginning of this part of the experiment all participants will be divided into pairs. You will not get to know the identity of the other person, neither during nor after the experiment. The other person will also not get to know your identity. We now describe how this part of the experiment proceeds. First you will be introduced to the basic decision situation, thereafter you will learn more specifically how the experiment is conducted. You will also be asked some control questions that will help you to understand the decision situation.

\section{The decision situation:}

You will be randomly paired with one other participant. In each pair one participant will be randomly assigned the role of a firm and the other participant will have the role of a worker. You will be informed about your role at the beginning of the experiment. You - as every other participant - will keep the assigned role throughout this part of the experiment.

You have to make a decision without knowing the decision of the other participant. The other participant in your pair also has to make a decision without knowing your decision. Which kind of decision you have to make depends on your role. If you are assigned the role of a firm you have to make a wage offer. The wage you offer can be any amount from 0 to 100 (as long as it is a multiple of 5). That is you can offer a wage of 0 , or 5 , or $10, \ldots$, or 90 , or 95 , or 100 . If you are assigned the role of a worker you have to decide which effort level you provide for each possible wage offered by the firm. The 


\begin{tabular}{|c|c|c|c|c|c|c|c|c|c|c|}
\hline$e$ & 1 & 2 & 3 & 4 & 5 & 6 & 7 & 8 & 9 & 10 \\
\hline \hline$c(e)$ & 0 & 1 & 2 & 4 & 6 & 8 & 10 & 12 & 15 & 18 \\
\hline
\end{tabular}

Table A.3: Effort table

effort level you choose can be any integer number from 1 to 10. That is you can decide to provide effort levels of 1 , or 2 , or $3, \ldots$, or 8 , or 9 , or 10 . You can choose different effort levels for different wage offers but you can also choose the same effort level for different wage offers. To each effort level correspond some costs the worker has to bear for this effort level. How the effort levels and costs are related is show in this table:

The earnings are calculated in the following way:

If you are a firm:

- first, multiply the effort level chosen by the worker with 10 ,

- second, subtract the wage you offered,

- third, add an endowment of 50 .

As formula:

Earnings of firm $=10 *$ effort level - wage offer +50

Note: if the earnings of the firm determined in this way would be negative they are set to zero. For example, if you are the firm and you offer a wage of 35 and the worker chooses an effort of 9 for this wage then you will earn $10^{*} 9-35+50=105$ points; if you are the firm and you offer a wage of 85 and

the worker chooses an effort of 2 for this wage you would earn $10^{*} 2-85+50=-15$ points, which will be set equal to 0 points.

If you are a worker:

- first, take the wage offered by the firm,

- second, subtract the costs associated with effort level chosen (see table),

- third, add an endowment of 20.

As formula:

Earnings of worker $=$ Wage offer - cost of effort +20

For example, if you are the worker, the firm offers a wage 35 and you choose an effort of 9 for this wage

then you will earn $35-15+20=40$ points; if you are the worker, the firm offers a wage of 85 and you

choose an effort of 2 for this wage you would earn $85-1+20=104$ points. 
Control questions - decision situation:

Please answer the following control questions. These questions are arbitrary examples of what could

happen in the experiment. In the experiment you will in the role of either a worker or a firm. The

questions will concern both roles. They will help you to gain an understanding of the calculation of your

earnings. Your earnings vary with your own decision and with the decisions of the other person you are

paired with.

Please answer all the questions and write down your calculations.

1. Assume that the firm has chosen a wage of 0 and the worker has chosen an effort level of 0 for a

wage offer of 0 .

What will your earnings be if you are the worker?

What will your earnings be if you are the firm?

2. Assume that the firm has chosen a wage of 100 and the worker has chosen an effort level of 10 for a

wage offer of 100 .

What will your earnings be if you are the worker?

What will your earnings be if you are the firm?

3. Assume that the firm has chosen a wage of 80 and the the worker has chosen an effort level of 2 for a

wage offer of 80 .

What will your earnings be if you are the worker?

What will your earnings be if you are the firm?

4. Assume that the firm has chosen a wage of 30 and the worker has chosen an effort level of 7 for a

wage offer of 30 .

What will your earnings be if you are the worker?

What will your earnings be if you are the firm?

The experiment: 


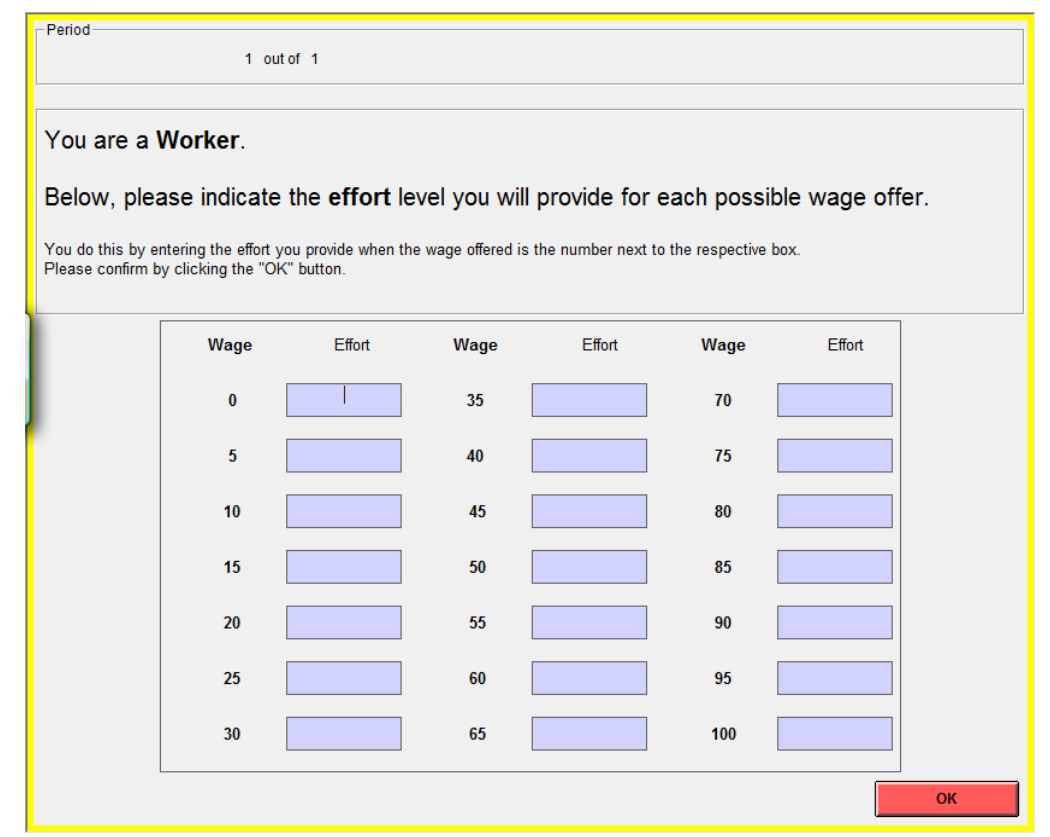

Figure A-2: Screenshot: conditional effort level

In experiment you will be confronted with the described decision situation only once. Before the experiment starts you will be assigned either the role of worker or the role of firm. What types of decisions you have to make depends on your role. Here we explain first the types of decisions for a workers and then the decisions for a firm.

Decisions for workers:

If you are a worker you have to indicate your effort level for each possible wage offer by the firm. What this means will be immediately clear to you if you take a look at the computer screen shown below. This screen shows a table as it will be presented to you in the experiment, in case you are a worker: The numbers to the left to the empty boxes are the possible wage offers of the firm. You simply have to insert in the boxes the effort level you will choose, conditional on the indicated wage offer. You have to make an entry into each of the boxes. For example, you will have to indicate your effort level if the firm offers a wage of 0 points, your effort level if the firm offers a wage of 5, 10, or 15 tokens, etc. You can insert any integer number from 0 to 10 in each box. When making your decisions you may want to consult the summary of the decision situation you received with these instructions. When you have made your entry in each box, please click "OK".

Note: You do not know the wage offer actually chosen by the firm when you make your effort level 


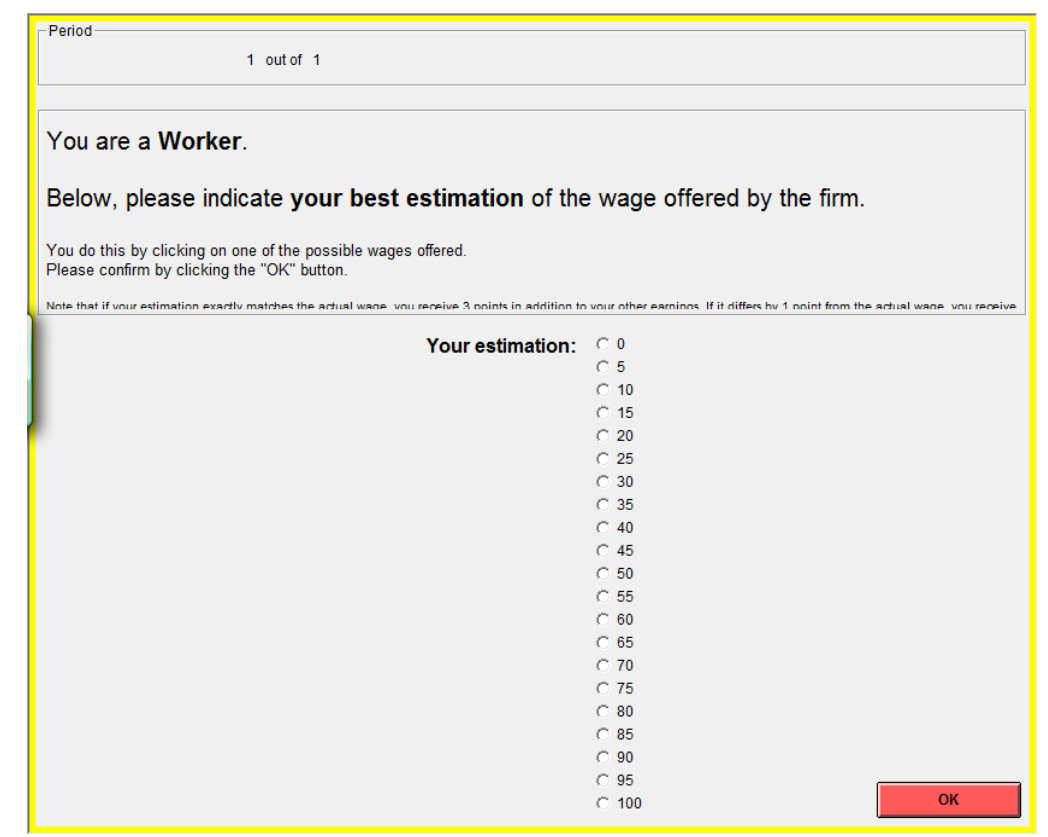

Figure A-3: Screenshot: expected wage

decisions.

After you have made your effort decisions you have to estimate the wage offer actually chosen by the

firm. You will be paid for the accuracy of your estimate:

- If your estimate is exactly right (that is, if your estimate exactly matches the actually chosen wage

offer by the firm), you will receive 3 points extra to your other earnings from the experiment.

- If your estimate deviates by 1 point from the actual result, you will receive 2 points extra.

- If your estimate deviates by 2 points from the actual result, you will receive 1 point extra

- If your estimate deviates by 3 or more points from the actual result, you will receive no points extra.

You will make your estimation decision on a screen as shown below.

Decisions for firms:

If you are a firm you have to indicate the wage level you offer the worker. What this means will be immediately clear to you if you take a look at the computer screen 


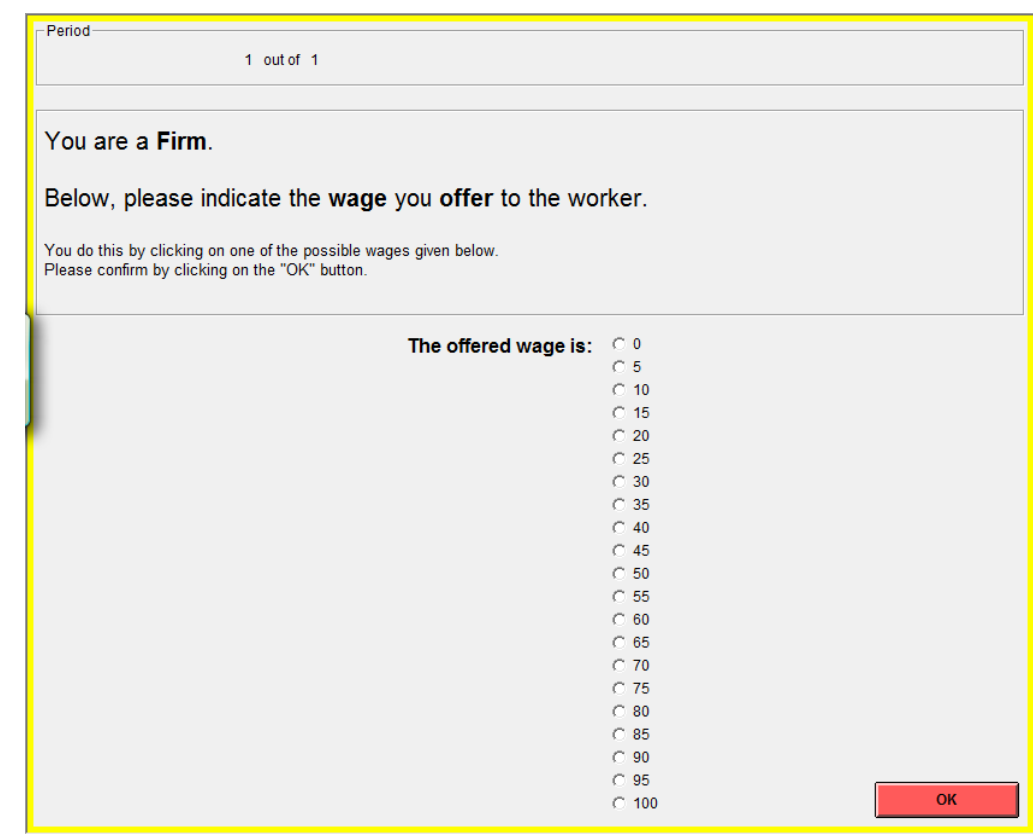

Figure A-4: Screenshot: wage offer

shown below. This screen shows a decision column as it will be presented to you in the experiment, in case you are a firm: The numbers to the right of the empty circles are the possible wage offers of the firm. You simply have to click on one of the circles to indicate your wage offer. You can only make one wage offer. When making your decisions you may want to consult the summary of the decision situation you received with these instructions. When you have made your entry in each box, please click "OK".

Note: You do not know the effort level actually chosen by the worker when you make your wage offer decision. After you have made your wage offer decision you have to estimate the effort level actually chosen for your wage offer. You will be paid for the accuracy of your estimate:

- If your estimate is exactly right (that is, if your estimate exactly matches the actually chosen effort by

the worker for your wage offer), you will receive 3 points extra to your other earnings from the

experiment.

- If your estimate deviates by 1 point from the actual result, you will receive 2 points extra. 


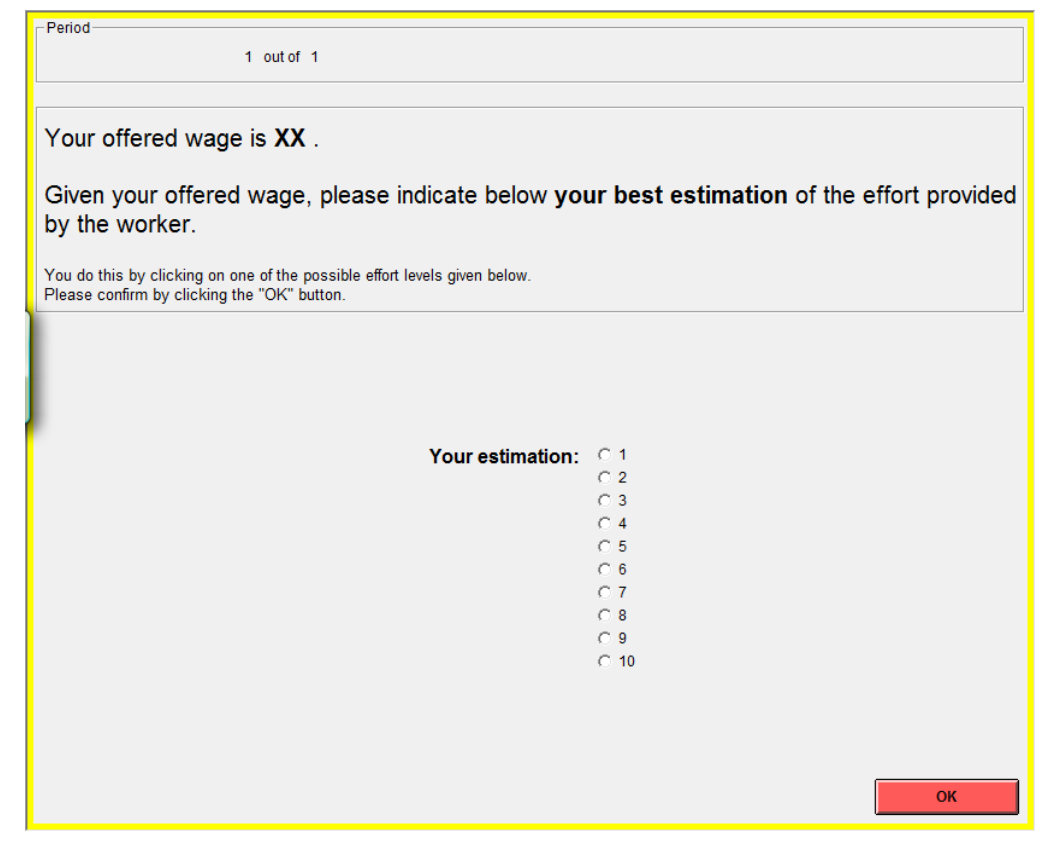

Figure A-5: Screeshot: expected effort

- If your estimate deviates by 2 points from the actual result, you will receive 1 point extra

- If your estimate deviates by 3 or more points from the actual result, you will receive no points extra.

You will make your estimation decision on a screen as shown below.

After all participants of the experiment have made their decisions you will be informed about the choice made by the participant with whom you are paired (and will be reminded of your own choices). You will also be informed about the number of points you have earned in this part of the experiment.

This is the end of the instructions. If you have a question please raise your hand.

\section{A.2.3 Specific instructions - Part 2}

In this part of the experiment you can earn money with the decisions you make. How much you earn depends on your own decisions and the decisions of other participants. We will not speak of Euro during the experiment, but rather of points. All you earnings will first be calculated in points. At the end of the experiment the total amount of points you earned in this part will be converted to Euro at the following rate: 


\begin{tabular}{|c|c|c|c|c|c|c|c|c|c|c|}
\hline$e$ & 1 & 2 & 3 & 4 & 5 & 6 & 7 & 8 & 9 & 10 \\
\hline \hline$c(e)$ & 0 & 1 & 2 & 4 & 6 & 8 & 10 & 12 & 15 & 18 \\
\hline
\end{tabular}

Table A.4: Effort table

1 point $=2$ Euro cent

At the beginning of this part of the experiment all participants will be divided into pairs. You will not get to know the identity of the other person, neither during nor after the experiment. The other person will also not get to know your identity. The decision situation in this part of the experiment is similar as in part 1, with one important exception that will be explained below. For your convenience we briefly describe the whole decision situation.

\section{The decision situation:}

You will be randomly paired with one other participant. In part 1, in each pair one participant was randomly assigned the role of a firm and the other participant was assigned the role of a worker. You - as every other participant - will keep the role assigned in part 1 also throughout this part of the experiment. Compared to part 1, there is an important difference in the sequence of the decisions in this part of the experiment. Now the firm first has to make a wage offer and this wage offer will be transmitted to the worker. Only then the worker has to decide on the effort level.

If you are assigned the role of a firm you have to make a wage offer.

The wage you offer can be any amount from 0 to 100 (as long as it is a multiple of 5). That is you can offer a wage of 0 , or 5 , or $10, \ldots$. , or 90 , or 95 , or 100 .

If you are assigned the role of a worker you will get informed about the wage offer by the firm, then you have to decide which effort level you provide for the received wage offer by the firm. The effort level you choose can be any integer number from 1 to 10 . That is you can decide to provide effort levels of 1 , or 2 , or $3, \ldots$, or 8 , or 9 , or 10 .

To each effort level correspond some costs the worker has to bear for this effort level. How the effort levels and costs are related is show in this table:

The earnings are calculated in the following way:

If you are a firm:

First, multiply the effort level chosen by the worker with 10 , second, subtract the wage you offered, third, add an endowment of 50 . 
As formula:

Earnings of firm $=10 *$ effort level - wage offer +50

Note: if the earnings of the firm determined in this way would be negative they are set to zero.

If you are a worker:

First, take the wage offered by the firm,

second, subtract the costs associated with effort level chosen (see table),

third, add an endowment of 20 .

As formula:

Earnings of worker $=$ Wage offer - cost of effort +20

In this part of the experiment you will be engaged in the decision situation for 10 successive periods. In each period you will be randomly rematched with another participant. Thus, in no period will your pair consist of the same two people for sure. If you are a firm, in each period you have to make a wage offer without knowing what effort level will be chosen by the worker. If you are a worker, in each period you have to decide on the effort level after being informed about the wage offer. At the end of a period firm and worker will be informed about the offered wage and chosen effort levels in the pair in that period. If you are a firm, in each period you will make your wage offer decision on a computer screen as shown here:

On this screen, you have indicate the wage level you offer the worker. You simply have to click on one. of the circles to indicate your wage offer. You can only make one wage offer. In each period, after you have made and confirmed your wage offer you have to estimate the effort level actually chosen for your wage offer. In each period you will indicate your estimation on a computer screen as shown here:

As in the part 1 of the experiment you can earn money with the accuracy of your estimate.

- If your estimate is exactly right (that is, if your estimate exactly matches the actually chosen effort by

the worker for your wage offer), you will receive 3 points extra to your other earnings from the

experiment. 


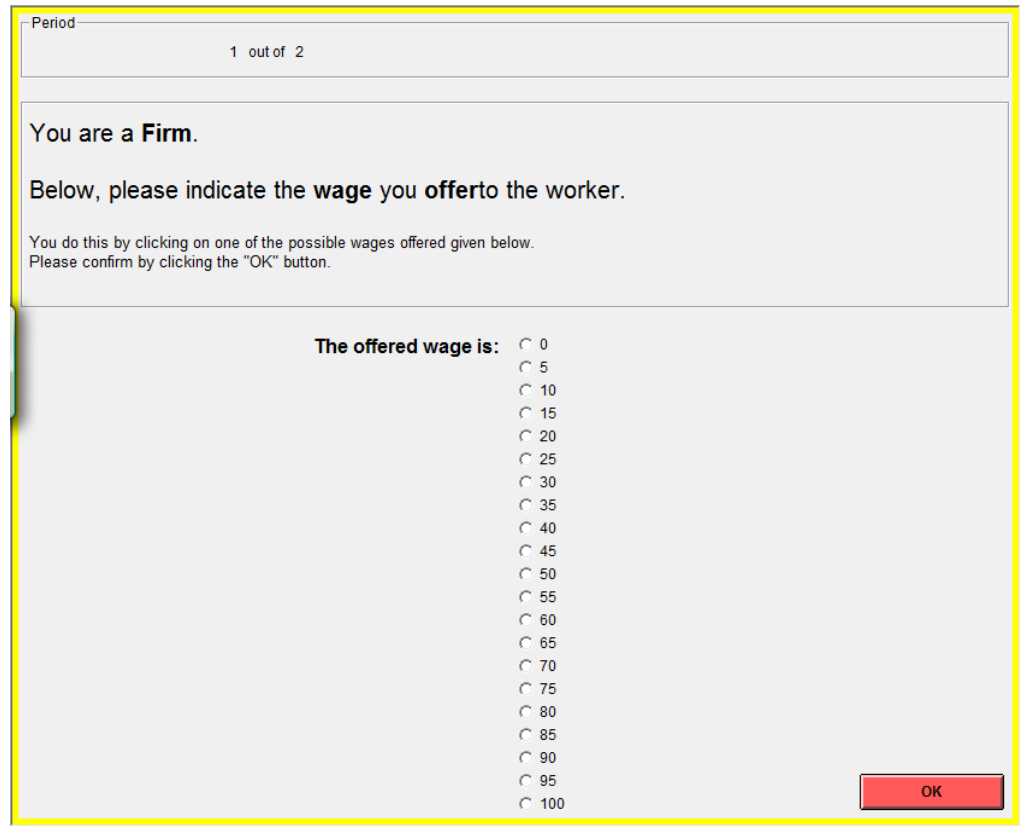

Figure A-6: Screenshot: wage offer repeated game

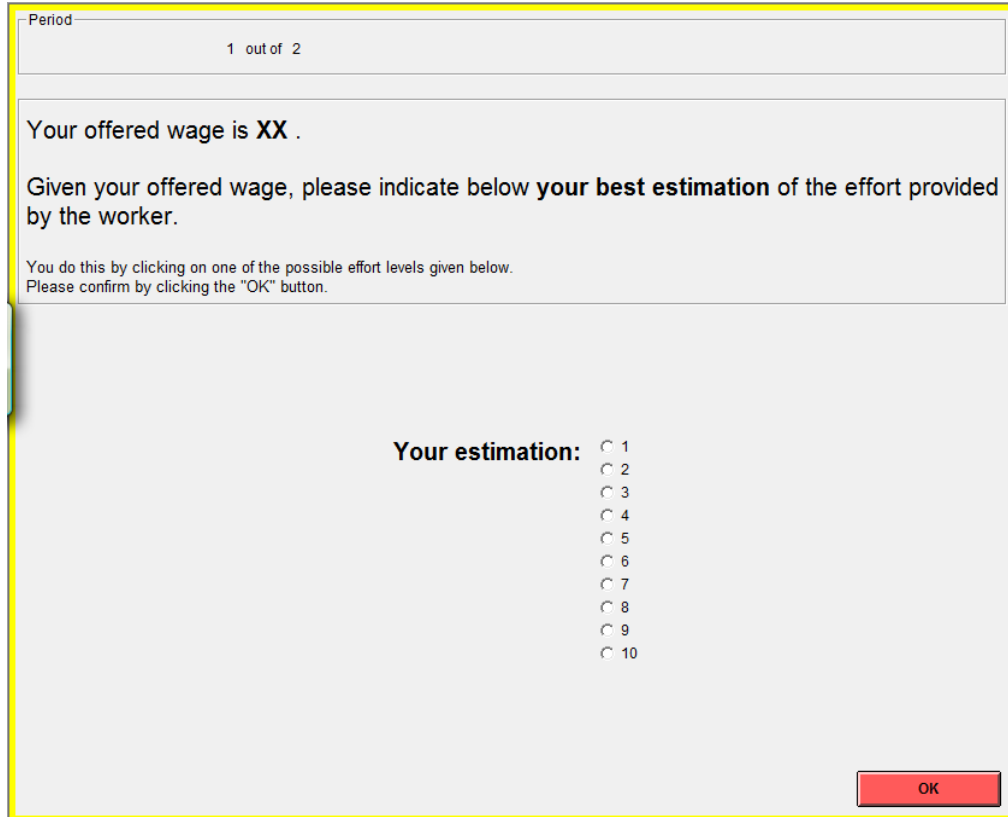

Figure A-7: Screenshot: expected effort 


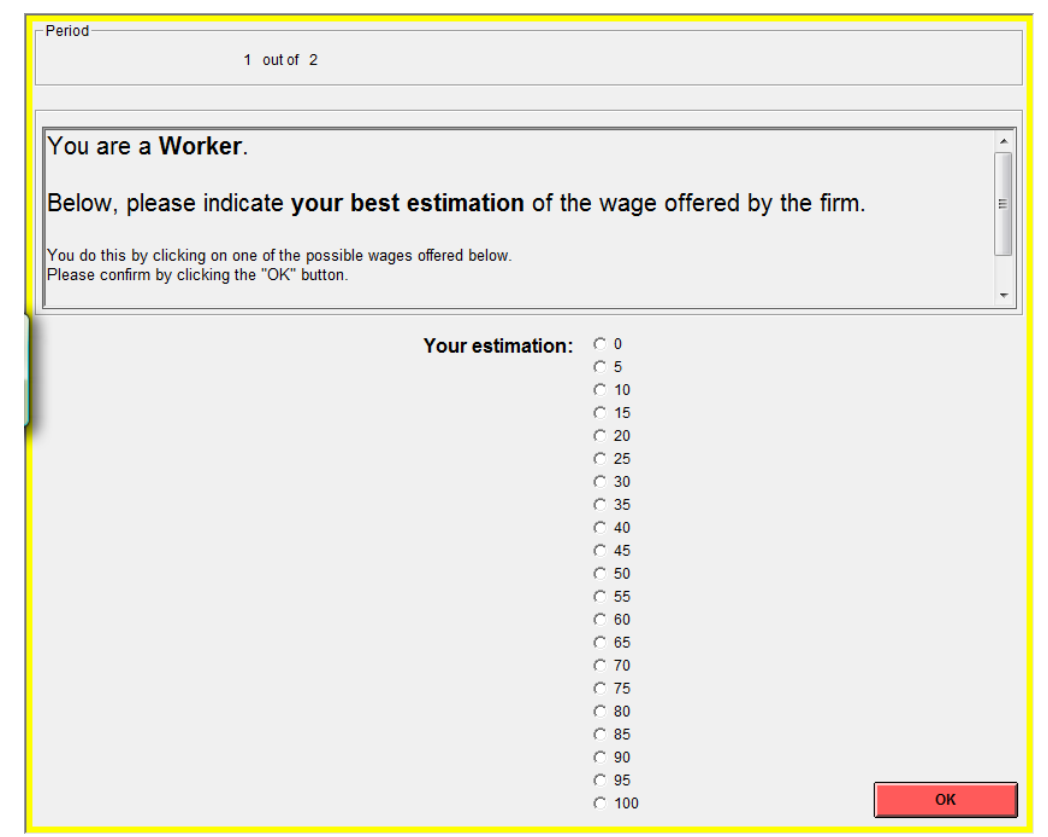

Figure A-8: Screenshot: expected wage

- If your estimate deviates by 1 point from the actual result, you will receive 2 points extra.

- If your estimate deviates by 2 points from the actual result, you will receive 1 point extra

- If your estimate deviates by 3 or more points from the actual result, you will receive no points extra.

If you are a worker, In each period, before you are informed about the actually chosen wage offer you have to estimate the wage offer actually chosen by the firm.

As in the part 1 of the experiment you can earn money with the accuracy of your estimate.

- If your estimate is exactly right (that is, if your estimate exactly matches the actually chosen effort by

the worker for your wage offer), you will receive 3 points extra to your other earnings from the

experiment.

- If your estimate deviates by 1 point from the actual result, you will receive 2 points extra. 
- If your estimate deviates by 2 points from the actual result, you will receive 1 point extra

- If your estimate deviates by 3 or more points from the actual result, you will receive no points extra.

Next, in each period after receiving your wage offer, you will make your effort level decision. You will be informed about the wage offered by the firm. You then have to indicate the effort level you choose. You simply have to click on one of the circles to indicate your effort level.

After the 10 periods of this part are over you will be asked to fill in a short questionnaire. Thereafter, the whole experiment is over and you will be confidentially be paid out your total earnings in the experiment in cash.

This is the end of the instructions. If you have a question please raise your hand. 


\section{Appendix B}

\section{Cooperators and reciprocators: A}

\section{within-subject analysis of pro-social}

\section{behavior}

\section{B.1 General instructions}

Welcome to this economic experiment. In the experiment you and other participants will make decisions. Next to the fee of 3 Euro for showing up in time, you can earn money in the experiment. How much you earn depends on your own decisions and the decisions of other participants. At the end of the experiment the show-up fee and the earnings from the different parts will be added up and confidentially paid out to you in cash.

The experiment consists of different parts that are all independent of one another. For each part you will receive specific instructions. These instructions will explain how you make decisions and how your decisions and the decisions of other participants influence your earnings. Therefore, it is important that you read the instructions carefully.

From now on you are not allowed to communicate in any other way than specified in the instructions. Please obey to this rule because otherwise we have to exclude you from the experiment and all earnings you have made will be lost. Please also do not ask questions aloud. If you have a question raise your hand. A member of the experimenter team will come to you and answer your question in private.

Before we start with the first part of the experiment we ask you to fill in a questionnaire. This questionnaire is unrelated to the other parts of the experiment. You do 
neither earn extra money for answering theses questions nor do your answers influence your earnings in the other part.

\section{B.2 Specific instructions - Part 1}

In this part of the experiment you can earn money with the decisions you make. How much you earn depends on your own decisions and the decisions of other participants. We will not speak of Euro during the experiment, but rather of points. All you earnings will first be calculated in points. At the end of the experiment the total amount of points you earned in this part will be converted to Euro at the following rate:

1 point $=30$ Euro cent

At the beginning of this part of the experiment all participants will be divided into groups of three. You will not get to know the identity of the other group members, neither during nor after the experiment. The other group members will also not get to know your identity.

We now describe how this part of the experiment proceeds. First you will be introduced to the basic decision situation, thereafter you will learn more specifically how the experiment is conducted. You will also be asked some control questions that will help you to understand the decision situation.

The decision situation:

You will be the member of a group of 3 people. Each group member receives an endowment of 20 points. You and each other group member has to decide on the allocation of his/her 20 points, simultaneously. You can put any (integer) share of these 20 points into your private account or you can contribute any (integer) share to a project.

Your earnings from the private account:

For each point you put into your private account, you will earn one point. That is,

Earnings from private account $=$ points in your private account $=20-$ your contributions to the project.

For example, if you put 20 points into your private account your earnings from your private account will be 20 points. If you put, for example, 6 points into your private account, your earnings from this account will be the 6 points. No one except you earns points from your private account. 
Your earnings from the project:

For each point you contribute to the project, each group member will profit equally. On the other hand, you will also profit from the other group members' contributions to the project. For each group member the earnings from the project will be determined as follows:

Earnings from the project $=$ sum of contributions of all group members $* 0.5$

For example, if you contribute 20 points to the project and each of the other two members also contributes 20 points to project then the sum of contributions is 60 points. This means that you and each of the other two group members earns $60 * 0.5=30$ points from the project. If, for example, you contribute 6 points to the project, and one of the other members contributes 2 points and the third 1 point to the project then the sum of contributions is 9 points. In this case you and each of the other two group members earns $9 * 0.5=4.5$ points from the project.

Your total earnings from the private account and the project:

Your total earnings are the sum of your earnings from your private account and from the project. That is,

Total earnings $=$ earnings from your private account + earnings from the project $=20$ - your contributions to the project $+(0.5 *$ sum of contributions to the project $)$.

For example:

- If the sum of contributions to the project was $(20+20+20)=60$, then

your total earnings $=(20-20)+(0.5 * 60)=30$

- If the sum of contributions to the project was $(6+2+1)=9$ and you contributed 6 to the project, then

your total earnings $=(20-6)+(0.5 * 9)=18.5$

- If the .sum of contributions to the project was $(2+9+19)=30$ and you contributed 2 to the project, then

your total earnings $=(20-2)+(0.5 * 30)=33$.

Control questions - decision situation:

Please answer the following control questions. These questions are arbitrary examples of what could happen in the experiment. They will help you to gain an understanding of the calculation of your earnings. Your earnings vary with your own decision and with the decisions of the other group members. 
Please answer all the questions and write down your calculations.

1. Each group member is endowed with 20 points. Assume that none of the group members (including you) contributes anything to the project.

What will your total earnings be?

What will the total earnings of each of the other group members be?

2. Each group member is endowed with 20 points. You contribute 20 points to the project. Each of the other 2 group members also contributes 20 points to the project.

What will your total earnings be?

What will the total earnings of each of the other group members be?

3. Each group member is endowed with 20 points. The other 2 group members contribute a total of 30 points to the project.

a) What will your total earnings be, if you - in addition to the 30 points - contribute 0 points to the project?

Your total earnings

b) What will your total earnings be, if you - in addition to the 30 points - contribute 8 points to the project?

Your total earnings

c) What will your total earnings be, if you - in addition to the 30 points - contribute 15 points to the project?

Your total earnings

4. Each group member is endowed with 20 points. Assume that you contribute 8 points to the project.

a) What will your total earnings be, if the other group members - in addition to your 8 points - contribute in total another 7 points to the project?

Your total earnings

b) What will your total earnings be, if the other group members - in addition to your 8 points - contribute in total another 12 points to the project?

Your total earnings

c) What will your total earnings be, if the other group members - in addition to your 8 points - contribute in total another 22 points to the project?

Your total earnings

The experiment 


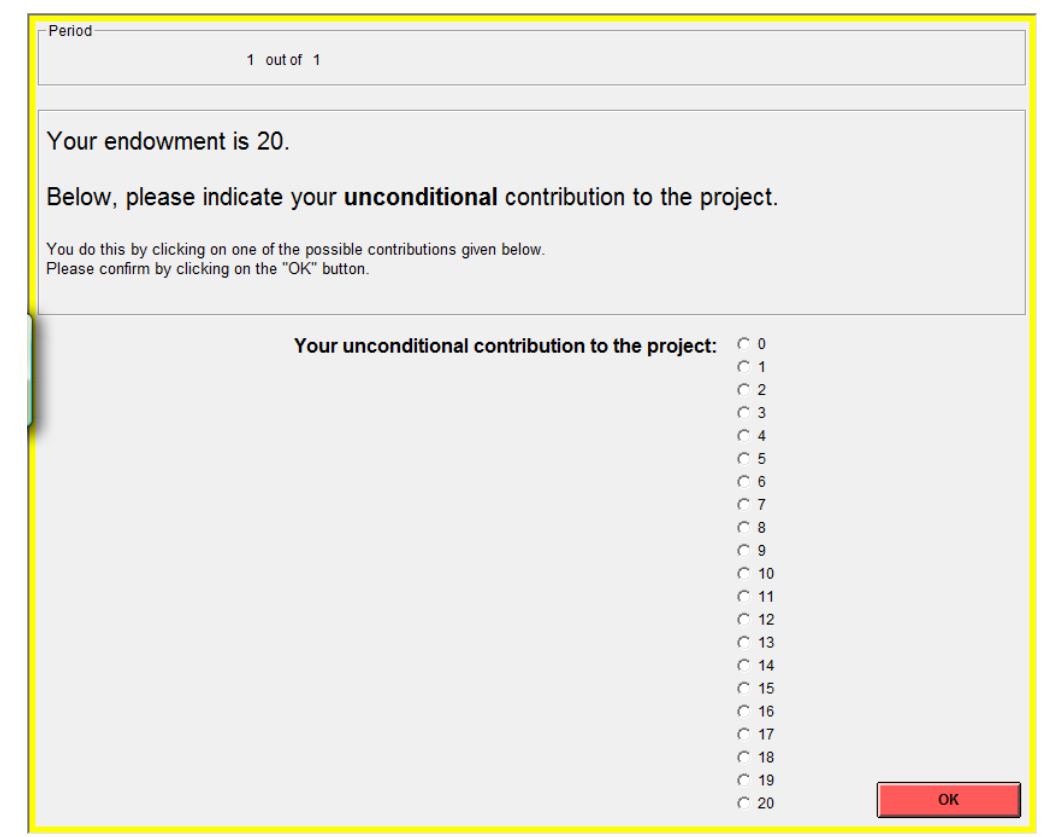

Figure B-1: Screenshot: unconditional contribution

In experiment you will be confronted with the described decision situation only once. As you know, you will have an endowment of 20 points at your disposal. You can put any share of it into a private account or you can contribute any share of it to a project. Each participant has to make two types of decisions in this experiment, which we will refer to below as the "unconditional contribution" and the "contribution table".

1. Unconditional contribution decisions: Here you decide how many of the 20 points you want to contribute to the project. When making your decisions you may want to consult the summary of the decision situation you received with these instructions.

You will have to indicate your contribution decision on a computer screen as shown here:

2. Contribution table decision: Here you have to fill in a "contribution table" where you indicate how many points you want to contribute to the project for each possible average contribution of the other group members (rounded to the next integer). What this means will be immediately clear to you if you take a look at the computer screen shown below. This screen shows a table as it will be presented to you in the experiment: The numbers to the left to the empty boxes are the possible (rounded) average contributions of the other group members. You simply have to insert in the boxes how many points you will contribute to the project, conditional on the indicated average contribution. You 


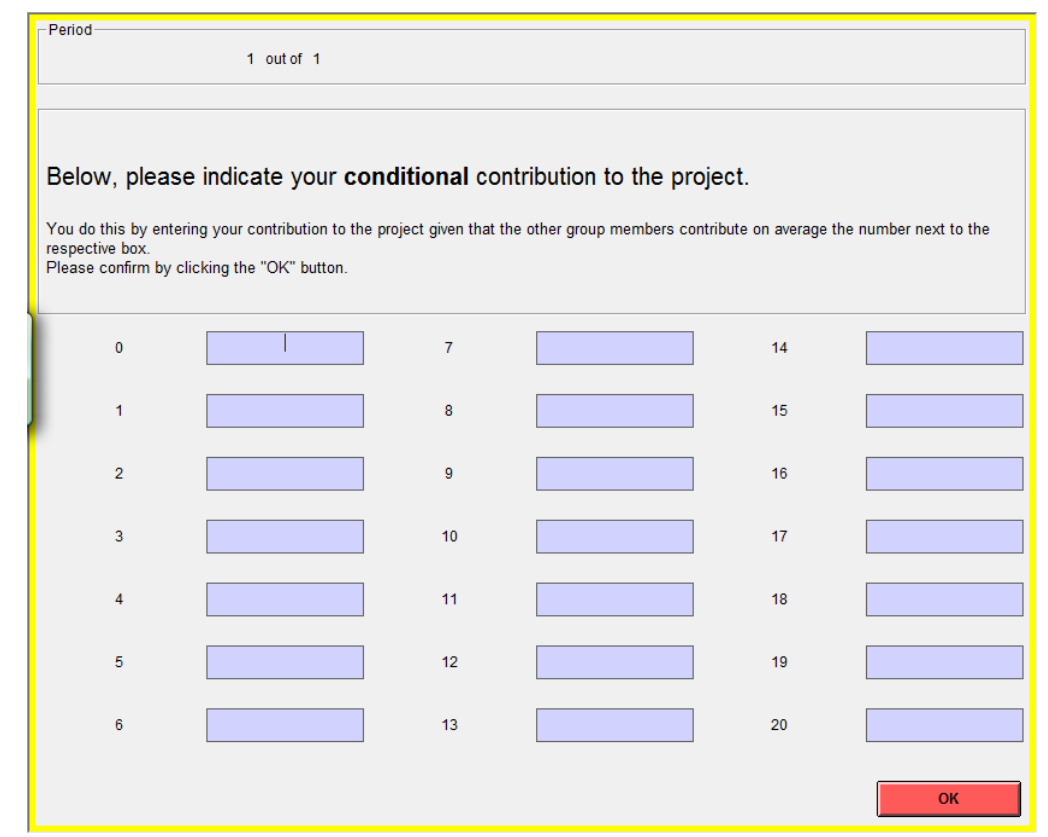

Figure B-2: Screeenshot: contribution table

have to make an entry into each of the boxes. For example, you will have to indicate how much you contribute to the project if the others contribute an average of 0 points to the project, how much you contribute if the others contribute an average of 1, 2, or 3 points, etc. You can insert any integer number from 0 to 20 in each box. When making your decisions you may want to consult the summary of the decision situation you received with these instructions. When you have made your entry in each box, please click "OK". have to estimate the actual average unconditional contribution to the project (rounded to an integer) of the other two group members. You will be paid for the accuracy of your estimate:

- If your estimate is exactly right (that is, if your estimate exactly matches the rounded actual average contribution of the other group members), you will receive 3 points extra to your other earnings from the experiment.

- If your estimate deviates by 1 point from the actual result, you will receive 2 points extra.

- If your estimate deviates by 2 points from the actual result, you will receive 1 point extra

- If your estimate deviates by 3 or more points from the actual result, you will receive no points extra. 


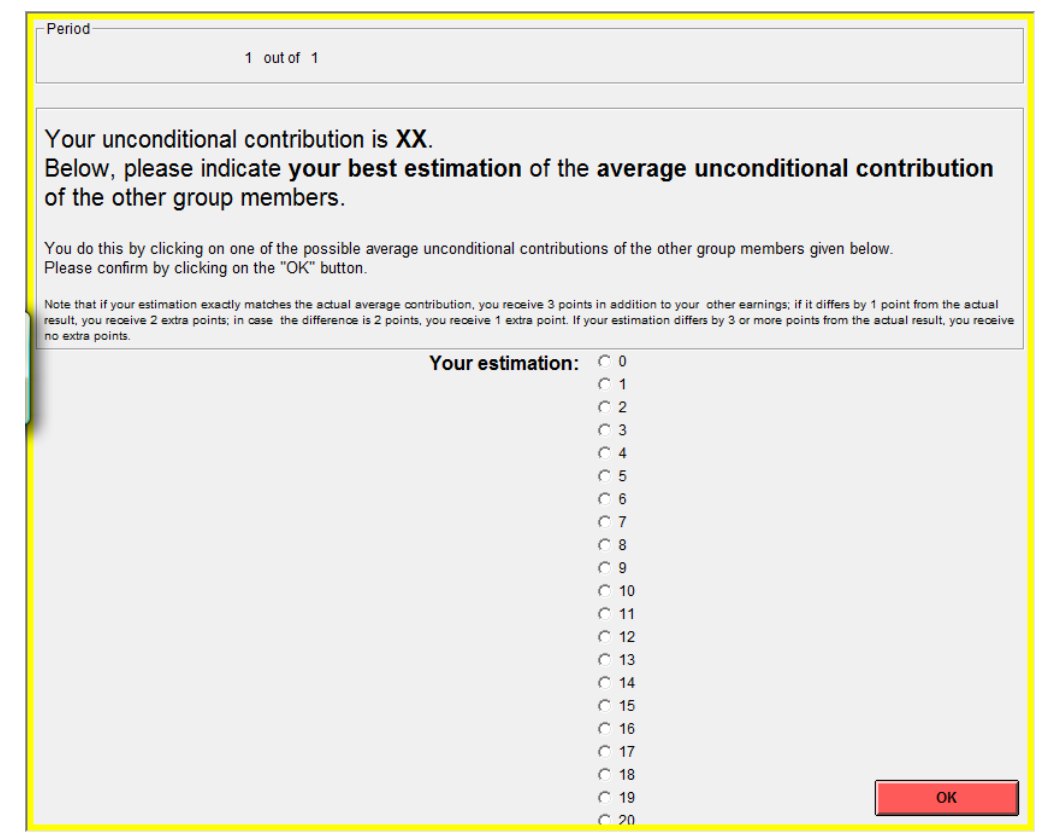

Figure B-3: Screenshot: belief determination

- You will make your estimation decision on a screen as shown below.

After all participants of the experiment have made their unconditional contribution decision, their contribution table decision, and their estimation a random mechanism will select a group member from every group. For this randomly selected group member only the contribution table will be the payoff-relevant decision. For the other two group members only the unconditional contribution will be the payoff-relevant decision. Obviously, when you make your unconditional contribution decisions and your contribution table decisions you do not know whether the random mechanism will select you or not. Therefore, you will have to think carefully about both types of decisions because both can become payoff relevant for you. Two examples will make this clear.

EXAMPLE 1: Assume that the random mechanism selects you. This implies that your relevant decision will be your contribution table. The unconditional contribution is the relevant decision for the other two group members. Assume that they made unconditional contributions of 1 and 3 points. The average contribution of these two group members, therefore, is 2 points. If you indicated in your contribution table that you will contribute 1 point if the others contribute 2 points on average, then the total contribution to the project is given by $1+3+1=5$ points. All group members, therefore,earn $0.5 \times 5=2.5$ points from the project .Your total earnings would be $20-1+2.5=21.5$ points. The other 
two group members earn the 2.5 points plus their respective earnings from their private accounts .If, instead, you indicated in your contribution table that you would contribute 16 points if the others contribute two points on average, then the total contribution of the group to the project is given by $1+3+16=20$ points. All group members therefore earn $0.5 \times 20=10$ points from the project. Your total earnings would be $20-16+10=14$ points. The other two group members earn the 14 points plus their respective earnings from their private accounts.

EXAMPLE 2: Assume that the random mechanism did not select you, implying that the unconditional contribution is taken as the payoff-relevant decision for you and one other group member. Assume that your unconditional contribution is 16 points and the other group member who was also not chosen contributes 20 points. The average unconditional contribution of you and that of the other group member, therefore, is $(20+16) / 2=18$ points. If the group member who was selected by the random mechanism indicates in the contribution table to contribute 1 point if the other two group members contribute on average 18 points, then the total contribution of the group to the project is given by $16+20+1=37$ points. All group members will therefore earn $0.5 \times 37=18.5$ points from the project. Your total earnings from the project would be $20-16+18.5=22.5$ points. The other two group members earn the18.5 points plus their respective earnings from their private accounts. If, instead, the randomly selected group member indicates in the contribution table to contribute 18 points if the others contribute on average 18 points, then the total contribution of the group to the project is given by $16+20+18=54$ points. All group members will therefore earn $0.5 \times 54=27$ points from the project. Your total earnings from the project would be $20-16+27=31$ points. The other two group members earn the 27 points plus their respective earnings from their private accounts.

The random selection of one of the group members will be implemented as follows. Each group member is assigned an integer number between 1 and 3. Please recall, that one participant, namely the one with the cubicle number 1, was randomly chosen at the very beginning of the experiment. After all participants have made all their decisions, this participant will throw a 6-sided die. The result of this throw determines for which member number in each group the contribution table decisions are payoff-relevant. The member with number 1 is selected if the die gives 1 or 4 ; the member with number 2 is selected if the die gives 2 or 5 ; the member with number 3 is selected if the die gives 3 or 
6.

If the participant at cubicle number 1 throws the member number that was assigned to you, then your contribution table will be payoff-relevant for you and the unconditional contribution will be the payoff-relevant decision for the other group members. Otherwise, your unconditional contribution is the payoff-relevant decision for you.

This is the end of the instructions. If you have a question please raise your hand.

\section{B.3 Specific instructions - Part 2}

In this part of the experiment you can earn money with the decisions you make. How much you earn depends on your own decisions and the decisions of other participants. We will not speak of Euro during the experiment, but rather of points. All you earnings will first be calculated in points. At the end of the experiment the total amount of points you earned in this part will be converted to Euro at the following rate:

$$
1 \text { point }=2 \text { Euro cent }
$$

At the beginning of this part of the experiment all participants will be divided into pairs. You will not get to know the identity of the other person, neither during nor after the experiment. The other person will also not get to know your identity.

The decision situation in this part of the experiment is similar as in part 1, with one important exception that will be explained below. For your convenience we briefly describe the whole decision situation.

The decision situation:

You will be randomly paired with one other participant. In part 1, in each pair one participant was randomly assigned the role of a firm and the other participant was assigned the role of a worker. You - as every other participant - will keep the role assigned in part 1 also throughout this part of the experiment.

Compared to part 1, there is an important difference in the sequence of the decisions in this part of the experiment. Now the firm first has to make a wage offer and this wage offer will be transmitted to the worker. Only then the worker has to decide on the effort level.

If you are assigned the role of a firm you have to make a wage offer. 


\begin{tabular}{|c|c|c|c|c|c|c|c|c|c|c|}
\hline$e$ & 1 & 2 & 3 & 4 & 5 & 6 & 7 & 8 & 9 & 10 \\
\hline \hline$c(e)$ & 0 & 1 & 2 & 4 & 6 & 8 & 10 & 12 & 15 & 18 \\
\hline
\end{tabular}

Table B.1: Effort table

The wage you offer can be any amount from 0 to 100 (as long as it is a multiple of 5). That is you can offer a wage of 0 , or 5 , or $10, \ldots$. , or 90 , or 95 , or 100 .

If you are assigned the role of a worker you will get informed about the wage offer by the firm, then you have to decide which effort level you provide for the received wage offer by the firm.

The effort level you choose can be any integer number from 1 to 10 . That is you can decide to provide effort levels of 1 , or 2 , or $3, \ldots$. , or 8 , or 9 , or 10 .

To each effort level correspond some costs the worker has to bear for this effort level. How the effort levels and costs are related is shown in this table:

The earnings are calculated in the following way:

If you are a firm:

- First, multiply the effort level chosen by the worker with 10,

- Second, subtract the wage you offered,

- Third, add an endowment of 50.

As formula:

Earnings of firm $=10 *$ effort level-wage offer +50

Note: if the earnings of the firm determined in this way would be negative they are set to zero.

If you are a worker:

- First, take the wage offered by the firm,

- Second, subtract the costs associated with effort level chosen (see table),

- Third, add an endowment of 20.

As formula:

Earnings of worker $=$ Wage offer - cost of effort +20

In this part of the experiment you will be engaged in the decision situation for 10 successive periods. In each period you will be randomly rematched with another participant. Thus, in no period will your pair consist of the same two people for sure..

If you are a firm, in each period you have to make a wage offer without knowing what effort level will be chosen by the worker. If you are a worker, in each period you have 


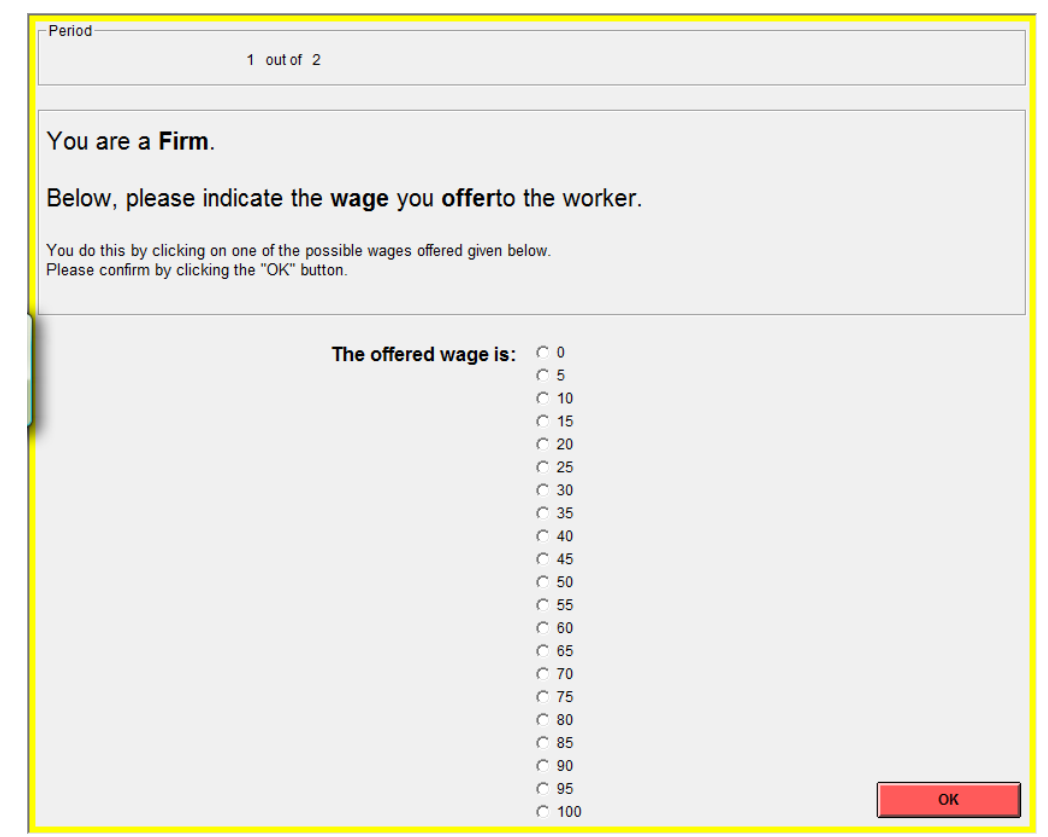

Figure B-4: Screenshot: wage offer

to decide on the effort level after being informed about the wage offer. At the end of a period firm and worker will be informed about the offered wage and chosen effort levels in the pair in that period.

If you are a firm, in each period you will make your wage offer decision on a computer screen as shown here:

On this screen, you have indicate the wage level you offer the worker. You simply have to click on one of the circles to indicate your wage offer. You can only make one wage offer.

In each period, after you have made and confirmed your wage offer you have to estimate the effort level actually chosen for your wage offer.

In each period you will indicate your estimation on a computer screen as shown here:

As in the part 1 of the experiment you can earn money with the accuracy of your estimate.

- If your estimate is exactly right (that is, if your estimate exactly matches the actually chosen effort by the worker for your wage offer), you will receive 3 points extra to your other earnings from the experiment.

- If your estimate deviates by 1 point from the actual result, you will receive 2 points extra. 


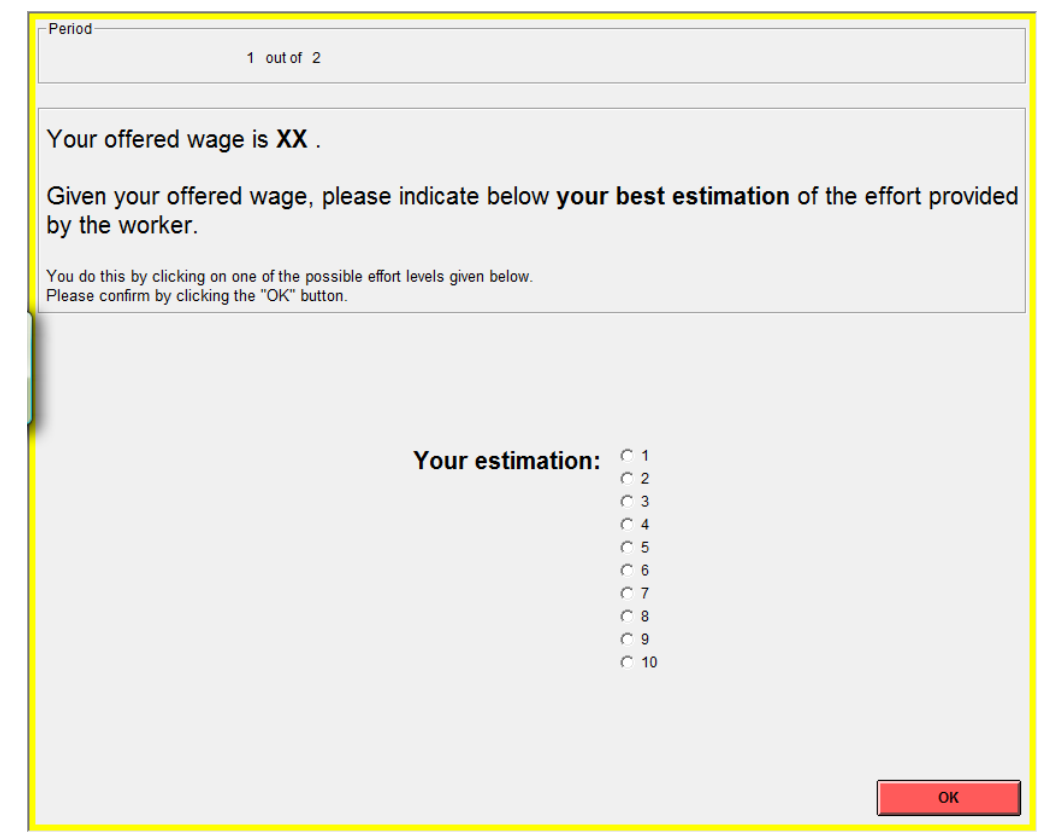

Figure B-5: Screenshot: expected effort

- If your estimate deviates by 2 points from the actual result, you will receive 1 point extra

- If your estimate deviates by 3 or more points from the actual result, you will receive no points extra.

If you are a worker, In each period, before you are informed about the actually chosen wage offer you have to estimate the wage offer actually chosen by the firm.

As in the part 1 of the experiment you can earn money with the accuracy of your estimate.

- If your estimate is exactly right (that is, if your estimate exactly matches the actually chosen effort by the worker for your wage offer), you will receive 3 points extra to your other earnings from the experiment.

- If your estimate deviates by 1 point from the actual result, you will receive 2 points extra.

- If your estimate deviates by 2 points from the actual result, you will receive 1 point extra

- If your estimate deviates by 3 or more points from the actual result, you will receive no points extra. 
Next, in each period after receiving your wage offer, you will make your effort level decision. In particular, you will be informed about the wage offered by the firm. You then have to indicate the effort level you choose. You simply have to click on one of the circles to indicate your effort level.

After the 10 periods of this part are over you will be asked to fill in a short questionnaire. Thereafter, the whole experiment is over and you will be confidentially be paid out your total earnings in the experiment in cash.

This is the end of the instructions. If you have a question please raise your hand. 


\section{Appendix C}

\section{Cooperation preferences and framing effects}

C.1 Additional statistics

C.1.1 Individual contribution schedules per treatment

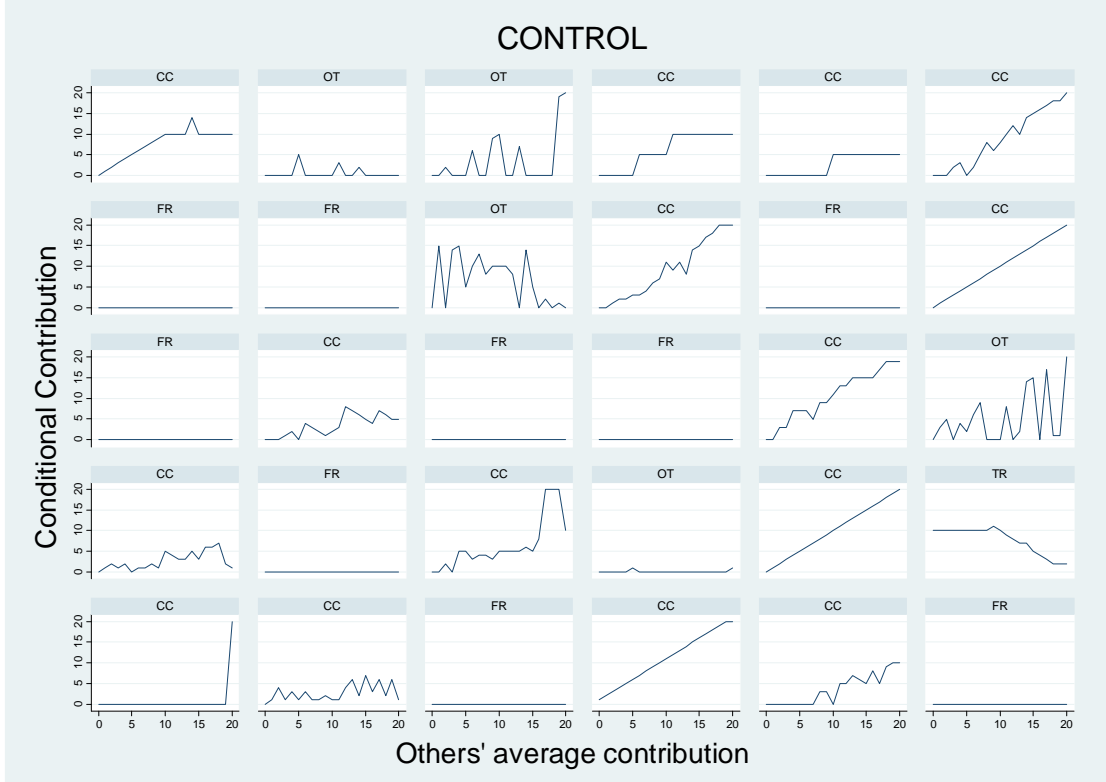



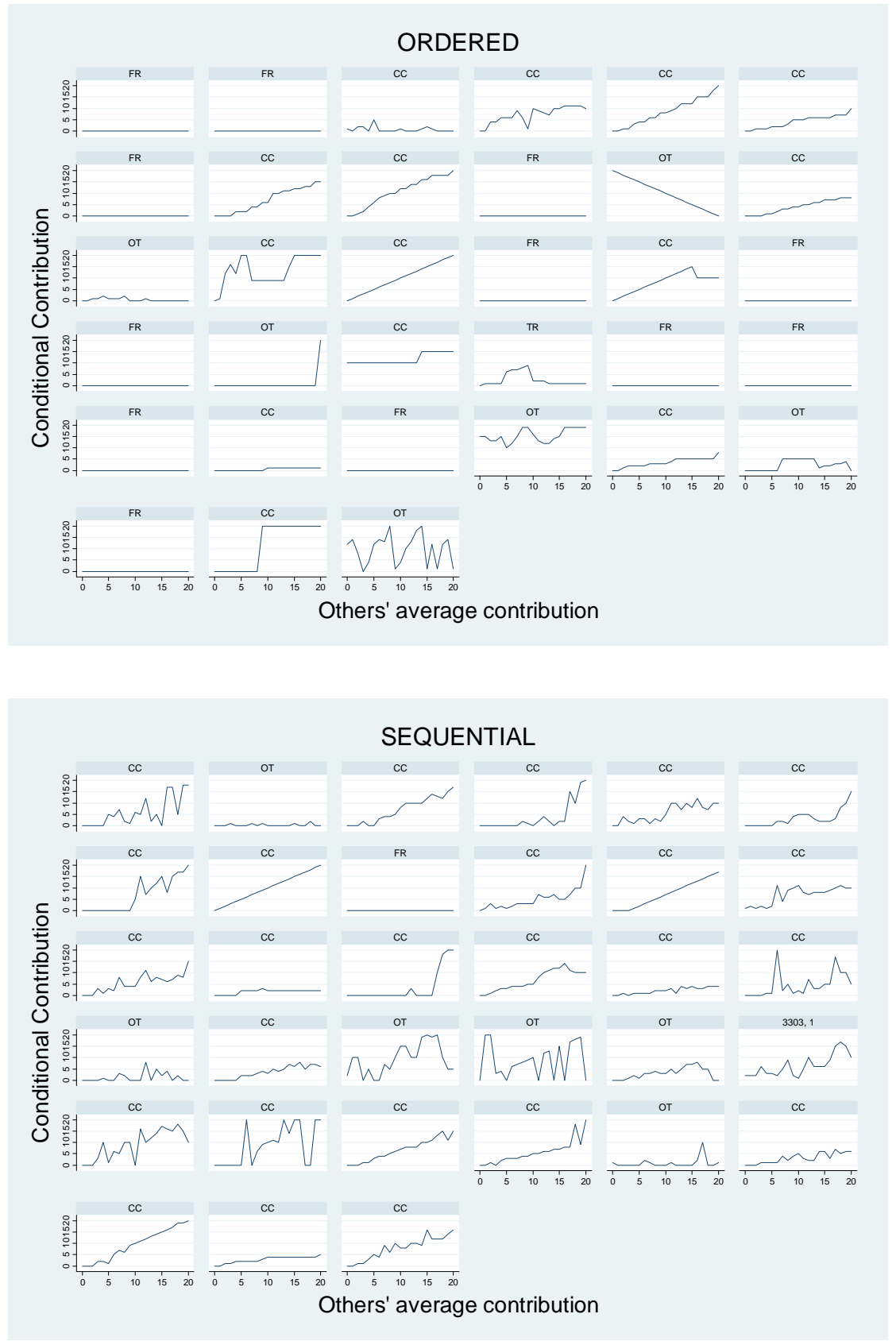

Individual contribution schedules

The letters on top of each subgraph indicate how that particular individual was classified. CC: conditional cooperator; FR: free rider; TR: triangle; OT: other.

\section{C.1.2 Determinants of beliefs in the finitely-repeated public good game}

This table investigates the determinants of beliefs in the finitely-repeated public good game. 


\begin{tabular}{cccc}
\hline \hline Treatments & CONTROL & ORDERED & SEQUENTIAL \\
\hline \hline Period & $-0.2375^{* * *}$ & $-0.3487^{* * *}$ & $-0.2477^{* * *}$ \\
& $(0.0302)$ & $(0.0606)$ & $(0.0570)$ \\
Average Contribution in SM & $0.0912^{* * *}$ & 0.0003 & $0.2371^{* * *}$ \\
& $(0.0207)$ & $(0.0690)$ & $(0.0639)$ \\
Average Contribution in One-Shot & $0.1343^{* * *}$ & $0.2927^{* * *}$ & $0.4484^{* * *}$ \\
& $(0.0517)$ & $(0.0524)$ & $(0.0582)$ \\
Constant & $2.1949^{* * *}$ & $3.2171^{* * *}$ & $2.6695^{* * *}$ \\
& $(0.3144)$ & $(0.0504)$ & $(0.5111)$ \\
\hline \hline
\end{tabular}

${ }^{*} \mathrm{p}<0.1,{ }^{* *} \mathrm{p}<0.05,{ }^{* * *} \mathrm{p}<0.01 ;$

Linear regression with random effects at the session level

Table C.1: Determinants of beliefs in the finitely-repeated public good game

The variables Average Contribution in $S M$ refers to the average contribution in the strategy method, and Average Contribution in One-Shot refers to the average contribution in the one-shot game.

\section{C.2 Instructions}

These are the instructions for the three parts of the SEQUENTIAL treatment. The instructions for the other treatments were appropriately adjusted.

\section{C.2.1 General instructions}

Welcome to this economic experiment. In the experiment you and other participants will make decisions. Next to the fee of $5 \mathrm{CHF}$ for showing up in time, you can earn money in the experiment. How much you earn depends on your own decisions and the decisions of other participants. At the end of the experiment the show-up fee and the earnings from the different parts will be added up and confidentially paid out to you in cash.

The experiment consists of three parts that are all independent of one another. For each part you will receive specific instructions. These instructions will explain how you make decisions and how your decisions and the decisions of other participants influence your earnings. Therefore, it is important that you read the instructions carefully.

From now on you are not allowed to communicate in any other way than specified in the instructions. Please obey to this rule because otherwise we have to exclude you from the experiment and all earnings you have made will be lost. Please also do not ask 
questions aloud. If you have a question raise your hand. A member of the experimenter team will come to you and answer your question in private.

You can now start reading the instructions for the first part of the experiment. Other instructions will follow after Part 1 is over.

\section{C.2.2 Specific instructions - Part 1}

In this part of the experiment, you can earn money with the decisions you make. How much you earn depends on your own decisions, as well as the decisions of other participants. We will not speak of Swiss francs during the experiment, but rather of tokens. All you earnings will first be calculated in tokens. At the end of the experiment the total amount of tokens you earned in this part will be converted to Swiss francs at the following rate:

$$
1 \text { token }=0.6 \text { Swiss francs }
$$

Earnings will be rounded up to the next integer.

At the beginning of this part of the experiment all participants will be divided into groups of three. You will not get to know the identity of the other group members, neither during nor after the experiment. The other group members will also not get to know your identity.

We now describe how this part of the experiment proceeds. First you will be introduced to the basic decision situation, thereafter you will learn more specifically how the experiment is conducted. You will also be asked some control questions that will help you to understand the decision situation.

The decision situation:

You will be the member of a group of 3 people. Each group member receives an endowment of 20 tokens. You and each other group member has to simultaneously decide on the assignment of his/her 20 tokens. You can put any (integer) share of these 20 tokens into your account A or you can put any (integer) share to account B.

The decision you will make is how many tokens you want to assign to account B. The assignment of tokens to your account A will automatically be calculated as:

Your assignment to your account $\mathrm{A}=(20$ - tokens you assigned to account $\mathrm{B})$

Your earnings from your account A: 
For each token you put into your account A, you will earn one token. That is,

Your earnings from your account $A=$ tokens assigned to your account $A=(20$ - tokens you assign to account B)

For example, if you put 20 tokens into your account A, your earnings from your account A will be 20 tokens. If you put, for example, 6 tokens into your account A, your earnings from this account will be the 6 tokens.

No one except you earns tokens from your account A. You do not earn anything from the assignments of the other group members to their account A. For example, if you put 10 tokens into your account $\mathrm{A}$, and the other group members each put 20 tokens in their respective account $\mathrm{A}$, then your earnings from your account A will be 10 tokens.

Your earnings from account B:

For each token you assign to account B, each group member will profit equally. On the other hand, you will also profit from the other group members' assignments to account B, and this regardless of whether you assign tokens to account B. For each group member the earnings from account $\mathrm{B}$ will be determined as follows:

Earnings from account $\mathrm{B}=0.5 *($ sum of assignments to account $\mathrm{B}$ of all group members)

For example, if you assign 20 tokens to account B and each of the other two members also assign 20 tokens to account B, then the sum of assignments is 60 tokens. This means that you and each of the other two group members earn $0.5 * 60=30$ tokens from account B. If, for example, you assign 6 tokens to account B, and one of the other members assigns 2 tokens and the third one 1 tokens to account $\mathrm{B}$, then the sum of assignments is 9 tokens. In this case you and each of the other two group members earn $0.5 * 9=4.5$ tokens from account B.

Notice that your decision is to allocate your 20 tokens between your account A and account B. In order to do so, you will be asked how many, out of these 20 tokens, you want to assign to account B. The assignment of tokens to account A will automatically be calculated as:

Your assignment to account $\mathrm{A}=(20$ - tokens you assigned to account $\mathrm{B})$

Your total earnings from your account A, account B and the tokens others assign to their respective account $\mathrm{A}$ are: 
Total earnings $=(20$ - tokens you assigned to account $\mathrm{B})+0.5^{*}($ sum of assignments to account B of all group members)

For example:

1.If the sum of assignments to account B was $(20+20+20)=60$, then your total earnings $=(20-20)+(0.5 * 60)=30$

2.If the sum of assignments to account B was $(6+2+1)=9$ and you assigned 6 to account B, then

your total earnings $=(20-6)+(0.5 * 9)=18.5$

3.If the sum of assignments to account B was $(2+9+19)=30$ and you assigned 2 to account $\mathrm{B}$, then

your total earnings $=(20-2)+(0.5 * 30)=33$

Control questions - decision situation:

Please answer the following control questions. These questions are arbitrary examples of what could happen in the experiment. They will help you to gain an understanding of the calculation of your earnings. Your earnings vary with your own decision and with the decisions of the other group members.

Please answer all the questions and write down your calculations.

1. Each group member is endowed with 20 tokens. Assume that none of the group members (including you) assigns anything to account B.

What will your total earnings be?

What will the total earnings of each of the other group members be?

2. Each group member is endowed with 20 tokens. You assign 20 token to account B. Each of the other 2 group members each assigns 0 token to account B.

What will your total earnings be?

What will the total earnings of each of the other group members be?

3. Each group member is endowed with 20 tokens. The other 2 group members assign a total of 30 tokens to account B.

a) What will your total earnings be, if you assign 0 token to account B?

Your total earnings

b) What will your total earnings be, if you assign 8 tokens to account B?

Your total earnings

c) What will your total earnings be, if you assign 15 tokens to account B? 
Your total earnings

4. Each group member is endowed with 20 tokens. Assume that you assign 8 tokens to account B.

a) What will your total earnings be, if the other group members assign, in total, 7 tokens to account B?

Your total earnings

b) What will your total earnings be, if the other group members assign, in total, 12 tokens to account B?

Your total earnings

c) What will your total earnings be, if the other group members assign, in total, 22 tokens to account B?

Your total earnings

ONCE YOU ARE DONE FILLING THE CONTROL QUESTIONS, PLEASE RAISE YOUR HAND AND ONE OF THE EXPERIMENTER WILL COME TO CHECK YOUR ANSWERS.

The experiment:

In this part of the experiment you will be confronted with the described decision situation only once. You can put any integer share of your 20 tokens into your account A or into account B. Each participant has to make two types of decisions in this part of the experiment, which we will refer to below as the "unconditional assignment decision" and the "assignment table".

1. Unconditional assignment decision: Here you decide how many of the 20 tokens you want to put in account B. When making your decision you may want to consult the summary of the decision situation you received with these instructions.

You will have to indicate your assignment decision on a screen as shown below:

You will see in total 21 such screens, each corresponding to a possible average assignment of the other group members to account B. You will never see the same average assignment twice. That is, each of the 21 screens will refer to a different average assignment of the other group members to account B. For the sake of brevity, we have shown to you only two of the 21 successive screens you will see.

After you have made your unconditional assignment decision and your assignment table decision (21 successive screens) you have to estimate the actual average unconditional 


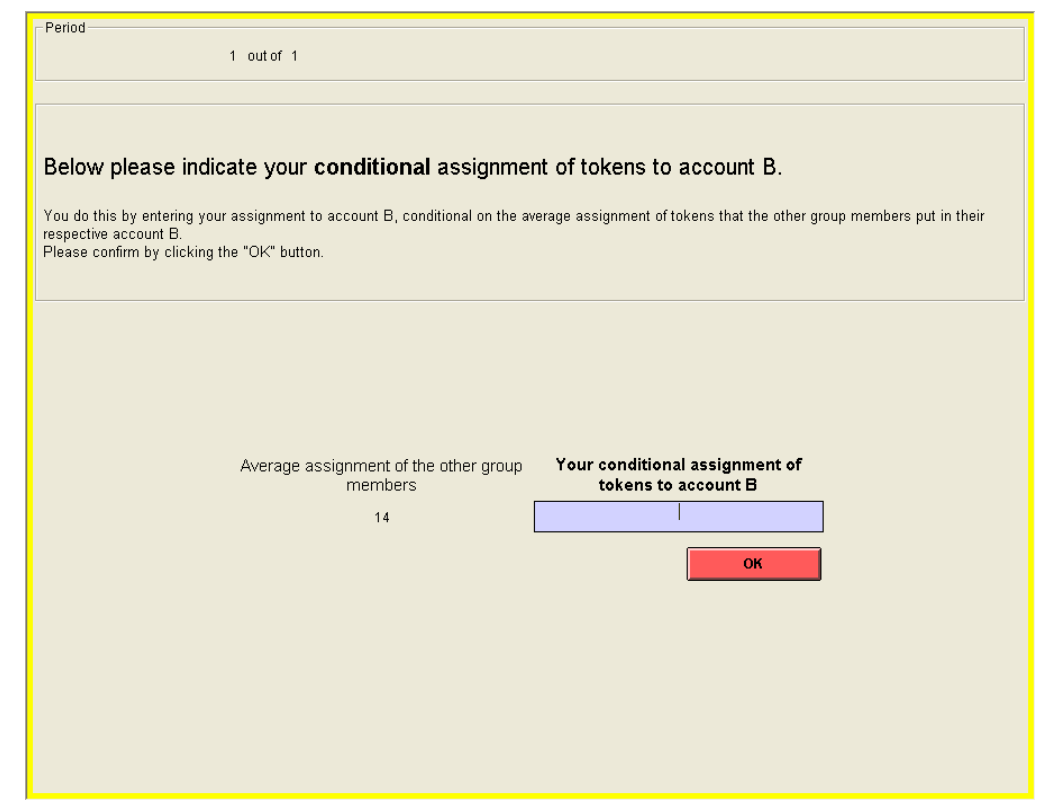

Figure C-1: Screenshot: conditional assignment

assignment to account B (rounded to an integer) of the other two group members. You will be paid for the accuracy of your estimate:

- If your estimate is exactly right (that is, if your estimate exactly matches the rounded actual average assignment of the other group members), you will receive 3 points extra to your other earnings from the experiment.

- If your estimate deviates by 1 point from the actual result, you will receive 2 points extra.

- If your estimate deviates by 2 points from the actual result, you will receive 1 point extra

- If your estimate deviates by 3 or more points from the actual result, you will receive no points extra.

You will make your estimation decision on a screen as shown below.

After all participants of the experiment have made their unconditional assignment decision and their assignment table decision, a random mechanism will select a group member from every group. For this randomly selected group member only the assignment table will be the payoff-relevant decision. For the other two group members only the unconditional assignment will be the payoff-relevant decision. Obviously, when you make your unconditional assignment decision and your assignment table decisions you do not 


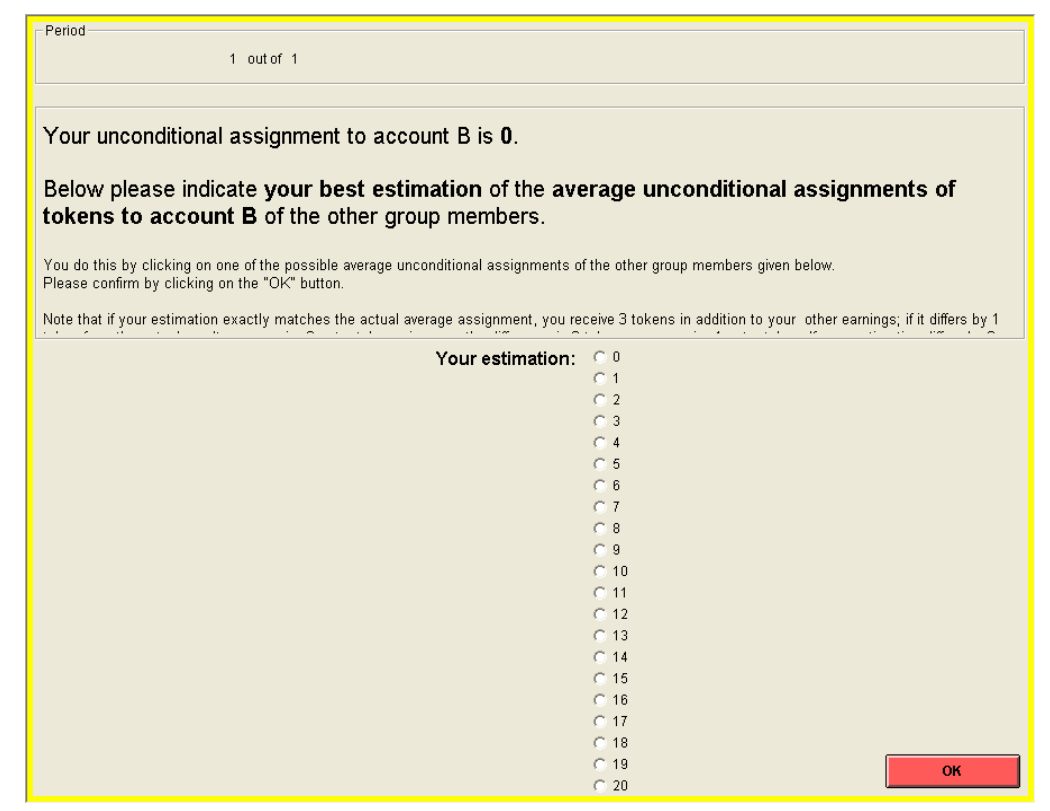

Figure C-2: Screenshot: unconditional assignment

know whether the random mechanism will select you or not. Therefore, you will have to think carefully about both types of decisions because both can become payoff relevant for you. Two examples will make this clear.

EXAMPLE 1: Assume that the random mechanism selects you. This implies that your relevant decision will be your assignment table. The unconditional assignment is the relevant decision for the other two group members. Assume that they made unconditional assignments of 1 and 3 tokens. The average assignment of tokens of these two group members, therefore, is 2 tokens. If you indicated in your assignment table that you would assign 1 token to account $B$ if the others put 2 tokens on average in account B, then your total earnings would be $(20-1)+0.5 * 5=21.5$. The other two group members earn the 2.5 tokens plus their respective earnings from their own account A. If, instead, you indicated in your assignment table that you would assign 16 tokens if the others assign two tokens on average, then the total assignment of the group to account B is given by $1+3+16=20$ tokens. All group members therefore earn $0.5 \times 20=10$ tokens from the account B.Your total earnings would be $(20-16)+10=14$ tokens. The other two group members earn the 14 tokens plus their respective earnings from their own account $\mathrm{A}$.

EXAMPLE 2: Assume that the random mechanism did not select you, implying that the unconditional assignment of tokens to your account B is taken as the payoff- 
relevant decision for you and one other group member. Assume that your unconditional assignment is 16 tokens and the other group member who was also not chosen put 20 tokens in account B. The average unconditional assignment of you and that of the other group member, therefore, is $(20+16) / 2=18$ tokens. If the group member who was selected by the random mechanism indicates in the assignment table to assign 1 token to account $\mathrm{B}$ if the other two group members put on average 18 tokens in account $\mathrm{B}$, then the total contribution of the group to the project is given by $16+20+1=37$ tokens. All group members will therefore earn $0.5 \times 37=18.5$ tokens from account B. Your total earnings would be $(20-16)+18.5=22.5$ tokens. The other two group members earn the 18.5 tokens plus their respective earnings from their own account A. If, instead, the randomly selected group member indicates in the assignment table to assign 18 tokens to account $\mathrm{B}$ if the others contribute on average 18 tokens to account B,then the total assignment of the group to account B is given by $16+20+18=54$ tokens. All group members will therefore earn $0.5 \times 54=27$ tokens from account B. Your total earnings would be $(20-16)+27=31$ tokens. The other two group members earn the 27 tokens plus their respective earnings from their own account $\mathrm{A}$

The random selection of one of the group members will be implemented as follows. Each group member is assigned an integer number between 1 and 3. Please recall, that one participant, namely the one with the cubicle number 1, was randomly chosen at the very beginning of the experiment. After all participants have made all their decisions, this participant will throw a 6 -sided die. The result of this throw determines for which member number in each group the contribution table decisions are payoff-relevant. The member with number 1 is selected if the die gives 1 or 4 ; the member with number 2 is selected if the die gives 2 or 5 ; the member with number 3 is selected if the die gives 3 or 6.

If the participant at cubicle number 1 throws the member number that was assigned to you, then your assignment table will be payoff-relevant for you and the unconditional assignment will be the payoff-relevant decision for the other group members. Otherwise, your unconditional assignment is the payoff-relevant decision for you.

This is the end of the instructions. If you have a question please raise your hand. 


\section{C.2.3 Specific instructions - Part 2}

In this part of the experiment you can earn money with the decisions you make. How much you earn depends on your own decisions and the decisions of other participants. We will not speak of Swiss Francs during the experiment, but rather of tokens. All you earnings will first be calculated in tokens. At the end of the experiment the total amount of tokens you earned in this part will be converted to Swiss Francs at the following rate:

$$
1 \text { token }=0.6 \mathrm{CHF}
$$

At the beginning of this part of the experiment all participants will be divided in groups of three. You will not get to know the identity of the other group members, neither during nor after the experiment. The other group members will also not get to know your identity.

The decision situation in this part of the experiment is the same as in part 1. For your convenience we briefly repeat the description of the decision situation.

\section{The decision situation:}

You will be the member of a group of 3 people. Each group member receives an endowment of 20 tokens. You and each other group member has to simultaneously decide on the assignment of his/her 20 tokens. You can put any (integer) share of these 20 tokens into your account A or you can put any (integer) share to account B.

The decision you will make is how many tokens you want to assign to account B. The assignment of tokens to your account A will automatically be calculated as:

Your assignment to your account $\mathrm{A}=(20$ - tokens you assigned to account $\mathrm{B})$

Your earnings from your account A:

For each token you put into your account A, you will earn one token. That is,

Your earnings from your account $A=$ tokens assigned to your account $A=(20$ - tokens you assign to account B)

Recall that no one except you earns tokens from your account A. You do not earn anything from the assignments of the other group members to their account A

Your earnings from account B:

For each token you assign to account B, each group member will profit equally. On the other hand, you will also profit from the other group members' assignments to account 


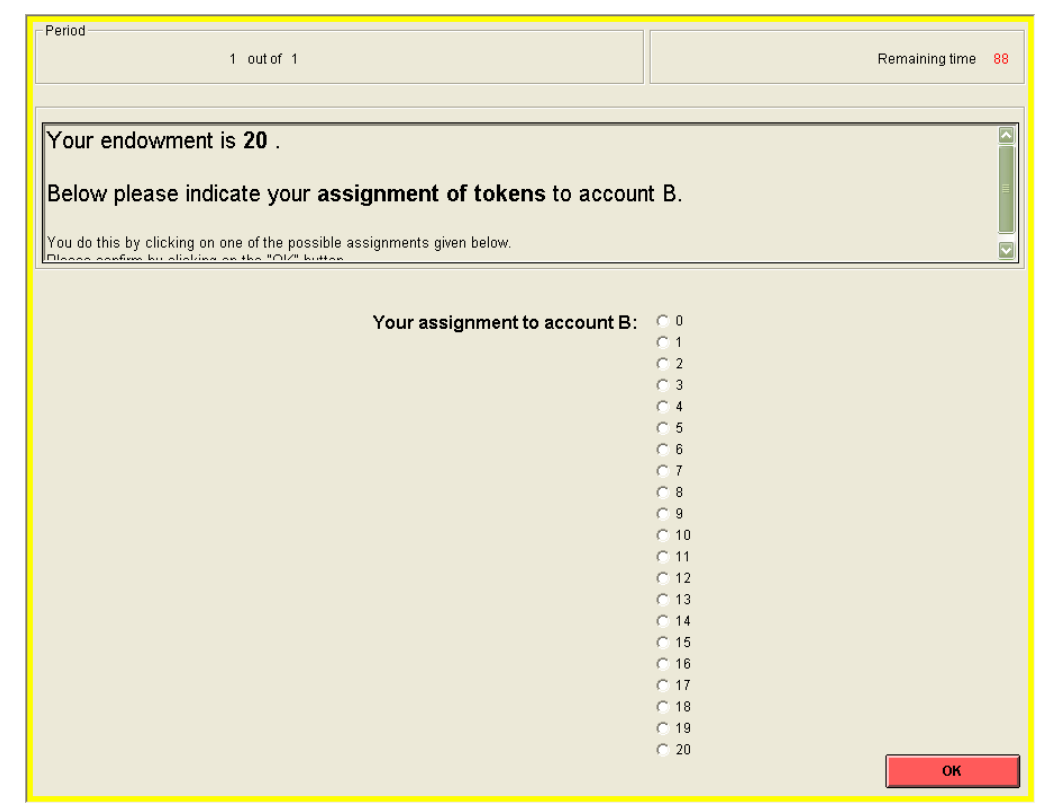

Figure C-3: Screenshot: assignment to account B

$\mathrm{B}$, and this regardless of whether you assign tokens to account B. For each group member the earnings from account $\mathrm{B}$ will be determined as follows:

Earnings from account $\mathrm{B}=0.5 *($ sum of assignments to account B of all group members)

Your total earnings from your account A, account B and the tokens others assign to their respective account $\mathrm{A}$ are:

Total earnings $=(20$ - tokens you assigned to account $\mathrm{B})+0.5^{*}($ sum of assignments to account $\mathrm{B}$ of all group members)

In this part of the experiment you will be engaged in the decision situation for 1 period.

You and the other group members have to make an assignment decision and an estimation of the actual average assignments of the other 2 group members. When you make your decisions you do not know the decisions of the other group members nor do the other group members know your decisions.

You will make your assignment decision on a computer screen as shown on the next page:

On this screen, you have to decide on your assignment of tokens to account B. That is, you have to decide how many of the 20 tokens you want to put in account B, and how many tokens you want to put into your account A. When making your decisions 


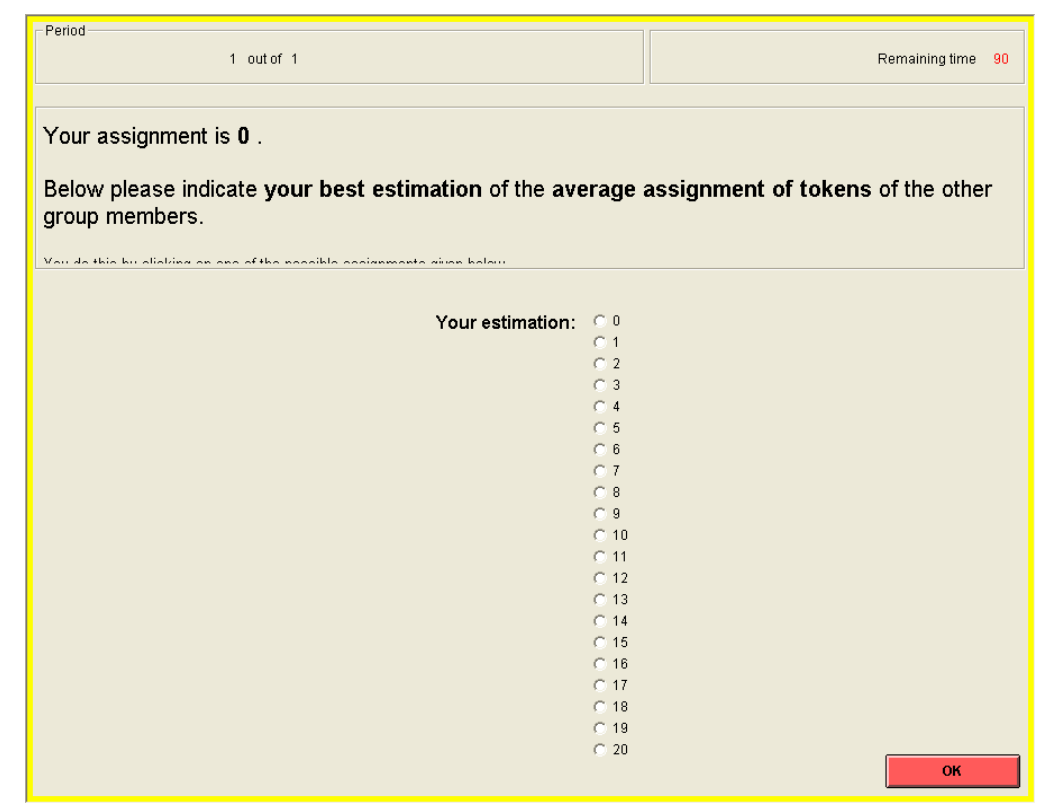

Figure C-4: Screenshot: expected assignment

you may want to consult the summary of the decision situation you received with these instructions.

After you have made and confirmed your decision you have to indicate your estimation of the actual average assignment to account B of the other 2 group members.

You will indicate your estimation on a computer screen as shown on the next page:

As in part 1 of the experiment you can earn money with the accuracy of your estimate.

3. If your estimate is exactly right (that is, if your estimate exactly matches the rounded actual average assignment to account B of the other group members), you will receive 3 tokens extra to your other earnings from the experiment.

4.If your estimate deviates by 1 token from the actual result, you will receive 2 tokens extra.

5.If your estimate deviates by 2 tokens from the actual result, you will receive 1 token extra

6.If your estimate deviates by 3 or more tokens from the correct result, you will receive no tokens extra.

At the end of the period, you will know your earnings in this part of the experiment and you will also receive information about the assignment decisions made by the others. As indicated in part 1 of the experiment, you will next be told the results of part 1 . After 
that, the third part of the experiment will start.

This is the end of the instructions. If you have a question please raise your hand.

\section{C.2.4 Specific instructions - Part 3}

In this part of the experiment you can earn money with the decisions you make. How much you earn depends on your own decisions and the decisions of other participants. We will not speak of Swiss Francs during the experiment, but rather of tokens. All you earnings will first be calculated in tokens. At the end of the experiment the total amount of tokens you earned in this part will be converted to Swiss Francs at the following rate:

$$
1 \text { token }=0.06 \mathrm{CHF}
$$

At the beginning of this part of the experiment all participants will be divided in groups of three. You will not get to know the identity of the other group members, neither during nor after the experiment. The other group members will also not get to know your identity.

The decision situation in this part of the experiment is the same as in Part 2. In this part of the experiment you will be engaged in the decision situation for 10 successive periods. In each period you and the other two group members will be randomly rematched. Thus, in no period will your group consist of the same three people.

For your convenience we briefly repeat the description of the decision situation.

\section{The decision situation:}

You will be the member of a group of 3 people. Each group member receives an endowment of 20 tokens. You and each other group member has to simultaneously decide on the assignment of his/her 20 tokens. You can put any (integer) share of these 20 tokens into your account A or you can put any (integer) share to account B.

The decision you will make is how many tokens you want to assign to account B. The assignment of tokens to your account A will automatically be calculated as:

Your assignment to your account $\mathrm{A}=(20$ - tokens you assigned to account $\mathrm{B})$

Your earnings from your account A:

For each token you put into your account A, you will earn one token. That is,

Your earnings from your account $A=$ tokens assigned to your account $A=(20$ - tokens you assign to account B) 
Recall that no one except you earns tokens from your account A. You do not earn anything from the assignments of the other group members to their account $\mathrm{A}$

Your earnings from account B:

For each token you assign to account B, each group member will profit equally. On the other hand, you will also profit from the other group members' assignments to account $\mathrm{B}$, and this regardless of whether you assign tokens to account B. For each group member the earnings from account $\mathrm{B}$ will be determined as follows:

Earnings from account B $=0.5 *$ (sum of assignments to account B of all group members)

Your total earnings from your account A, account B and the tokens others assign to their respective account $\mathrm{A}$ are:

Total earnings $=(20$ - tokens you assigned to account $\mathrm{B})+0.5^{*}($ sum of assignments to account $\mathrm{B}$ of all group members)

As said above, in this part of the experiment you will be engaged in the decision situation for 10 successive periods. In each period you and the other two group members will be randomly rematched. Thus, in no period will your group consist of the same three people.

In each period you and the other group members have to make an assignment decision and an estimation of the actual average assignments of the other 2 group members. When you make your decisions you do not know the decisions of the other group members nor do the other group members know your decisions. At the end of each period you will be informed about the total assignments in your group in that period as well as your earnings in that period.

In each period, you will make your assignment decision on a computer screen as shown below:

On this screen, you have to decide on your assignment of tokens to account B. That is, you have to decide how many of the 20 tokens you want to put in account B, and how many tokens you want to put into your account A. When making your decisions you may want to consult the summary of the decision situation you received with these instructions.

In each period, after you have made and confirmed your decision you have to indicate your estimation of the actual average assignment to account B of the other 2 group 


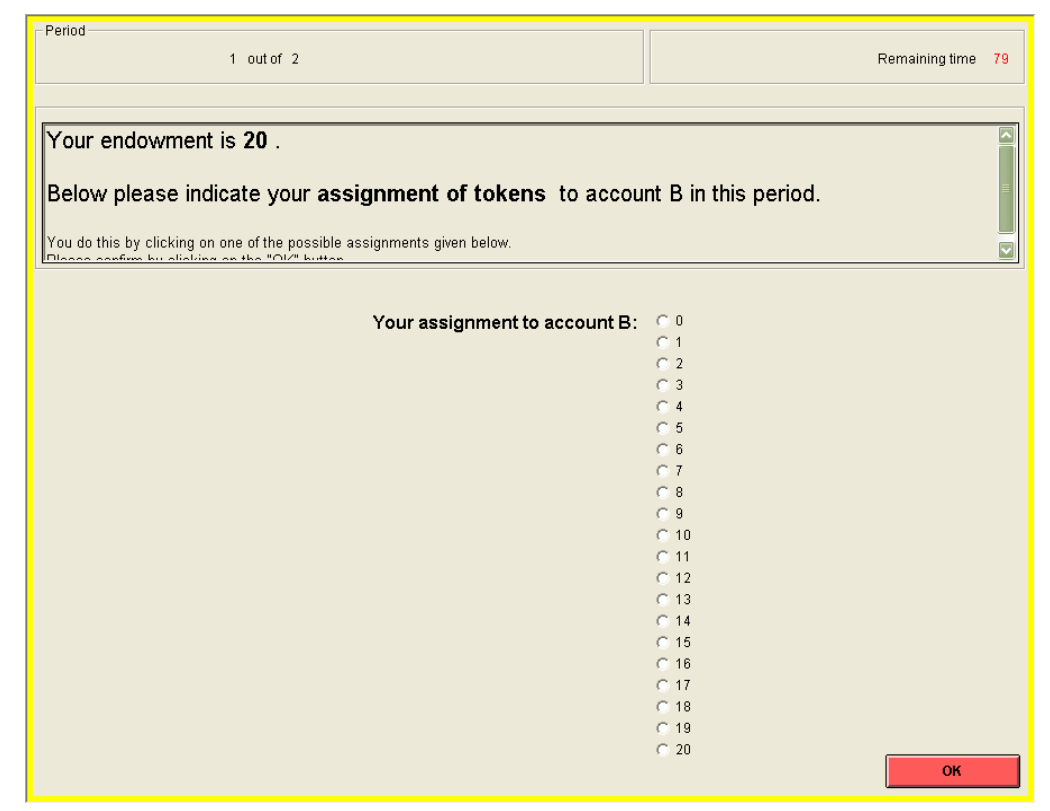

Figure C-5: Screenshot: assignment to account B

members.

In each period, you will indicate your estimation on a computer screen as shown on the next page:

As in part 1 and 2 of the experiment you can earn money with the accuracy of your estimate.

7.If your estimate is exactly right (that is, if your estimate exactly matches the rounded actual average assignment to account B of the other group members), you will receive 3 tokens extra to your other earnings from the experiment.

8.If your estimate deviates by 1 token from the actual result, you will receive 2 tokens extra.

9.If your estimate deviates by 2 tokens from the actual result, you will receive 1 token extra

10.If your estimate deviates by 3 or more tokens from the correct result, you will receive no tokens extra.

After the 10 periods of this part are over you will be asked to fill in a short questionnaire. Thereafter, the whole experiment is over and you will be confidentially paid out your total earnings in the experiment in cash.

This is the end of the instructions. If you have a question please raise your hand. 


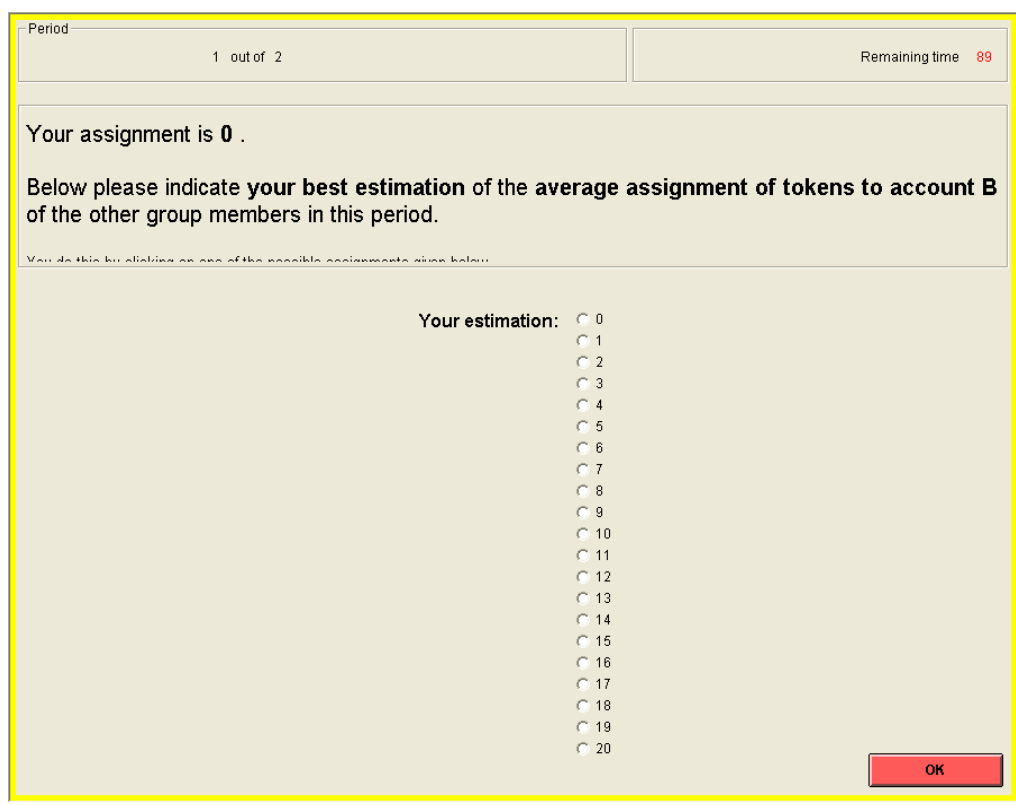

Figure C-6: Screenshot: expected assignment 


\section{Appendix D}

\section{Social networks in an experimental}

\section{labor market with adverse selection}

\section{D.1 Theoretical framework concerning the impact of the social network: referral market equilibrium}

In this appendix, we show that our game has equilibria with properties similar to this in Montgomery (1991). The central assumption in his model is that workers tend to refer others of similar ability. Similar to our experiment, in the model, there are two stages and each worker lives for one stage. A worker can be either of high productivity $(H)$ or low productivity $(L)$ with an equal probability. Firms can employ at most one worker per stage, but cannot observe the worker's type prior to hiring them. Each stage-1 worker is tied to at most one stage-2 worker with a certain probability (network density), and a stage- 1 worker knows a stage- 2 worker of his same type with probability $\alpha>1 / 2$ (homophily or inbreeding bias). Stage-2 workers can have multiple ties with stage-1 workers. At the end of the first stage, a firm can decide to offer a referral wage to the worker linked with their stage-1 worker. The stage-2 worker can either accept or reject this offer. If he accepts it, then he is hired in the referral market. If he rejects it, he goes to the public market and receives the equilibrium wage in this market. ${ }^{1}$ As mentioned in

\footnotetext{
${ }^{1}$ Our experiment differs from Montgomery's (1991) model in at least three respects. First, unlike Montgomery, we do not allow for more than one link for stage- 2 workers. Second, in our experiment, there is no free entry and exit of firms and there are more workers than firms. Third, firms cannot make simultaneous offers in the referral and public market. We decided to allow for this possibility in our experiment as we believe that this set-up is more realistic and also closer to the experiment on long-term
} 
the chapter, the main findings of Montgomery's model are the following: $(i)$ A firm will offer a wage in the referral market if, and only if, it employed an $H$ worker in stage 1. (ii) Wages in the referral market will be higher than in the public market. (iii) Firms will be willing to pay a "wage premium" in stage 1 in order to attract $H$ workers as this will improve their chances of also hiring an $H$ worker in stage 2.

Consider a situation in which firms all hired a worker in period 1. In stage 2, firms can decide to hire by making a referral offer or by going to the public market. We are interested in constructing some market equilibrium for the stage- 2 market in the $R$ treatment . We introduce the following notion of an equilibrium.

Market equilibrium with referral: Price-allocation pair $(p, x)$ is such that,

(i) All firms employ a worker, either in the public market or in the referral market.

(ii) The public market wage is at most equal to the (expected) average productivity in the public market.

(iii) No firm has an incentive to change the price offered in either one of the two markets.

(iv) Workers accept the highest wage offered. No worker has an incentive to change its decision rule.

\section{D.1.1 Stage-1: Public Market}

It is important to understand what happens in the stage-1 public market in isolation. First, we need to know whether we are looking for a Walrasian equilibrium, a situation in which agents are price-takers, or whether there is some game-theoretical structure. The impact of the price-setting structures has an impact on the resulting market equilibrium.

Walrasian Equilibrium: A Walrasian equilibrium is a price-allocation pair where supply equal demands

By drawing the supply and demand curves, it is easy to see that there is only one Walrasian equilibrium at $p=30$. This is the only intersection between supply and demand. .

\section{Game-theoretic structure:}

Firms simultaneously set a price at which they are willing to hire a worker. Workers, upon observing the wage offers, announce simultaneously their decision rule -for instance

relationship by Brown, Falk and Fehr (2004). 
a worker may say that he accepts any wage $30 \leq w \leq 35$. We now describe the rationing mechanism (Wilson, 1979, 1980). The rationing mechanism chosen is a key driving-force of the equilibrium. It starts at the highest wage offered. If there is excess supply at that wage, workers are assigned randomly to buyers who offered such a price. The unassigned workers are then successively added to the supply at the second highest price etc... So there is potentially excess supply at all but the lowest price announced.

For example, consider the following situation where firms offer, respectively, 30, 31, 32 , and 34. And each worker's decision rule is "accept wage from $w=35$ to $w=30 \mathrm{j}$. Then there is excess supply at $w=34$ since all workers accept this offer. Each worker has probability $1 / 4$ of being employed at that wage. One is chosen. Next, three workers remain and are all willing to accept $w=33$. Each has probability $1 / 3$ of being employed at that wage. One is chosen. Next, two workers remain and are all willing to accept $w=32$ etc.

Because of the choice of the rationing mechanism, workers never have to trade-off a higher wage with the probability of employment. This is a key driving-force of equilibrium behavior. For instance, a rationing mechanism which would force all firms to clear their position simultaneously - i.e. selecting simultaneously a worker out of the pool of those that accept their offers - may have a dramatic impact on the equilibrium set.

There is a unique (subgame perfect) equilibrium which corresponds to the unique Walrasian equilibrum. All firms offer a wage of 30, and workers accept any wage greater than their reservation value.

\section{D.1.2 Stage-2: Referral Market}

Consider a market equilibrium wage $w \geq 30$, what is the probability that firm $j$ is getting an $H$ worker? That is, we look for

$$
P(\text { firm } j \text { hires an } H \mid w \geq 30)
$$

To calculate this probability, we need to know events in which firm $j$ gets an $H$. Recall that 4 workers are chosen out of 6 and assigned with equal to probability to firms. Given that we sample 4 out of 6 (unordered without replacement), the combination formula 
gives

$$
\frac{n !}{r !(n-r) !}=\frac{6 !}{4 ! 2 !}=15
$$

Hence there are 15 different ways of choosing 4 out of 6 when order does not matter. These 15 ways are

$$
\begin{aligned}
& H_{1} H_{2} H_{3} L_{1} ; H_{1} H_{2} H_{3} L_{2} ; H_{1} H_{2} H_{3} L_{3} ; H_{1} H_{2} L_{1} L_{2} \\
& H_{1} H_{2} L_{1} L_{3} ; H_{1} H_{2} L_{2} L_{3} ; H_{1} H_{3} L_{1} L_{2} ; H_{1} H_{3} L_{1} L_{3} \\
& H_{1} H_{3} L_{2} L_{3} ; H_{2} H_{3} L_{1} L_{2}, H_{2} H_{3} L_{1} L_{3} ; H_{2} H_{3} L_{2} L_{3} \\
& H_{1} L_{1} L_{2} L_{3} ; H_{2} L_{1} L_{2} L_{3} ; H_{3} L_{1} L_{2} L_{3}
\end{aligned}
$$

Notice that all types accept such a market wage since it exceeds both types reservation values. We have that

$$
P(\text { firm } j \text { hires an } H \mid w \geq 30)=\frac{3}{4}\left(\frac{3}{15}\right)+\frac{1}{2}\left(\frac{9}{15}\right)+\frac{1}{4}\left(\frac{3}{15}\right)=\frac{9+18+3}{60}=\frac{1}{2}
$$

Therefore, if all firms offer the same wage and all workers accept that wage level, the probability that firm $j$ hires an $H$ is $\frac{1}{2}$. Given this, the expected payoff of the firm is

$$
\begin{aligned}
\Pi_{F_{j}}\left(w_{F_{j}}, w \geq 30\right)= & P(\text { firm } j \text { hires an } H \mid w \geq 30)(20-30) \\
& +(1-P(\text { firm } j \text { hires an } H \mid w \geq 30))(60-30) \\
= & \frac{1}{2}(-10)+\frac{1}{2}(30)=10
\end{aligned}
$$

We are now going to check whether there exists a market equilibrium with referral in period 2 of the following kind:

(i) each firm who got an $\mathrm{H}$ in stage 1 makes a referral offer at $w=30$

(ii) each firm who got an $\mathrm{L}$ in stage 1 makes a public offer at $w=10$

(iii) Period 2 workers who get a referral accept it

Consider now firm $i$ that hired an $\mathrm{H}$ in stage 1 and makes a referral at $w_{R}=30$. Given inbreeding bias $\alpha$, its expected profit is

$$
\alpha(30)+(1-\alpha)(-10)=0.75(30)+(0.25)(-10)=20
$$


Notice that firm $i$ does want to offer a lower referral wage -it would not be accepted by a high type worker. It also does not want to go the public market and offer a wage $w=10$ since its profit would not exceed 10. Likewise going to the public market and offering $w>10$ can never be profitable. In particular, trying to attract high type worker on the public market by offering $w \geq 30$ leads to an expected profit that is obviously less than 20 -the probability to get a high type on the public market never reaches $\alpha$.

We now compute the expected profit of a firm that got an L in period 1 , and is therefore an actor in the stage 2 public market. Before doing so, it is useful to recall some basic probabilities on the possible matchings that can be realized following hiring in period 1 .

(i) Given any match of stage-1 workers to firm in period 1, the link structure between stage- 1 and stage- 2 workers is defined as follows:

Probability of a perfect matching: $\alpha^{3}$

Probability of one mismatch matching: $3 \alpha^{2}(1-\alpha)$

Probability of a two mismatch matching: $3 \alpha(1-\alpha)^{2}$

Probability of a perfect mismatch matching: $(1-\alpha)^{3}$

When a firm hires a period-1 L worker (say worker $L_{1}$ ), it faces several possible matchings. We need to know these in order to compute the firm's expected profits. There are 10 possible such matchings:

$$
\begin{aligned}
& L_{1} H_{1} H_{2} H_{3} ; L_{1} L_{2} H_{1} H_{2} ; L_{1} L_{2} H_{1} H_{3} ; L_{1} L_{2} H_{2} H_{3} \\
& L_{1} L_{3} H_{1} H_{2} ; L_{1} L_{3} H_{1} H_{3} ; L_{1} L_{3} H_{2} H_{3} ; L_{1} L_{2} L_{3} H_{1} \\
& L_{1} L_{2} L_{3} H_{2} ; L_{1} L_{2} L_{3} H_{3}
\end{aligned}
$$

In all the matching above, firm i hires worker $L_{1}$ in period 1 . With probability $\frac{1}{10}$, the other firms all got a period- $1 \mathrm{H}$ worker. With probability $\frac{6}{10}$, the other firms got a period-1 L and two period-1 H workers. Finally, with probability $\frac{3}{10}$, the other firms got two period-1 L workers and one period-1 H worker. Given the firms' strategies (referral if hired an $\mathrm{H}$, public market otherwise): with probability $1 / 10$, firm $\mathrm{i}$ is alone in the public market, with probability 6/10 it has to share the public market with another firm, and with probability $3 / 10$ it has to share the public market with two other firms. We now compute, for each of the three preceeding probabilities, the probability of each possible 
pool of period-2 workers who are in the public market.

a) With probability $1 / 10$, firm $\mathrm{i}$ is alone in the public market:

with probability $\alpha^{3}$, there are 3 period-2 L in the public market

with probability $3 \alpha^{2}(1-\alpha)$, there are one period- $2 \mathrm{H}$ and two period-2 $\mathrm{L}$ in the public market

with probability $3 \alpha(1-\alpha)^{2}$, there are two period- $2 \mathrm{H}$ and one period- $2 \mathrm{~L}$ in the public market

with probability $(1-\alpha)^{3}$, there are three period-2 $\mathrm{H}$ workers in the public market

b) With probability $6 / 10$, firm i shares the public market:

with probability $\alpha^{3}$, there are one period-2 $\mathrm{H}$ and three period-2 L in the public market with probability $2 \alpha^{2}(1-\alpha)$, there are two period- $2 \mathrm{H}$ and two period-2 $\mathrm{L}$ in the public market

with probability $\alpha^{2}(1-\alpha)$, there are one period-2 $\mathrm{H}$ and three period-2 $\mathrm{L}$ in the public market

with probability $2 \alpha(1-\alpha)^{2}$, there are two period- $2 \mathrm{H}$ and two period- $2 \mathrm{~L}$ in the public market

with probability $\alpha(1-\alpha)^{2}$, there are three period- $2 \mathrm{H}$ and one period- $2 \mathrm{~L}$ in the public market

with probability $(1-\alpha)^{3}$, there are three period- $2 \mathrm{H}$ workers and one period-2 $\mathrm{L}$ in the public market

c) With probability $3 / 10$, firm i shares the public market with two other firms (only one firm makes a referral):

with probability $\alpha^{3}$, there are two period-2 $\mathrm{H}$ and three period-2 L in the public market with probability $2 \alpha^{2}(1-\alpha)$, there are two period- $2 \mathrm{H}$ and three period-2 $\mathrm{L}$ in the public market

with probability $\alpha^{2}(1-\alpha)$, there are three period- $2 \mathrm{H}$ and two period-2 $\mathrm{L}$ in the public market

with probability $2 \alpha(1-\alpha)^{2}$, there are three period- $2 \mathrm{H}$ and two period- $2 \mathrm{~L}$ in the public market

with probability $\alpha(1-\alpha)^{2}$, there are two period- $2 \mathrm{H}$ and three period- $2 \mathrm{~L}$ in the public market 
with probability $(1-\alpha)^{3}$, there are three period- $2 \mathrm{H}$ workers and two period- $2 \mathrm{~L}$ in the public market

We are now ready to compute firm i's expected profit from offering a wage of 10 in the public market. Let us first compute the probability to employ a worker given the wage offered. For firm i not to want to make a referral of 10 directly, the probability of employment should be greater than $\alpha$.

$\mathbf{P}\left(\right.$ Hiring a period-2 $\mathbf{L}$ in pub market $\left.\mid w_{P}=10\right)=$

$$
\begin{aligned}
& \left.(1 / 10)\left[1-(1-\alpha)^{3}\right)\right]+(6 / 10)\left[1-0.5\left(\alpha(1-\alpha)^{2}+(1-\alpha)^{3}\right]+\right. \\
& (3 / 10)\left[1-2 / 3\left(\alpha^{2}(1-\alpha)+2 \alpha(1-\alpha)^{2}+(1-\alpha)^{3}\right)\right]
\end{aligned}
$$

Plugging for $\alpha=0.75$, we get that,

$\mathrm{P}\left(\right.$ Hiring a period-2 L in pub market $\left.\mid w_{P}=10\right) \approx 0.9296$

Since $\mathrm{P}\left(\right.$ Hiring a period-2 $\mathrm{L}$ in pub market $\left.\mid w_{P}=10\right)>\alpha$, firm $i$ has no incentive to try to get a low quality worker through a referral offer.

Given the probability of employment, firm $i$ 's expected profit is

$\mathrm{P}\left(\right.$ Hiring a period-2 $\mathrm{L}$ in pub market $\left.\mid w_{P}=10\right) *\left(20-w_{P}\right) \approx 9.2968$

We need now to check two things: local and non-local deviations. First, we should check that firm $i$ does not want to deviate to offering a market wage of 11 -local deviation. Next, we should check that firm $i$ does not want to deviate to offering a market wage of 30 and try to attract the period- $2 \mathrm{H}$ workers who did not receive a referral offer.

\section{Checking for small deviations: firm i offers $w^{\prime}=11$}

Given the way the rationing mechanism works, workers only respond to market incentives and can safely ignore the probability of employment. That is, whenever workers observe that a firm offers a higher wage than the other firms in the public market, workers all accept the offer of firm $i$ and can ignore the fact that each workers does the same. This is so because, in effect, this strategy for worker $j$ does not lead to a decrease in the probability that $j$ is employed. Therefore, whenever firm $i$ offer a higher wage than the 
prevailing public market wage, it captures the entire supply in the public market. To compute firm $i$ 'exepcted profits, we proceed as above and first compute the probability of employing a worker given the wage offered.

$\mathbf{P}\left(\right.$ Hiring a period-2 $\mathbf{L}$ in pub market $\left.\left.\mid w^{\prime}=11>w_{P}\right)=1-(1-\alpha)^{3}\right) \approx 0.9843$

Firm $i$ ' expected profits from offering a wage of 11 is thus:

$\mathrm{P}\left(\right.$ Hiring a period-2 L in pub market $\left.\mid w^{\prime}=11>w_{P}\right) *\left(20-w^{\prime}\right) \approx 8.8593$

Hence this deviation cannot be profitable.

\section{Checking for large deviations: firm i offers $\mathrm{w}^{\prime}=\mathbf{3 0}$}

In such a case, the probability of employing a worker is now equal to 1 . However we need to distinguish cases in which the firm will hire a period- $2 \mathrm{~L}$ worker and the case in which it will hire a period-2 $\mathrm{H}$ worker. As before, we compute the probability of employment before computing the expected profit. We compute separately the probability of hiring a period-2 L and the probability of hiring a period- $2 \mathrm{H}$ worker.

$\mathbf{P}\left(\right.$ Hiring a period-2 $\mathbf{L}$ in pub market $\left.\mid w^{\prime}=30>w_{P}\right)=$

$$
\begin{gathered}
(1 / 10)\left[\alpha^{3}+\frac{1}{2}\left(3 \alpha^{2}(1-\alpha)+3 \alpha(1-\alpha)^{2}\right)-(1-\alpha)^{3}\right]+ \\
(6 / 10)\left[\frac{3}{4}\left(\alpha^{3}\right)+\frac{1}{2} 2 \alpha^{2}(1-\alpha)+\frac{3}{4} \alpha^{2}(1-\alpha)+\frac{1}{2} 2 \alpha(1-\alpha)^{2}+\frac{1}{4} \alpha(1-\alpha)+\frac{1}{4}(1-\alpha)^{3}\right]+ \\
(3 / 10)\left[\frac{3}{5} \alpha^{3}+\frac{3}{5} 2 \alpha^{2}(1-\alpha)+\frac{2}{5} \alpha^{2}(1-\alpha)+\frac{2}{5} 2 \alpha(1-\alpha)^{2}+\frac{3}{5} \alpha(1-\alpha)^{2}+\frac{2}{5}(1-\alpha)^{3}\right.
\end{gathered}
$$

Plugging for $\alpha=0.75$ we get,

$\mathrm{P}\left(\right.$ Hiring a period-2 $\mathrm{L}$ in pub market $\left.\mid w^{\prime}=30>w_{P}\right)=0.60875$

Hence,

$\mathrm{P}\left(\right.$ Hiring a period- $2 \mathrm{H}$ in pub market $\left.\mid w^{\prime}=30>w_{P}\right)=(1-0.60875)=0.39125$

Firm i's expected profits from offering $w^{\prime}=30$ in the public market is thus

$$
0.60875 *(20-30)+0.39125(60-30)=5.65
$$




\begin{tabular}{|c|c|c|}
\hline \multicolumn{3}{|c|}{ Description of average wage offered } \\
\hline \hline Average wages & No Referral & Referrals \\
\hline Average offered wage by firm & 19.24 & 19.37 \\
\hline Average accepted wage by worker & 26.62 & 25.51 \\
\hline \hline
\end{tabular}

Table D.1: Averages wages offered and accepted

Hence this deviation cannot be profitable.

Now if firm i is offering a wage $w^{\prime}=31$, given our assumption on workers' response to incentives, firm $\mathrm{i}$ is capturing the entire market as each period-2 worker responds positively ot its offer. Its expected profit is then

$$
\frac{1}{2}(20-31)+\frac{1}{2}(60-31)=\frac{29-11}{2}=9
$$

Hence this deviation cannot be profitable either. We have exhausted all the possible deviations on behalf of the firms. It is straightforward that given wages offered (public market and referral) that workers respond optimally. We conclude that we have constructed a market equilibrium with referral.

\section{D.2 Robustness check: all wages offered}

Result 1: Average wage offered are lower than average accepted wages

SUPPORT: We notice that on average firms offer lower wages than the ones that are accepted. In the $N R$ treatment the average wage offered is 19.24 , in the $R$ treatment it is 19.34. In contrast, the $N R$ treatment the average accepted wage is 26.62 and 25.51 in the $R$ treatment. The difference is confirmed by a Wilcoxon sign-rank test $(p$-value $=0.0431$ for $N R$ and $p$-value $=0.0277 R$ treatments). This result is explained by the fact that firms make several low wage offers that are not accepted. In contrast, higher wage offers are mostly accepted by workers. Indeed, in the $N R$ treatment $13.52 \%$ of the offered wages that are less or equal to 21 are accepted whereas $92 \%$ of the offered wages that are greater or equal to 30 are accepted. In the $R$ treatment, $18.62 \%$ of the offered wages that are less or equal to 21 are accepted whereas $77.88 \%$ of the offered wages that are greater or equal to 30 are accepted. 
Result 2: Firms are more likely to make offers that satisfy the participation constraint of high-ability workers in the first stage of treatment $R$, than in treatment $N R$.

SUPPORT: We find that there is a higher percentage of offered wages $w>30$ in the first stage of the $R$ treatment. Indeed, in stage 1 of the NR treatment $85.81 \%$ of the offered wages are below 30 against $77.26 \%$ for the $\mathrm{R}$ treatment. The fraction of offered wages with $w>30$ is greater in the first stage of treatment $\mathrm{R}(22.74 \%)$ than in treatment NR $(14.19 \%)$. Using the proportion of offered wages strictly greater than 30 in stage 1 in each session as an independent observation, we find that the difference is statistically significant (Mann-Whitney; $p$-value $=0.0176)$.

Result 3: Three wages are the most offered in each treatment, 15, 20 and 31. Firms on average offer a wage of 20.

SUPPORT: In each treatment and stage, we observe a concentration of wages between 15 and 25 and 31 and 35 with a peak at 15, 20 and 31. If we only consider accepted wages, in each stage and treatment, 31 is the modal accepted wage. But, if we concentrate on all offered wages, the results are slightly different. Offered wages are mainly concentrated below 20. On average, in both stages and treatments we find that offered wages are not significantly different from 20 (Wilcoxon sign-rank test; $p$-value $=0.8927$ for the $N R$ treatment; $p$-value $=0.2489$ for the $R$ treatment) but are significantly different from 15 and 30 (Wilcoxon sign-rank test; $p$-value $=0.0431$ for the $N R$ treatment; $p$-value $=0.0277$ for the $R$ treatment).

Result 4: Offered wages in the referral market are higher on average than those in the public market.

SUPPORT: The average offered wage in the referral market in the second stage of treatment $R$ is 21.52 . In contrast, the average offered wage in the public market is 17.98 in the second stage of the $R$ treatment. In line therefore with our expectations and Montgomery (1991), private offers are significantly higher than public offers (Wilcoxon signed-rank test at the session level; $p$-value $=0.0277$ both for accepted wages). For completeness, we report that wages accepted in the second stage of treatment $N R$ are (weakly) significantly lower than those in the referral market of treatment $R$ (Mann-Whitney at the session level; $p$-value $=0.01005$ for accepted wages). 


\section{D.3 Instructions}

These are the instructions from the Referrals treatment. The instructions for the other treatment were appropriately adjusted.

\section{D.3.1 General instructions}

Welcome! You will be now taking part in an economic experiment. In the experiment you and other participants will make decisions. How much money you earn depends on your own decisions, the decisions of other participants, and random events. At the end of the experiment the earnings from the experiment will be added up and confidentially paid out to you.

The experiment is divided into periods. In each period you have to make decisions, which you will enter on a computer screen. There are 15 periods in total. You will also receive specific instructions for the experiment. These instructions will explain how you make decisions and how your decisions, the decisions of other participants and random events influence your earnings. Therefore, it is important that you read these instructions very carefully.

From now on you are not allowed to communicate in any other way than specified in the instructions. Please obey to this rule because otherwise we have to exclude you from the experiment and all earnings you have made will be lost. Please also do not ask questions aloud. If you have a question raise your hand. A member of the experimenter team will come to you and answer your question in private.

\section{D.3.2 Specific instructions - Firms}

In this experiment you can earn money with the decisions you make. How much you earn depends on your own decisions, the decisions of other participants, and random events. We will not speak of Euro during the experiment, but rather of points. All your earnings will first be calculated in points. At the end of the experiment the total amount of points you earned will be converted to Euro at the following rate:

1 point $=0.0225$ Euro 
First you will be introduced to the basic decision situation, thereafter you will learn more specifically how the experiment is conducted. You will also be asked some control questions that will help you to understand the decision situation.

- $\quad-$ Periods

The experiment consists of 15 periods and each period consists of two stages called stage 1 and stage 2 .

In each period you will make decisions on a labor market. In stage 1 and stage 2 of the labor market each firm may offer wages to workers. If a worker accepts a wage offer a labor contract is concluded between the involved firm and worker.

\section{- $\quad$ - Groups}

At the beginning of the experiment all participants will be randomly assigned either the role of a firm or the role of a worker. Everyone will keep his/her assigned role throughout the 15 periods.

Workers will be divided into two groups of the same size:

- Half of the workers will be active in stage 1 (stage 1 workers). Active means that a worker can accept a wage offer and be hired.

- The other half will be active in stage 2 (stage 2 workers).

For example, if a worker is active in stage 1, it means that he will be inactive in stage 2. And vice-versa. Inactive means that a worker does not make any decisions.

If you are going to be a worker, whether you are a stage 1 or a stage 2 worker is determined at random at the beginning of each period. That is, a participant in the role of a worker will be a stage 1 worker in some periods and a stage 2 worker in other period, depending on the random event

Number of participants

In total 16 participants are active in each period: 4 firms, 6 stage- 1 workers, and 6 stage- 2 workers.

Stage- 1 workers are active in stage 1 only ( Inactive in stage 2)

Stage-2 workers are active in stage 2 only ( Inactive in stage 1 )

Firms are active in both stage 1 and stage 2

Note: In each period and stage there are more workers than firms. 
Workers' Types

In each stage (i.e. both stage 1 and stage 2 ) there are two types of workers:

- Low productivity workers produce 20 points if hired

- High productivity workers produce 60 points if hired

The productivity of a worker is that worker's private information and it is therefore only known to him/her.

Workers only know their own productivity and do not know and also do not get to know the productivity of specific other workers.

Firms also do not know any specific workers' productivity before hiring a worker.

All participants know that:

In each stage, there are 3 low productivity workers and 3 high productivity workers.

After a firm has hired a worker, this worker's productivity is disclosed to the firm.

The productivity of a worker and whether he/she is active in stage 1 or stage 2 is randomly assigned at the beginning of each period. Hence, a participant in the role of a worker will be a low productivity worker in some periods and a high productivity worker in some other periods, as he/she will be a stage- 1 worker in some periods and a stage-2 worker in some other periods, depending on the chance event.

- $\quad$ - Link between stage-1 and stage-2 workers:

At the beginning of each period, each stage-1 worker is randomly linked to one (and only one) stage-2 worker (called referral worker). Each stage-2 worker is linked to only one stage-1 worker. Importantly, the likelihood that a stage 1 worker is linked to a stage 2 worker of the same productivity is $75 \%$ (i.e. probability $=0.75$ ). As a stage 1 worker, you do not know the productivity of your referral worker. As a firm, recall that you do not know the productivity of stage 1 and stage 2 workers before a worker is hired.

All participants know that:

The likelihood of a stage- 1 worker to be linked to a stage- 2 worker of the same productivity is $75 \%$ (probability $=0.75$ ).

For example, if a firm has hired a high productivity stage-1 worker then there is a chance of 3 out of 4 that this worker is linked to a high productivity stage- 2 worker. The chance that the high productivity stage- 1 worker is linked with a low productivity stage-2 worker is 1 out of 4 .

This links are changed and formed randomly at the beginning of each period. 
- $\quad$ - Stages and trading phase

Which kind of decision you have to make depends on your role (firm or worker). In each period the procedures are as follow:

Each period consists of two trading phases called stage 1 and stage 2. Each trading phase lasts at most 2 minutes.

Stage 1: Firms and stage 1 workers participate in a public market where each firm can make wage offers and each worker can respond to wage offers by any firm. If a stage-1 worker accepts a wage offer from a given firm, a labor contract is concluded and the firm learns this stage 1 worker's productivity.

Each wage offer is binding and a firm may employ at most one worker in stage 1. As long as none of her wage offers is accepted, the firm can make as many wage offers as it wishes.

A stage-1 worker may accept at most one wage offer.

Once a wage offer is accepted the involved firm and worker leaver the market are not active any more in stage 1 of this period.

Stage 2: Firms and stage-2 workers participate in a public and/or referral market. Firms can submit two types of wage offers: public offers or/and referral offers.

Public offers: Like in stage 1, a public wage offer is submitted to all stage-2 workers and can be accepted by any stage- 2 worker.

Referral offers: A firm may make an offer to the stage-2 worker who is linked with the firm's stage- 1 worker in the way described above. Referral wage offers made by a firm are submitted only to the stage-2 referral worker of this firm. A referral wage offer made by a firm can be accepted (or rejected) only by this firm's referral worker.

Firms are free to make wage offers in both markets or only in one.

Note: If a firm makes a referral offer it does not know the productivity of its referral worker. However, a firm knows:

- The productivity (20 or 60 ) of the worker hired in stage 1

- The likelihood that a stage-1 worker is linked to a stage-2 worker of the same productivity is $75 \%$ (probability $=0.75$ ).

If a stage- 2 worker accepts a wage offer, a labor contract is concluded and the firm learns its stage-2 worker's productivity. 
A firm may employ at most one worker in stage 2. It can make as many public and referral wage offers as it wishes. A stage 2 worker may accept at most one wage offer.

In stage 1 and in stage 2 , submitted wages by a firm have to follow an improvement rule. That is, subsequent wages offers of a firm have to be increasing. Submitted wages can be accepted at any time during the trading phase.

- $\quad$ - The Experimental Procedures in Detail

As explained above, there are 4 firms, 6 stage- 1 workers and 6 stage- 2 workers. In each stage, 3 workers are low productivity workers and 3 are high productivity workers.

Each stage-1 worker is linked with exactly one stage-2 worker. Each stage-2 worker is linked with exactly one stage 1 worker.

The likelihood of a worker to be linked to a worker of the same productivity is $75 \%$.

If you are a firm you stay a firm throughout the whole experiment. If you are a worker you stay a worker throughout the whole experiment. However, each worker's productivity and the stage in which he/she is active are newly and randomly assigned in each period.

During the experiment you will enter your decisions on a computer screen. In the following we describe in detail how you make decisions in each period and stage.

YOU are a firm YOU have to make wage offers.

1A-The trading phases if you are a firm

- $\quad$ - Stage 1 of each period

Each period starts with stage 1 . During stage 1 each firm may hire a stage 1 worker. In order to do so each firm can submit as many wage offers as it wishes. Recall that, in each stage, there are more workers (6) than firms (4). As a firm, in each stage 1 you will see the following screen:

- In the top left corner of the screen you see in which period of the experiment you are.

- In the header "Help", you see in which period and stage of the experiment you are as well as some additional useful information.

- In the top right corner of the screen you see the time remaining in this period and stage, displayed in seconds. Each stage lasts 2 minutes (120 seconds). When this time is up the trading phase is over. Hereafter, no further offers can be submitted or accepted in this stage. 


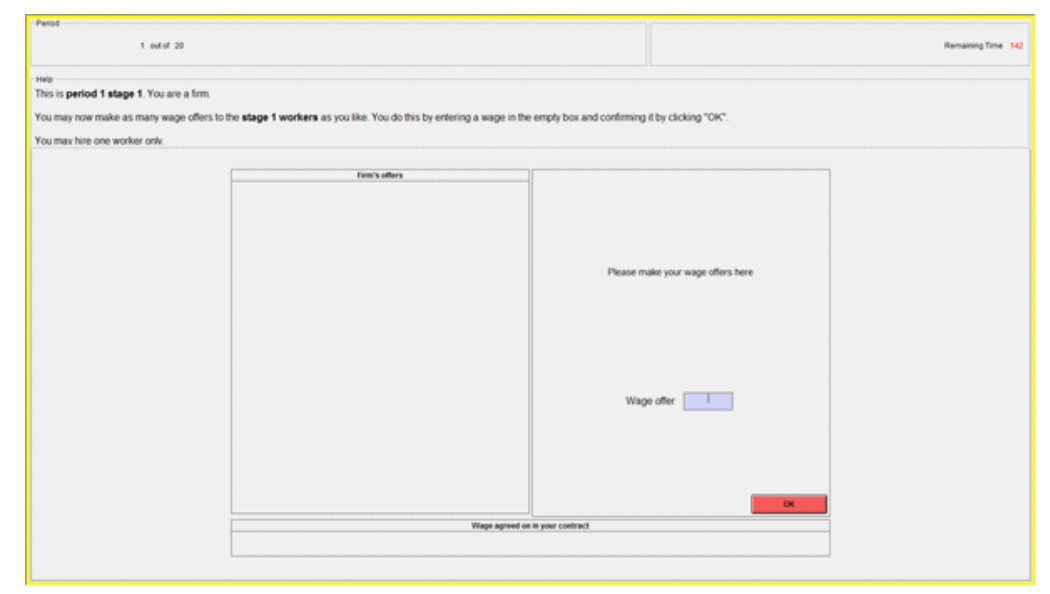

Figure D-1: Screenshot: wage offers in the public market

- Once the above screen is displayed the trading phase starts. As a firm you now have the opportunity to submit wage offers to stage 1 workers on a public market.

o You can submit a public wage offer by using the right side of the screen. You have to enter a wage in the empty box and then click the "OK" button to submit your offer. After you click "OK" the offer will be displayed to all workers. Public offers are seen by all firms and stage-1 workers.

o To determine which wage you offer you just have to enter a (integer) number between 0 and 60 .

o On the left side of your screen you see the header "Firm's offer". All public offers in stage 1 are displayed there. Your public offers as well as those of all others firms will be displayed. A public offer can therefore be accepted by any worker.

o You can make as many wage offers as you want. Each wage offer that is submitted can be accepted at any time during the trading phase. But wage offers have to follow the improvement rule: each new offer that you make must be higher than the previous one.

o In each stage each firm can hire at most one worker. Once a stage 1 worker has accepted your offer you will be notified in the header "Wage agreed on in your contract". As you can conclude only one trade in each stage all your other offers will be automatically canceled. Also, you will not be able to submit any further offers.

- Once all firms have hired a worker or after 2 minutes have gone, stage 1 is over.

- No firm is forced to submit offers, and no worker is forced to accept a wage offer. 


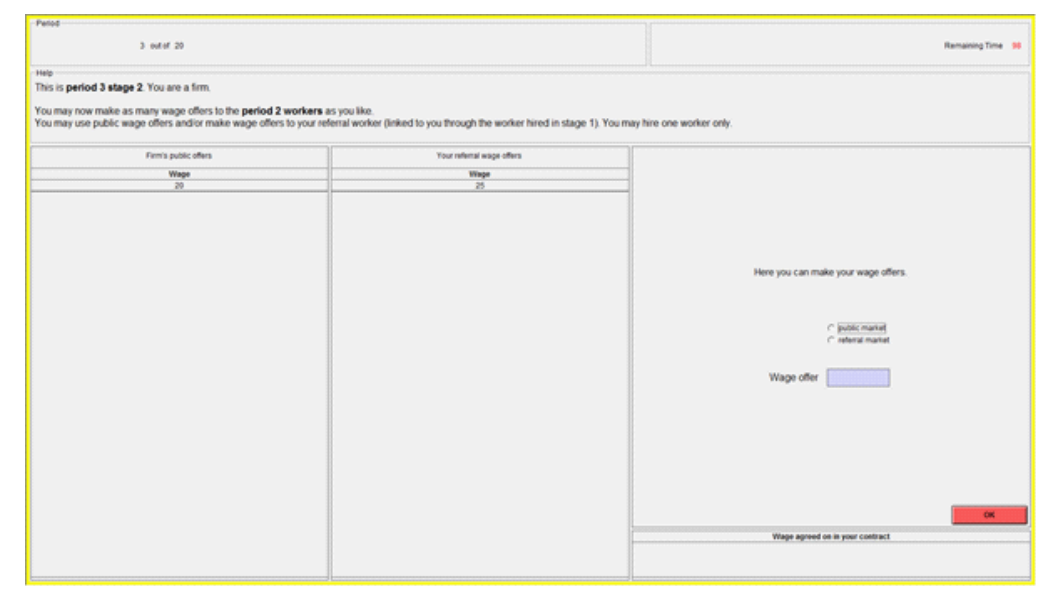

Figure D-2: Screenshot: wage offers in the public and referral markets

- After stage 1 is over each firm learn the productivity of the worker it has hired in stage 1. That is, it learns if the worker it has hired produces 20 or 60 points.

- $\quad$ - Stage 2 of each period

During stage 2 each firm hires at most one stage-2 worker.

Note: the likelihood of a stage-1 worker to be linked to a stage-2 worker of the same productivity is $75 \%$ (probability $=0.75$ )

The main difference between stage 1 and stage 2: first, now other workers, the stage-2 workers, are active; second, two markets are now open, the public market and the referral market. Recall that, in each stage, there are more workers (6) than firms (4). You will see the following screen:

- In the top left corner of the screen you see in which period of the experiment you are.

- In the header "Help", you see in which period and stage of the experiment you are as well as some additional useful information.

- In the top right corner of the screen you will see the time remaining in this period and stage, displayed in seconds. The trading phase in each stage lasts 2 minutes (120 seconds). When this time is up the trading phase is over. Hereafter, no further offers can be submitted or accepted in this stage.

- Once the above screen is displayed the stage 2 starts. As a firm you now have the opportunity to submit wage offers to stage- 2 workers on a public market or/and the referral market. 
o Public offers. The rules are precisely as in stage 1. All public wage offers appear on the left side of the screen. To enter a public wage offer you have to click on the button "public market", enter the wage in the empty box "wage offer". And then click on the "OK" button. Public offers are seen by all firms and stage-2 workers.

o Referral offers. A referral offer is transmitted to one stage-2 worker only. Specifically, it is transmitted to your referral worker, i.e. to the stage-2 worker who is linked with your stage 1 worker. Only the referral worker is informed about the referral wage offer and only this referral worker can accept the offer. Note that each firm can have at most one referral worker. No two firms will have the same referral worker.

No other firm or worker will be informed about your referral offer(s). All referral offers appear in the middle of the screen in the header "your referral wage offers". Your referral worker can only receive referral offers from you.

o You can only make referral offers if you have hired a stage-1 worker. If you haven't hired a stage- 1 worker you may use only the public offers.

o If you want to submit a referral offer, select "referral market" and then enter your wage offer in the empty box. Then click on the "OK" button.

o To determine which wage you offer you just have to enter a (integer) number between 0 and 60

o Like in stage 1, you can make as many public wage offers and referral offers as you want, as long as you follow the improvement rule.

Each wage offer, public or referral, which is submitted, can be accepted at any time during the trading phase.

oIn each stage each firm can hire at most one worker. Once a stage-2 worker has accepted your offer it will be notified in the header "Wage agreed on in your contract". As you can conclude at most one trade in each stage all your other offers will be automatically canceled. Also, you will not be able to submit any further offers.

- Once all firms have hired a worker or after 2 minutes are over, stage 2 ends.

- No firm is forced to submit offers, and no worker is forced to accept a wage offer.

- After stage 2 is over each firm learns the productivity of the stage- 2 worker it has hired.

1B-Determination of your earnings (firm)

Before Period 1 starts, each firm is given an "initial budget" of 120 points. 
As a firm you can submit wages between 0 and 60 points.

Each wage has to be an integer number, that is $(0,1,2,3,4,5,6,7,8,9,10, \ldots, 60)$

In each stage a hired worker can be of low or high productivity. A high productivity worker produces 60 points if he is hired and a low productivity worker produces 20 points if he is hired.

If one of your offers is accepted, your earnings depend on the productivity of the worker and the wage that is accepted by the worker.

In each stage, your earnings are calculated in the following way:

- if you hire a worker:

You earn the productivity of your worker minus the accepted wage plus an extra 20 points .

Your earnings in a stage $=$ worker's productivity - accepted wage +20

Please note that as a firm, you can make losses (negative earnings) in each period. These losses have to be paid out of your budget of 120 points and earnings in other periods. Note, also that you can always avoid losses through your own decisions. In each stage, you will see your earnings in that stage as well as your current budget.

- If you don't hire any worker during a stage you receive 0 points in that stage.

No contract in a stage $=0$ points

Your total earnings in one period is equal to the total of your earning in stage 1 and 2

Earnings in a period $=$ earnings stage $1+$ earnings stage 2

- After stage 1 you will see the "earning screen". The screen looks as follows.

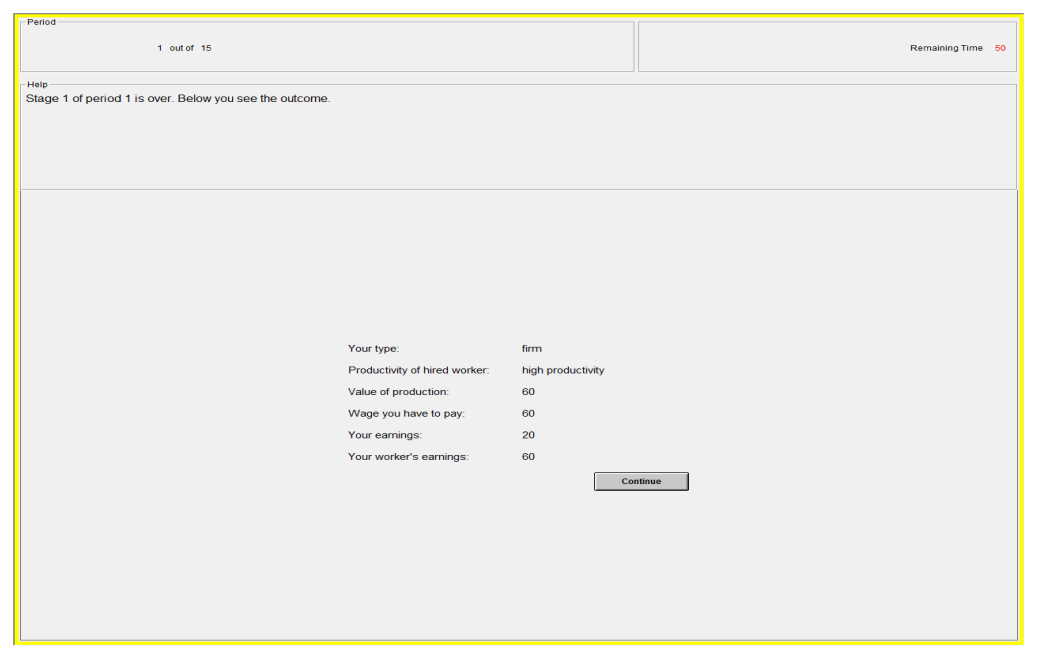

Screenshot: profits of the firms

- After stage 2 is over, you will see a second earning screen which looks as follows: 
- Once you have finished studying the earning screen please on the "continue" button. Otherwise it will automatically change to the next period after 1 minute.

After the 15 periods are over you will be asked to fill in a short questionnaire. Thereafter, the experiment is over and you will confidentially be paid out your total earnings in the experiment in cash.

The earnings of the workers are calculated this following way:

Before Period 1 starts, each worker is given an initial budget (endowment) of 120 points. These 120 points will be added to his final earnings at the end of the 15 periods.

Worker's earnings will depend on whether he accepts a wage offer or not, and in case the worker does not accept an offer it will depend on his productivity.

A worker can receive any wage between between 0 and 60 .

In each period, worker's earnings are calculated in the following way:

- Low productivity worker:

olf a he accepts a wage in the stage in which he is active:

He earns the wage that he has accepted

oIf he does NOT accept a wage in the stage he is active:

He earns (reservation wage) 10 points

Earning of the low productivity worker in the stage in which he is active

$=$ accepted wage if hired

Or

$=10$ points if not hired

Earning of the low productivity worker in the stage in which he is inactive

$=10$ points

Total earnings in a period: earnings when active + earnings when inactive

- High productivity worker:

If he accepts a wage in the stage in which he is active:

He earns the wage he has accepted

If he does NOT accept a wage in the stage in which he is active:

He earns 30 points

Earning of a high productivity worker in the stage in which he is active

$=$ accepted wage if he is hired

or 
$=30$ points if he is not hired

Earnings of a high productivity worker in the stage in which he is inactive

$=30$ points

Total earnings in a period: earnings when active + earnings when inactive

\section{D.3.3 Specific instructions - Workers}

In this experiment you can earn money with the decisions you make. How much you earn depends on your own decisions, the decisions of other participants, and random events. We will not speak of Euro during the experiment, but rather of points. All your earnings will first be calculated in points. At the end of the experiment the total amount of points you earned will be converted to Euro at the following rate:

1 point $=0.0225$ Euro

First you will be introduced to the basic decision situation, thereafter you will learn more specifically how the experiment is conducted. You will also be asked some control questions that will help you to understand the decision situation.

- $\quad-$ Periods

The experiment consists of 15 periods and each period consists of two stages called stage 1 and stage 2 .

In each period you will make decisions on a labor market. In stage 1 and stage 2 of the labor market each firm may offer wages to workers. If a worker accepts a wage offer a labor contract is concluded between the involved firm and worker.

- - Groups

At the beginning of the experiment all participants will be randomly assigned either the role of a firm or the role of a worker. Everyone will keep his/her assigned role throughout the 15 periods.

Workers will be divided into two groups of the same size:

- Half of the workers will be active in stage 1 (stage 1 workers). Active means that a worker can accept a wage offer and be hired.

- The other half will be active in stage 2 (stage 2 workers). 
For example, if a worker is active in stage 1, it means that he will be inactive in stage 2. And vice-versa. Inactive means that a worker does not make any decisions.

If you are going to be a worker, whether you are a stage 1 or a stage 2 worker is determined at random at the beginning of each period. That is, a participant in the role of a worker will be a stage 1 worker in some periods and a stage 2 worker in other period, depending on the random event

Number of participants

In total 16 participants are active in each period: 4 firms, 6 stage- 1 workers, and 6 stage- 2 workers.

Stage- 1 workers are active in stage 1 only (inactive in stage 2 )

Stage- 2 workers are active in stage 2 only (inactive in stage 1)

Firms are active in both stage 1 and stage 2

Note: In each period and stage there are more workers than firms.

Workers' Types

In each stage (i.e. both stage 1 and stage 2) there are two types of workers:

- Low productivity workers produce 20 points if hired

- High productivity workers produce 60 points if hired

The productivity of a worker is that worker's private information and it is therefore only known to him/her.

Workers only know their own productivity and do not know and also do not get to know the productivity of specific other workers.

Firms also do not know any specific workers' productivity before hiring a worker.

All participants know that:

In each stage, there are 3 low productivity workers and 3 high productivity workers.

After a firm has hired a worker, this worker's productivity is disclosed to the firm.

The productivity of a worker and whether he/she is active in stage 1 or stage 2 is randomly assigned at the beginning of each period. Hence, a participant in the role of a worker will be a low productivity worker in some periods and a high productivity worker in some other periods, as he/she will be a stage- 1 worker in some periods and a stage- 2 worker in some other periods, depending on the chance event.

- $\quad$ - Link between stage-1 and stage-2 workers: 
At the beginning of each period, each stage- 1 worker is randomly linked to one (and only one) stage-2 worker (called referral worker). Each stage-2 worker is linked to only one stage-1 worker. Importantly, the likelihood that a stage 1 worker is linked to a stage 2 worker of the same productivity is $75 \%$ (i.e. probability=0.75). As a stage 1 worker, you do not know the productivity of your referral worker. As a firm, recall that you do not know the productivity of stage 1 and stage 2 workers before a worker is hired.

All participants know that:

The likelihood of a stage- 1 worker to be linked to a stage- 2 worker of the same productivity is $75 \%$ (probability $=0.75$ ).

For example, if a firm has hired a high productivity stage- 1 worker then there is a chance of 3 out of 4 that this worker is linked to a high productivity stage- 2 worker. The chance that the high productivity stage- 1 worker is linked with a low productivity stage-2 worker is 1 out of 4 .

This links are changed and formed randomly at the beginning of each period.

- $\quad$ - Stages and trading phase

Which kind of decision you have to make depends on your role (firm or worker). In each period the procedures are as follow:

Each period consists of two trading phases called stage 1 and stage 2. Each trading phase lasts at most 2 minutes.

Stage 1: Firms and stage 1 workers participate in a public market where each firm can make wage offers and each worker can respond to wage offers by any firm. If a stage 1 worker accepts a wage offer from a given firm, a labor contract is concluded and the firm learns this stage 1 worker's productivity.

Each wage offer is binding and a firm may employ at most one worker in stage 1. As long as none of her wage offers is accepted, the firm can make as many wage offers as it wishes.

A stage 1 worker may accept at most one wage offer.

Once a wage offer is accepted the involved firm and worker leaver the market are not active any more in stage- 1 of this period.

Stage 2: Firms and stage-2 workers participate in a public and/or referral market. Firms can submit two types of wage offers: public offers or/and referral offers. 
Public offers: Like in stage 1, a public wage offer is submitted to all stage-2 workers and can be accepted by any stage- 2 worker.

Referral offers: A firm may make an offer to the stage-2 worker who is linked with the firm's stage-1 worker in the way described above. Referral wage offers made by a firm are submitted only to the stage-2 referral worker of this firm. A referral wage offer made by a firm can be accepted (or rejected) only by this firm's referral worker.

Firms are free to make wage offers in both markets or only in one.

Note: If a firm makes a referral offer it does not know the productivity of its referral worker. However, a firm knows:

- The productivity (20 or 60 ) of the worker hired in stage 1

- The likelihood that a stage-1 worker is linked to a stage-2 worker of the same productivity is $75 \%$ (probability $=0.75$ ).

If a stage- 2 worker accepts a wage offer, a labor contract is concluded and the firm learns its stage- 2 worker's productivity.

A firm may employ at most one worker in stage 2. It can make as many public and referral wage offers as it wishes. A stage 2 worker may accept at most one wage offer.

In stage 1 and in stage 2 , submitted wages by a firm have to follow an improvement rule. That is, subsequent wages offers of a firm have to be increasing. Submitted wages can be accepted at any time during the trading phase.

\section{- $\quad$ - The Experimental Procedures in Detail}

As explained above, there are 4 firms, 6 stage- 1 workers and 6 stage- 2 workers. In each stage, 3 workers are low productivity workers and 3 are high productivity workers.

Each stage-1 worker is linked with exactly one stage-2 worker. Each stage-2 worker is linked with exactly one stage 1worker.

The likelihood of a worker to be linked to a worker of the same productivity is $75 \%$.

If you are a firm you stay a firm throughout the whole experiment. If you are a worker you stay a worker throughout the whole experiment. However, each worker's productivity and the stage in which he/she is active are newly and randomly assigned in each period.

During the experiment you will enter your decisions on a computer screen. In the following we describe in detail how you make decisions in each period and stage.

You are a worker 


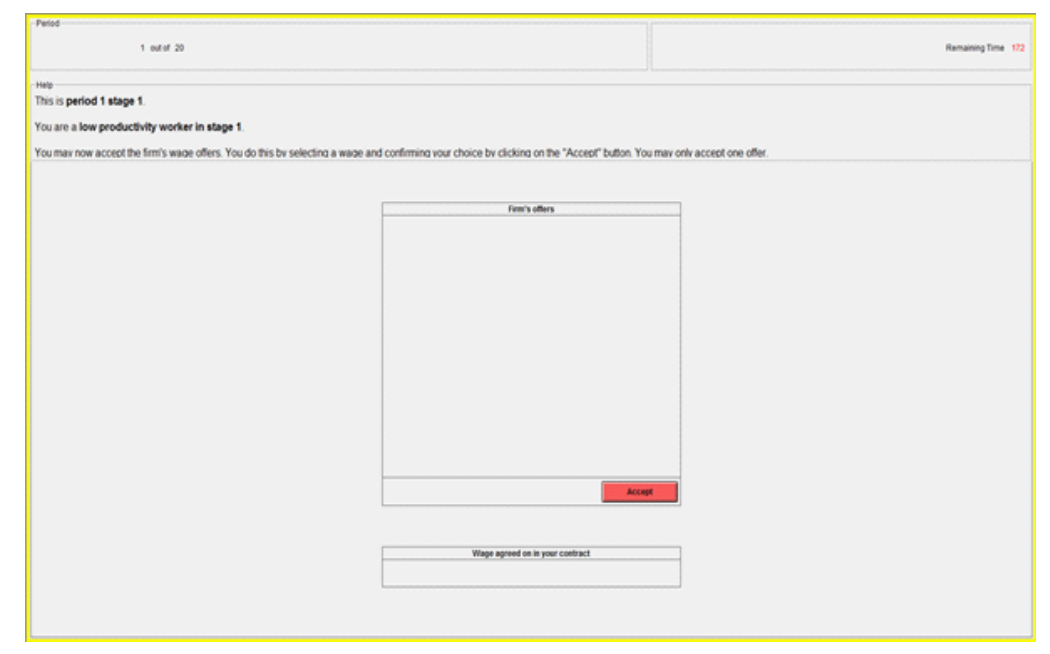

Figure D-3: Screenshot: workers' wage offers in the public market

1A-The trading phases if you are a worker

Stage 1 of each period

In this stage, only stage 1 workers are active. Stage 2 workers are inactive and they will have to wait till stage 2 starts.

During stage 1, each stage 1 worker can be hired by a firm. Recall that, in each stage, there are more workers (6) than firms (4). As a worker you will see the following screen:

-In the top left corner of the screen you see in which period of the experiment you are.

-In the header "Help", you see in which period and stage of the experiment you are, your productivity, as well as some additional useful information.

-In the top right corner of the screen you see the time remaining in this period and stage, displayed in seconds. The trading phase in each stage lasts 2 minutes (120 seconds). When this time is up the trading phase is over. Hereafter, no further offers can be submitted or accepted in this stage.

- Once the above screen is displayed the trading phase starts. As a worker you can now accept public wage offers submitted by the firms. You do this by selecting a wage in the header "Firm's offers" and then click the "Accept" button. All wage offers appear in this header and can be seen by all firms and workers.

- In any stage each worker can accept at most one wage offer. Once you have accepted a wage offer it is notified in the header "Wage agreed on in your contract" at the bottom of the screen. As you can accept at most one wage, you will not be able to accept any 


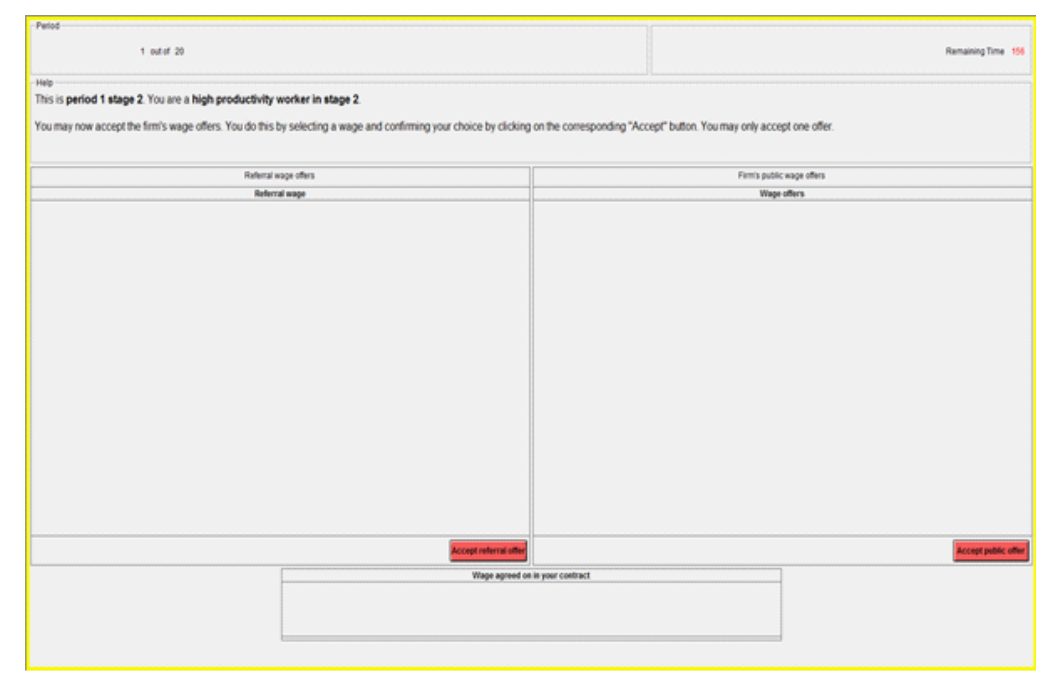

Figure D-4: Screenshot: workers' wage offers in the public and referral markets

further offers.

- Once all firms have hired a worker or after 2 minutes are over, stage 1 ends.

- No firm is forced to submit offers, and no worker is forced to accept a wage offer.

- After stage 1 is over, each firm learns the productivity of the worker it hired.

- $\quad$ - Stage 2 of each period.

If you are a stage- 1 worker, you are inactive and you will have to wait until stage- 2 is over. Only stage- 2 workers are active in this stage.

During stage 2 of the trading phase each stage- 2 worker can be hired by a firm. Recall that, in each stage, there are more workers (6) than firms (4). As a worker you will see the following screen:

- In the top left corner of the screen you see in which period of the experiment you are.

- In the header "Help", you see in which period and stage of the experiment you are, your productivity, as well as some additional useful information.

- In the top right corner of the screen you will see the time remaining in this period and stage, displayed in seconds. The trading phase in each stage lasts 2 minutes (120 seconds). When this time is up the trading phase is over. Hereafter, no further offers can be submitted or accepted in this stage.

- Once the above screen is displayed, stage 2 starts. As a worker you now have the opportunity to accept at most one wage on a public market or on the referral market. 
o Public offers. The rules are the same as in stage 1. All public wage offers appear in the right side of the screen. As a worker you can now accept public wage offers submitted by the firms. You do this by selecting a wage in the header "Firm's public offers" and then click the "Accept" button. All wage offers can be seen by all firms and workers.

o Referral offers. All referral offers appear in the left side of the screen. You can only receive referral offers if your stage-1 linked worker has been hired. A referral offer is submitted to you only (if any). You are the only one to receive it and you are the only one who can accept it. No other firm or worker will be informed about that offer. If you want to accept a referral wage offer, you select a wage in the header "Your referral wage offer" and then click the "Accept" button.

o Like in stage 1, you can receive many public and/or referral offers. Each wage offer that is submitted can be accepted at any time during the trading phase.

o In any stage each worker can accept at most one wage. Once a stage-2 worker has accepted a wage offer it is notified it in the header "Wage agreed on in your contract" at the bottom of the screen. As you can accept at most one wage, you will not be able to accept any further offers.

- Once all firms have hired a worker or after 2 minutes are over, stage 2 ends.

- No firm is forced to submit offers, and no worker is forced to accept a wage offer.

1B-Determination of your earnings (worker)

Before Period 1 starts, each worker is given an initial budget (endowment) of 120 points. These 120 points will be added to your final earnings at the end of the 15 periods.

Your earnings will depend on whether you accept a wage offer or not, and in case you do not accept an offer it will depend on your productivity.

You can receive any wage between 0 and 60 .

In each period, your earnings are calculated in the following way:

- If you are a low productivity worker:

o If you accept a wage in the stage in which you are active:

You earn the wage you have accepted

o If you do NOT accept a wage in the stage you are active:

You earn (reservation wage) 10 points

Your earning in the stage in which you are active

$=$ accepted wage if you are hired 
or

$=10$ points if you are not hired

Your earning in the stage in which you are inactive $=10$ points

Your total earnings in a period: earnings when active + earnings when inactive

- If you are a high productivity worker:

o If you accept a wage in the stage in which you are active:

You earn the wage you have accepted

o If you do NOT accept a wage in the stage in which you are active:

You earn 30 points

Your earning in the stage in which you are active

$=$ accepted wage if you are hired

or

$=30$ points if you are not hired

Your earning in the stage in which you are inactive $=30$ points

Your total earnings in a period: earnings when active + earnings when inactive

Earnings Screens (workers)

Whether you are a low or a high productivity worker, you will see two earning screens.

-If you are active in stage 1, you will see two earnings screen. One at the end of stage 1 , and one at the end of stage 2 . The screens look as follows:

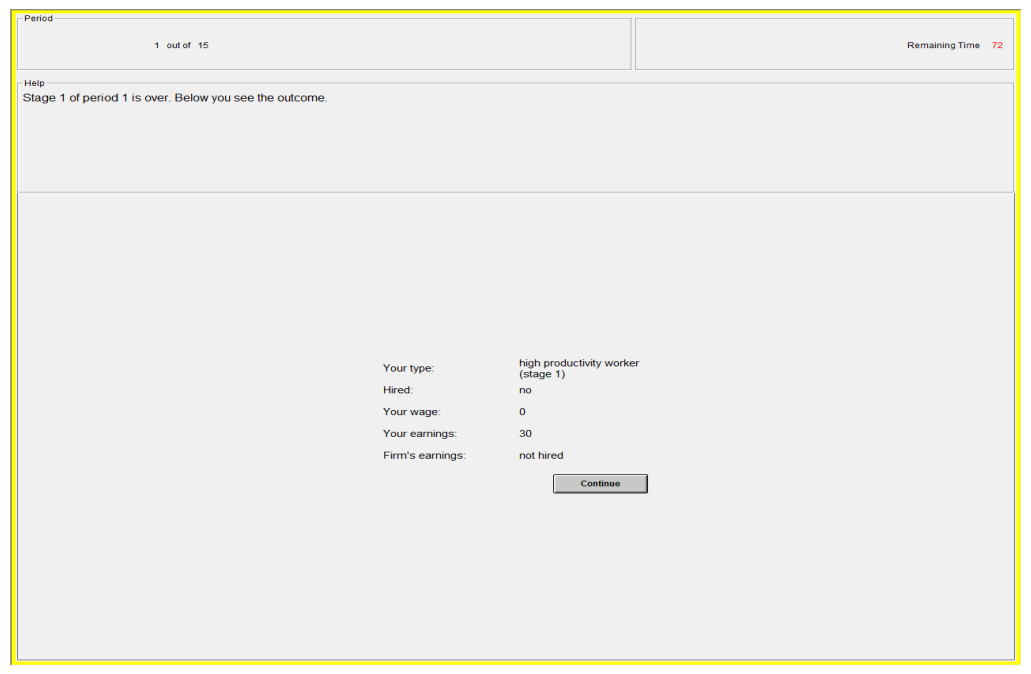

Screenshot: earnings of the workers 


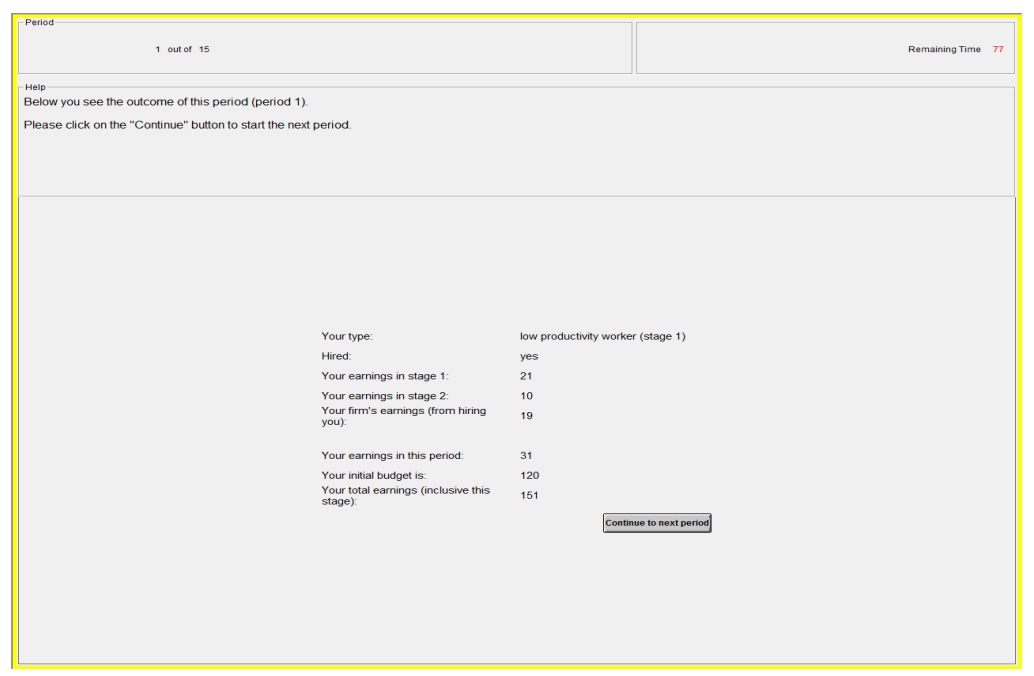

Screenshot: earnings of the workers

-If you are active in stage 2, you will see two earning screens. One at the end of stage 1, and one at the end of stage 2 . The screens look as follows:

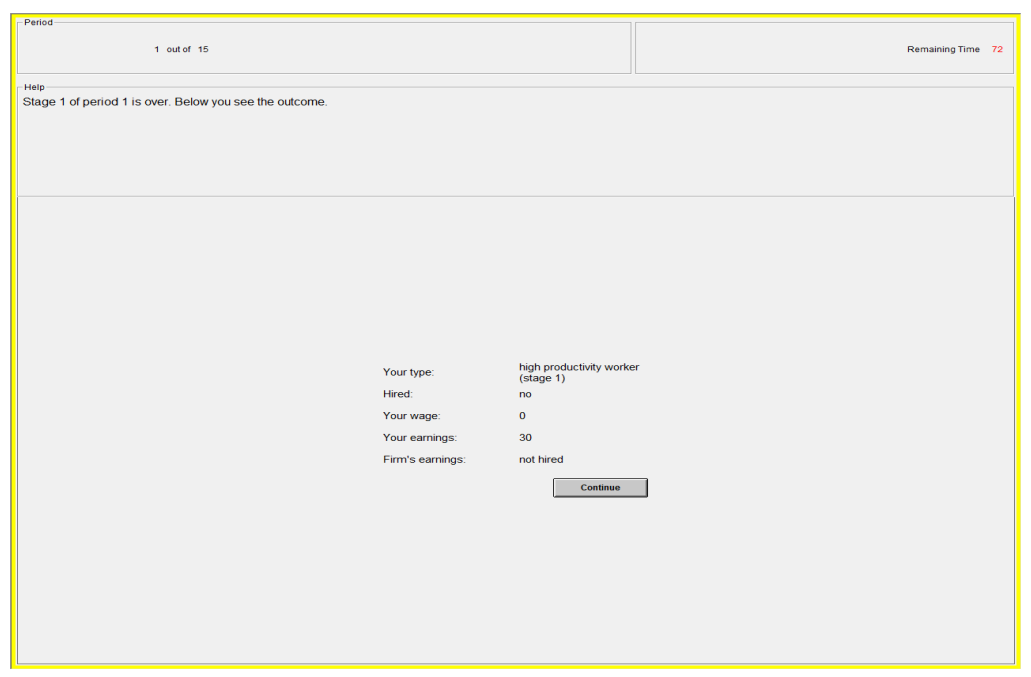

Screenshot: earnings of the workers

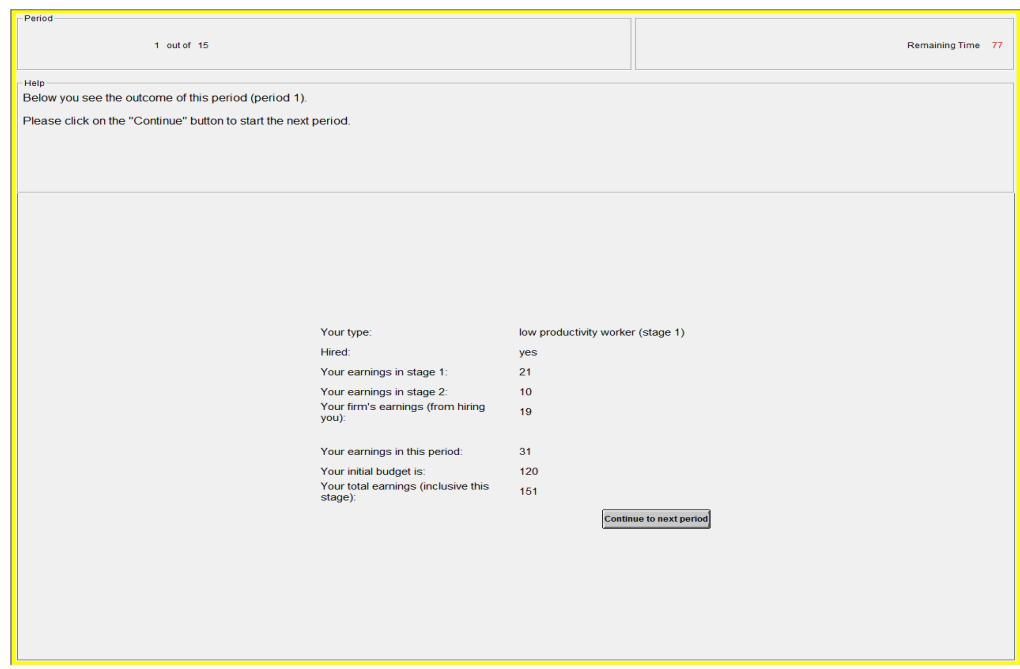


Screenshot: earnings of the workers

Once you have finished studying the earnings screen please click on the "Continue" button. Otherwise it will automatically change to the following period after 2 minutes.

Recall that at the end of the 15 periods, your total earnings made during the 15 periods will be calculated and your endowment of 120 points will be added to these earnings.

After the 15 periods are over you will be asked to fill in a short questionnaire. Thereafter, the experiment is over and you will confidentially be paid out your total earnings in the experiment in cash.

Determination of the earnings of the FIRMS

Before Period 1 starts, each firm is given an "initial budget" of 120 points.

A firm can submit wages between 0 and 60 points.

Each wage has to be an integer number, that is $(0,1,2,3,4,5,6,7,8,9,10, \ldots, 60)$

If one of offers is accepted, the earnings of a firm depend on the productivity of the worker and the wage that is accepted by the worker.

In each stage, the earnings of a firm are calculated in the following way:

-If it hires a worker:

It earns the productivity of its worker minus the accepted wage plus an extra 20 points

Earnings of a firm in a stage $=$ worker's productivity - accepted wage +20

-If it does not hire any worker during a stage it receives 0 points in that stage.

No contract in a stage $=0$ points

Total earnings in one period is equal to the total of the firm's earnings in stage 1 and 2

Earnings in a period $=$ earnings stage $1+$ earnings stage 2

\section{D.3.4 Control questions public market - decision situation}

Please answer the following control questions. These questions are arbitrary examples of what could happen in the experiment. In the experiment you will be either a worker or a firm. The questions will concern both roles. They will help you to gain an understanding of the calculation of your earnings. Your earnings vary with your own decision and with the decisions of the other person you are paired with.

Please answer all the questions and write down your calculations. 
Once you are done, please RAISE YOUR HAND and the experimenter will come check your answers.

1. A firm did not make an offer in stage 1 and 2. What are the firm's total earnings in this period?

- The firm's earnings $=$

3. A firm hired a high productivity worker in stage 1 at a wage of 30 . In stage 2 the firm hired a high productivity worker at a wage of 38 .

- The firm's earnings in stage $1=$

- The firm's earnings in stage $2=$

- The firm's total earnings in this period=

- Earnings of the hired stage-1 worker in stage $1=$

- Earnings of the hired stage- 2 worker in stage $2=$

- Total earnings of stage- 1 worker $=$

- Total earnings of stage- 2 worker $=$

4. A firm hired a low productivity worker in stage 1 at a wage of 20 and a low productivity worker in stage 2 at a wage of 20 .

- The firm's total earnings in this period=

- Earnings of the hired stage- 1 worker in stage $1=$

- Earnings of the hired stage- 2 worker in stage $2=$

5. A firm hired a high productivity worker in stage 1 at a wage of 31 and a low productivity worker in stage 2 at a wage of 25 .

- The firm's total earnings in this period=

- Earnings of the hired stage- 1 worker in stage $1=$

- Earnings of the hired stage- 2 worker in stage $2=$

6. A firm made several wage offers in stage 1 but did not manage to hire anyone.

- The firm's earnings in stage $1=$

7. At the end of stage 1 , one of the stage- 1 high productivity worker is not hired.

- This worker's earnings in stage $1=$

- This worker's earnings in stage $2=$

8. At the end of stage 2 , one of the stage- 2 high productivity worker is not hired.

- This worker's earnings in stage $1=$ 
- This worker's earnings in stage $2=$

9. At the end of stage 1 , one of the stage- 1 low productivity worker is not hired.

- This worker's earnings in stage $1=$

- This worker's earnings in stage $2=$

This is the end of the instructions.

PLEASE RAISE YOUR HAND, the experimenter will come check your answers.

\section{D.3.5 Control questions referral market - decision situation}

Please answer the following control questions. These questions are arbitrary examples of what could happen in the experiment. In the experiment you will be either a worker or a firm. The questions will concern both roles. They will help you to gain an understanding of the calculation of your earnings. Your earnings vary with your own decision and with the decisions of the other person you are paired with.

Please answer all the questions and write down your calculations.

Once you are done, please RAISE YOUR HAND and the experimenter will come check your answers.

1. A firm did not make an offer in stage 1 and 2. What are the firm's total earnings in this period?

- The firm's earnings $=$

2. A firm did not hire a worker in stage 1 , can it make a referral wage offer in stage 2 ?

3. A firm hired a high productivity worker in stage 1 at a wage of 30 . In stage 2 the firm hired a high productivity worker at a wage of 38 .

- The firm's earnings in stage $1=$

- The firm's earnings in stage $2=$

- The firm's total earnings in this period=

- Earnings of the hired stage- 1 worker in stage $1=$

- Earnings of the hired stage- 2 worker in stage $2=$

- Total earnings of stage- 1 worker ( stage $1+$ stage 2$)=$

- Total earnings of stage- 2 worker (stage $1+$ stage 2$)=$

4. A firm hired a low productivity worker in stage 1 at a wage of 20 and a low productivity worker in stage 2 at a wage of 20 .

- The firm's total earnings in this period= 
- Earnings of the hired stage- 1 worker in stage $1=$

- Earnings of the hired stage- 2 worker in stage $2=$

5. A firm hired a high productivity worker in stage 1 at a wage of 31 and a low productivity worker in stage 2 at a wage of 25 .

- The firm's total earnings in this period=

- Earnings of the hired stage-1 worker in stage $1=$

- Earnings of the hired stage- 2 worker in stage $2=$

6. A firm made several wage offers in stage 1 but did not manage to hire anyone.

- The firm's earnings in stage $1=$

7. At the end of stage 1 , one of the stage- 1 high productivity worker is not hired.

- This worker's earnings in stage $1=$

- This worker's earnings in stage $2=$

8. At the end of stage 2 , one of the stage- 2 high productivity worker is not hired.

- This worker's earnings in stage $1=$

- This worker's earnings in stage $2=$

9. At the end of stage 1, one of the stage-1 low productivity worker is not hired.

- This worker's earnings in stage $1=$

- This worker's earnings in stage $2=$

This is the end of the instructions.

PLEASE RAISE YOUR HAND, the experimenter will come check your answers. 


\section{Bibliography}

[1] Andreoni, J., 1995. Warm-Glow Versus Cold-Prickle: The Effects of Positive and Negative Framing on Cooperation in Experiments. Quarterly Journal of Economics, $110,1-21$.

[2] Andreoni, J., Miller, J.H., 2002. Giving according to GARP: An Experimental Test of the Consistency of Preferences for Altruism. Econometrica, 70, 737-753.

[3] Akerlof, G., 1982. Labor Contracts as Partial Gift Exchange. Quarterly Journal of Economics, 97 (4), 543-569.

[4] Akerlof, G., 1984. Gift Exchange and Efficiency-Wage Theory: Four Views. American Economic Review, 74(2), 79-83.

[5] Altmann, S., Dohmen, T., Wibral, M., 2008. Do the Reciprocal Trust Less? Economics Letters, 99, 454-457.

[6] Babcock, L., Camerer, C., Issacharo, S., Camerer, C. F., 1995. Biased Judgments of Fairness in Bargaining. American Economic Review, 85:1337-1343.

[7] Bayer, P., Ross, S., Topa, G., 2008. Place of Work and Place of Residence: Informal Hiring Networks and Labor Market Outcomes. Journal of Political Economy 116, $1150-1196$.

[8] Beaman, L., 2012. Social Networks and the Dynamics of Labor Market Outcomes: Evidence from Refugees Resettled in the U.S. Review of Economic Studies, 79 (1), $128-161$.

[9] Beaman, L., Magruder, J., 2012. Who Gets the Job Referral? Evidence from a Social Networks Experiment. American Economic Review. 102(7), 3574-3593 
[10] Blanco, M., Engelmann, D., Normann, H.T., 2011. A Within-Subject Analysis of Other-Regarding Preferences. Games and Economic. Behavior 72, 321-338.

[11] Bolton, G.E., Ockenfels, A., 2000. ERC: A Theory of Equity, Reciprocity and Competition. American Economic Review, 90, 166-193.

[12] Boorman, S., 1975. A Combinatorial Optimization Model of Transmission of Job Information Through Contact Networks. Bell Journal of economics and Management Science, 6, 216-49.

[13] Bougherara, D., Denant-Boemont, L., Masclet, D., 2011. Cooperation and Framing Effects in Provision Point Mechanisms: Experimental Evidence. Ecological Economics, 70(6),1200-1210.

[14] Brandts, J., Charness, G., 2000. Hot vs. Cold: Sequential Responses and Preference Stability in Experimental Games. Experimental Economics, 2, 227-238.

[15] Brandts, J., Charness, G., 2011. The Strategy Versus the Direct-Response Method: A First Survey of Experimental Comparisons. Experimental Economics, 14(3):375398.

[16] Brandts, J., Riedl, A., Winden, F. v., 2009. Competitive Rivalry, Social Disposition, and Subjective Well-Being: An experiment. Journal of Public Economics, 93(11/12):1158-1167.

[17] Brandts, J., Schwieren, C., 2007. Frames and Games. Working paper, Insitut d'anàlisi Econòmia and University of Heidelberg.

[18] Brewer, M.B., Kramer, Mr., 1986. Choice Behavior in Social Dilemmas: Effects of Social Identity, Group Size, and Decision Framing. Journal of Personality and Social Psychology, 50, 543-549.

[19] Brosig, J., Weimann, J., Yang, C.L., 2003. The Hot versus Cold Effect in a Simple Bargaining Experiment. Experimental Economics, 6, 75-90.

[20] Burlando, R., Guala, F., 2005. Heterogeneous Agents in Public Goods Experiments. Experimental Economics, 8, 35-54. 
[21] Bowles, S., 1998. Endogenous preferences: The Cultural Consequences of Markets and Other Economic Institutions. Journal of Economic Literature, 36:75-111.

[22] Bowles, S., Polania-Reyes, S., 2012. Economic Incentives and Social Preferences: Substitutes or Complements? Journal of Economic Literature, 50(2):368-425.

[23] Brown, M., Falk, A., Fehr, E., 2004. Relational Contracts and the Nature of Market Interactions. Econometrica, 72:747-780.

[24] Brown, M., Setren, E., Topa, G., 2012. Do Informal Referrals Lead to Better Matches? Evidence From a Firm's Employee Referral System. Federal Reserve Bank Of New York Staff Reports, no.568

[25] Camerer, C. F., Fehr, E., 2004. Measuring Social Norms and Preferences Using Experimental Games: A guide for social scientists. In Henrich, J., Boyd, R., Bowles, S., Camerer, C., Fehr, E., and Gintis, H., editors, Foundations of Human Sociality: Economic Experiments and Ethnographic Evidence from Fifteen Small-Scale Societies, chapter 3, pages 55-95. Oxford University Press, Oxford, UK.

[26] Camerer, C. F., 2003. Behavioral Game Theory: Experiments in Strategic Interaction, Princeton: Princeton. University Press

[27] Casoria, F., Riedl, A., 2013. Experimental Labor Markets and Policy Considerations: Incomplete Contracts and Macroeconomic Aspects. Journal of Economic Surveys. forthcoming

[28] Casella, A., Hanaki, N., 2008. Information Channels in Labor Markets: On the Resilience of Referral Hiring. Journal of Economic Behavior $\& 5$ Organization, 66(34), 492-513.

[29] Calvó-Armengol, A., 2003. Job Contact Networks. Journal of Economic Theory, $115,191-206$.

[30] Calvó-Armengol, A., Jackson, M., 2004. The Effect of Social Networks on Employment and Inequality. American Economic Review, 94, 426-454

[31] Calvó-Armengol, A., Zenou Y., 2005. Job Matching, Social Network and Word-ofMouth Communication. Journal of Urban Economics, 57, 500-522. 
[32] Cubitt, R., Drouvelis, M., Gächter, S., 2011. Framing and Free Riding: Emotional Responses and Punishment in Social Dilemma Games. Experimental Economics, 14, $254-272$.

[33] Charness, G., 2004. Attribution and Reciprocity in an Experimental Labor Market. Journal of Labor Economics, 22:665-688.

[34] Charness, G., Frechette, G., Kagel, J., 2004. How Robust is Laboratory Gift Exchange? Experimental Economics, 7:189-205.

[35] Charness, G., Kuhn, P., 2011. Lab labor: What Can Labor Economists Learn from the Lab? In Ashenfelter, O. and Card, D., editors, Handbook of Labor Economics, volume 4A, pages 229-330. Elsevier B.V.

[36] Charness, G., Rabin, M., 2002. Understanding Social Preferences with Simple Tests. Quarterly Journal of Economics, 117:817-869.

[37] Cheung, S. L., 2012. New Insights into Conditional Cooperation and Punishment from a Strategy Method Experiment. IZA Discussion Papers 5689, Institute for the Study of Labor (IZA).

[38] Cookson, R., 2000. Framing Effect in Public Goods Experiments. Experimental Economics, 3, 55-79.

[39] Cooper, D. J., Kagel, J. H., 2012. Other-Regarding Preferences: A Selective Survey of Experimental Results. In Kagel, J. H. and Roth, A. E., editors, Handbook of Experimental Economics, volume 2. Princeton University Press, Princeton, New Jersey. forthcoming.

[40] Cox, J.C., Friedman, D., Gjerstadt, S., 2007. A Tractable Model of Reciprocity and Fairness. Games ans Economics Behavior, 59, 17-45.

[41] Dufwenberg, M., Gächter, S., Hennig-Schmidt, H., 2011. The Framing of Games and the Psychology of Play. Games and Economics Behavior,73(2), November 2011, $459-478$.

[42] Dufwenberg, M., Kirchsteiger, G., 2004. A Theory of Sequential Reciprocity. Games and Economic Behavior, 47:268-298 
[43] Dustmann, C., Glitz, A., Schönberg, U., 2011. Referral-Based Job Search Networks, IZA Discussion Papers 5777, Institute for the Study of Labor.

[44] Ellingsen, T., Johannesson, M., Mollerstrom, J., Munkhammar, S., 2012. Social Framing Effects: Preferences or Beliefs? Games and Economic Behavior, 76, 117130.

[45] Engelmann, D., Ortmann, A., 2009. The Robustness of Laboratory Gift Exchange: A reconsideration. Working Paper, Charles University

[46] Fafchamps, M ., Moradi, A., 2010. Referral and job performance: Evidence from the Ghana Colonial Army. BREAD Working Paper 238.

[47] Falk, A., Fischbacher, U., 2006. A Theory of Reciprocity. Games and Economic Behavior, 54:293-315.

[48] Fehr, E., Falk, A., 1999. Wage Rigidity in a Competitive Incomplete Contract Market. Journal of Political Economy, 107:106-134.

[49] Fehr, E., Gächter, S., 2000. Fairness and Retaliation: The Economics of Reciprocity. Journal of Economic Perspectives, 14:15-181.

[50] Fehr, E., Gächter, S., Kirchsteiger, G., 1997. Reciprocity as Contract Enforcement Device: Experimental Evidence. Econometrica, 65:833-860.

[51] Fehr, E., Goette, L., Zehnder, C., 2009. A Behavioral Account of the Labor Market: The Role of Fairness Concerns. Annual Review of Economics, 1:355-384.

[52] Fehr, E., Kirchler, E., Weichbold, A., Gächter, S., 1998a. When Social Norms Overpower Competition: Gift Exchange in Experimental Labor Markets. Journal of Labor Economics, 16:324-351.

[53] Fehr, E., Kirchsteiger, G., Riedl, A., 1993. Does Fairness Prevent Market Clearing? An Experimental Investigation. Quarterly Journal of Economics, 108:437-459.

[54] Fehr, E., Kirchsteiger, G., Riedl, A., 1998b. Gift Exchange and Reciprocity in Competitive Experimental Markets. European Economic Review, 42:1-459. 
[55] Fehr, E., Schmidt, K.M., 1999. A Theory of Fairness, Competition and Cooperation. Quarterly Journal of Economics. 114, 817-868.

[56] Fischbacher, U. 2007. z-tree: Zurich Toolbox for Ready-Made Economic Experiments. Experimental Economics, 10(2):171-178.

[57] Fischbacher, U., Gächter, S., 2010. Social Preferences, Beliefs, and the Dynamics of Free Riding in Public Goods. American Economic Review, 100(1):541-556.

[58] Fisman, R., Kariv, S., Markovits, D., 2007. Individual Preferences for Giving. American Economic Review, 97, 1858-1877.

[59] Fischbacher, U., Gächter, S., Fehr, E., 2001. Are People Conditionally Cooperative? Evidence from a Public Goods Experiment. Economics Letters, 71, 397-404.

[60] Fosgaard, T., Gårn Hansen, L.,Wengström, E., 2011. Framing and Misperceptions in a Public Good Experiment. FOI Working Paper 2011/11, University of Copenhagen, Institute of Food and Resource Economics.

[61] Gächter, S., Riedl, A., 2005. Moral Property rights in Bargaining with Infeasible claims. Management Science, 51(2):249-263.

[62] Gächter, S., Thoni, C., 2010. Social Comparison and Performance: Experimental evidence on the fair wage-effort hypothesis. Journal of Economic Behavior \& Organization, 76:531-543.

[63] Galeotti, A., Merlino, P., 2010. Endogenous Job Contact Networks. ISER Working Paper Series, 2010-14, Institute for social and Economic Research.

[64] Gangadharan, L., Nikiforakis, N., 2009. Does the Size of the Action Set Matter for Cooperation? Economics Letters 104, 115-117.

[65] Gneezy, U., Imas A., Madarasz K., 2011. Conscience Accounting: Emotional Dynamics and Social Behavior. Working paper.

[66] Gneezy, U.,List, J., 2006. Putting Behavioral Economics to Work: Testing for gift exchange in labor markets using field experiments. Econometrica, 74(5):1365-1384. 
[67] Granovetter, M., 1975, 1995. Getting a job: A Study of Contacts and Careers. 2nd Edition, University of Chicago Press, Chicago.

[68] Granovetter, M., 1985. Economic Action and Social Structure: The Problem of Embeddedness. American Journal of Sociology, 91,481-510.

[69] Greiner, B., 2004. The Online Recruitment System ORSEE 2.0 - A Guide for the Organization of Experiments in Economics, Working Paper Series in Economics 10, University of Cologne, Department of Economics.

[70] Gueth, W., Huck, S., Mueller, W., 2001. The Relevance of Equal Splits in Ultimatum Games. Games and Economic Behavior, 37, 161-169.

[71] Grossman, S. J., Hart, O. D., 1981. Implicit Contracts, Moral Hazard, and Unemployment. The American Economic Review, 71(2):pp. 301-307.

[72] Hannan, R., Kagel, J., Moser, D., 2002. Partial Gift Exchange in an Experimental Labor Market: Impact of Subject Population Differences, Productivity Differences, and Effort Requests on Behavior. Journal of Labor Economics, 20:923-951.

[73] Herrman, B., Thöni, C., 2009. Measuring Conditional Cooperation: A Replication Study in Russia. Experimental Economics, 12(1), 87-92.

[74] Ioannides, Y., Loury, L., 2004. Job Information Networks, Neighborhood Effects and Inequality. Journal of Economic Literature, 42, 1056-1093.

[75] Jackson, M., 2008. Social and Economic Networks, Princeton University Press, New Jersey.

[76] Kay, A. C., Ross, L., 2003. The perceptual Push: the Interplay of Implicit Cues and Explicit Situational Construals on Behavioral Intentions in the Prisoner's Dilemma. Journal of Experimental Social Psychology, 39, 634-643.

[77] Kagel, J. H., Owens, M. F., 2010. Minimum Wage Restrictions and Employee Effort in Incomplete Labor Markets: An Experimental Investigation. Journal of Economic Behavior \&3 Organization, 73:317-326.

[78] Kocher, M., Cherry, T., Kroll, S., Netzer, R., Sutter, M., 2008. Conditional Cooperation on Three Continents. Economics Letters, 101(3), 175-78. 
[79] Kotani, K., Managi, S., Tanaka, K., 2008. Further Investigations of Framing Effects on Cooperative Choices in a Provision point Mechanism. Economics Bulletin, 51(3), $1-9$.

[80] Kube, S., Marechal, M., Puppe, C., 2013. Do Wage Cuts Damage Work Morale? Evidence From a Natural Field Experiment. Journal of the European Economic Association, forthcoming.

[81] Kugler, A., 2003. Employee Referrals and Efficiency Wages. Labour Economics, 10, $531-556$.

[82] Lévy-Garboua, L., Maafi, H.,Masclet, D.,Terracol, A., 2012. Risk Aversion and Framing Effects. Experimental Economics, 15, 128-144.

[83] Liberman, V., Samuels, S M., Ross, L., 2004. The Name of the Game: Predictive Power of Reputations Versus Situational Labels in Determining Prisoner's Dilemma Game Moves. Personality and Social Psychology Bulletin, 30, 1175-1185.

[84] Loury, L., 2006. Some Contacts are More Equal Than Others: Informal Networks, Job Tenure, and Wages. Journal of Labor Economics, 24, 299-318.

[85] Magruder, J., 2010. Intergenerational Networks, Unemployment, and Persistent Inequality in South Africa. American Economic Journal: Applied Economics, 2, 62-85.

[86] Mas-Colell, A., Whinston, M. D., Green, J. R., 1995. Microeconomic Theory. Oxford University Press, Oxford, UK.

[87] Maximiano, S., Sloof, R., Sonnemans, J., 2007. Gift Exchange in a Multiworker Firm. Economic Journal, 117:1025-1050.

[88] Maximiano, S., Sloof, R., Sonnemans, J., 2013. Gift Exchange and the Separation of Ownership and Control. Games and Economic Behavior, 77:41-60.

[89] McCusker, C., Carnevale, P.J., 1995. Framing in Resource Dilemmas: Loss Aversion and the Moderating Effects on Sanctions. Organizational Behavior and Human Decision Processes, 61, 190-201.

[90] McDaniel, W. C., Sistrunk, F., 1991. Management Dilemmas and Decisions: Impact of Framing and Anticipated Responses. Journal of Conflict Resolution, 35, 21-42. 
[91] McElroy, T., Seta , JJ., 2003. Framing effect: An Analytic-Holistic Perspective. Journal of Experimental Social Psychology, 39, 610-617.

[92] McPherson, M., Smith-Loving, L., Cook, J M., 2001. Birds of a Feather: Homophily in Social Networks. Annual Review of Sociology, 27, 415-444.

[93] Montgomery, J., 1991. Social Networks and Labor Market Outcomes: Towards an Economic Analysis. American Economic Review, 81, 1408-1418.

[94] Mortensen, D., Topa, G., 2001. Social Interactions, Local Spillovers and Unemployment. Review of Economic Studies, 68,261-95.

[95] Mortensen, D., Vishwanath, T., 1994. Personal Contacts and Earnings. It is who you know! Labour Economics, 1, 187-201.

[96] Topa, G., 2011. Labor Markets and referrals. In: J.Benhabib, A. Bisin and M.O. Jackson (Eds.), Handbook of Social Economics, Amsterdam: Elsevier Science, pp. 1193-1221.

[97] Muller, L., Sefton, M., Steinberg, R., Vesterlund, L., 2008. Strategic Behavior and Learning in Repeated Voluntary Contribution Experiments. Journal of Economic Behavior and Organization, 67, 782-793.

[98] Munshi, K., 2003. Networks in the Modern Economy: Mexican Migrants in the US Labor Market. Quarterly Journal of Economics, 118, 549-599.

[99] Nikiforakis, N., 2010. Feedback, Punishment and Cooperation in Public Good Experiments. Games and Economic Behavior 68, 689-702.

[100] Park, E.S., 2000. Warm-Glow Versus Cold-Prickle: A Further Experimental Study of Framing Effects on Free Riding. Journal of Economic Behavior and Organization, $43,405-421$.

[101] Pissarides, C., 2000. Equilibrium Unemployement Theory. Cambridge: MIT Press.

[102] Pellizzari, M., 2010. Do Friends and Relatives Really Help in Getting a Good Job? Industrial \& Labor Relations Review, 63, (3), 494-510. 
[103] Rege, M.,Telle, K., 2004. The Impact of Social Approval and Framing on Cooperation in Public Good Situations. Journal of Public Economics, 88, 1625-1644.

[104] Rees, A., 1966. Information Networks in Labor Markets. 1966 The American Economic Review, Vol. 56, No $\frac{1}{2}$.

[105] Ross, L., Ward, A., 1996. Naive Realism in Everyday Life: Implications for Social Conflict and Misunderstanding. In Reed, E. S., et al., (Eds.), Values and Knowledge. Lawrence Erlbaum Associates, Mahwah, New Jersey.

[106] Rustagi, D., Engel, S., Kosfeld, M., 2010. Conditional Cooperation and Monitoring Explain Success in Forest Commons Management. Science , 330, 961-965.

[107] Sell, J., Son, Y., 1997. Comparing Public Goods and Common Pool Resources: Three Experiments. Social Psychology Quaterly, 60, 118-137.

[108] Selten, R. 1967. Die Strategiemethode zur Erforschung des eingeschrankt rationalen Verhaltens im Rahmen eines Oligopolexperiments. In Sauermann, H., editor, Beitrge zur experimentellen Wirtschaftsforschung, volume I, pages 136-168. JCB Mohr (Paul Siebeck), Tubingen.

[109] Shapiro, C., Stiglitz, J. E., 1984. Equilibrium Unemployment as a Worker Discipline Device. American Economic Review, 74(3):433-444.

[110] Sobel, J., 2005. Interdependent Preferences and Reciprocity. Journal of Economic Literature, XLIII:392-436.

[111] Sonnemans, J., Schram, A., Offerman, T., 1998. Public Good Provision and Public Bad Prevention: The Effect of Framing. Journal of Economic Behavior and Organization, 34, 143-161.

[112] Schwartz Nelson., 2013. In Hiring, a Friend in Need is a Prospect, Indeed. New York Times.http://www.nytimes.com/2013/01/28/business/employersincreasingly-rely-on-internal-referrals-in-hiring.html?pagewanted=all\&્ $r=0$

[113] Thöni, C., Tyran, J., Wengström, E., 2012. Microfoundations of Social Capital. Journal of Public Economics, 96 (7), 635-643. 
[114] Topa, G., 2001. Social Interactions, Local Spillovers and Unemployment. Review of Economic Studies, 68,261-95.

[115] Topa G., 2011, Labor Markets and Referrals, In: J.Benhabib, A. Bisin and M.O. Jackson (Eds.), Handbook of Social Economics, Amsterdam: Elsevier Science, pp. $1193-1221$.

[116] Tversky, A., Kahnemann, D., 1981. The Framing of Decisions and the Psychology of Choice. Science, 211, 453-458.

[117] Van Dijk, E., Wilke, H., 2000. Decision-induced Focusing in Social Dilemmas: GiveSome, Keep-Some, Take-Some, and Leave-Some dilemmas. Journal of Personality and Sociallogy, 78, 92-104.

[118] Volk, S., Thöni, C., Ruigrok, W., 2012. Temporal Stability and Psychological Foundations of Cooperation Preferences. Journal of Economic Behavior and Organization, 81,664-676.

[119] Willinger, M., Ziegelmeyer, A., 1999. Framing and Cooperation in Public Good Games: An Experiment with an Interior Solution." Economics letters, 65, 323-328.

[120] Wilson, C., 1979. Equilibrium and Adverse Selection. The American Economic Review, vol 69 (2), 313-317

[121] Wilsom, C., 1980. The Nature of Equilibrium in Markets with Adverse Selection The Bell Journal of Economics, vol 11 (1), 108-130.

[122] Zenou, Y., 2013. Social Interactions and the Labor Market. Revue d'Economie Politique, Forthcoming. 


\section{Short Curriculum Vitae}

Aurélie Petit dit Dariel received a bachelor degree in Economics from the University of Grenoble in 1999. She then went to Montreal and obtained a Masters in Economics with Honors from the University of Montreal in 2001. In Montreal, she also worked as a research assistant at the CIRANO research center. After obtaining her Masters, she worked for four years for the French government as a project manager. She started her doctoral studies at Maastricht University in 2006.

Aurelie's research so far has focused on topics in behavioral and experimental economics, and in particular, in investigating the role and economic significance of social preferences. 